\title{
Action research analysis of the forces affecting farmer participation in a West Virginia Cooperative Extension Service farmer education program
}

John Robert Edalgo

West Virginia University

Follow this and additional works at: https://researchrepository.wvu.edu/etd

\author{
Recommended Citation \\ Edalgo, John Robert, "Action research analysis of the forces affecting farmer participation in a West \\ Virginia Cooperative Extension Service farmer education program" (2005). Graduate Theses, \\ Dissertations, and Problem Reports. 875. \\ https://researchrepository.wvu.edu/etd/875
}

This Thesis is protected by copyright and/or related rights. It has been brought to you by the The Research Repository @ WVU with permission from the rights-holder(s). You are free to use this Thesis in any way that is permitted by the copyright and related rights legislation that applies to your use. For other uses you must obtain permission from the rights-holder(s) directly, unless additional rights are indicated by a Creative Commons license in the record and/ or on the work itself. This Thesis has been accepted for inclusion in WVU Graduate Theses, Dissertations, and Problem Reports collection by an authorized administrator of The Research Repository @ WVU. For more information, please contact researchrepository@mail.wvu.edu. 
Action Research Analysis of the Forces Affecting Farmer Participation in a West Virginia Cooperative Extension Service Farmer Education Program

\author{
John Robert Edalgo
}

Thesis submitted to the College of Arts and Sciences at West Virginia University in partial fulfillment of the requirements for the degree of

\author{
Master of Arts \\ In \\ Applied Social Research
}

Ronald Althouse, Ph.D., Chair Jim Nolan, Ph.D.

Thomas R. McConnell, Extension Specialist

School of Applied Sociology

Division of Sociology

Morgantown, WV

2005

Keywords: Action Research, Handheld Computer, Cooperative Extension, Field Theory and Recordkeeping Copyright 2005 John Robert Edalgo 


\section{ABSTRACT \\ Action Research Analysis of the Forces Affecting Farmer Participation in a West Virginia Cooperative Extension Service Farmer Education Program John R Edalgo}

This study uses action research principles and Kurt Lewin's field theory to investigate the forces dictating farmer participation in the Decision Enabling Data Collection and Management System Initiative (DEDCMSI). These forces were classified in Chapter IV under the following project categories: Hardware, Software, Perception of DEDCMSI, Perception of Technology, and Sociocultural. This West Virginia University Cooperative Extension Service (WVUCES) initiative organized four farm finance groups located in the following counties: Ohio, Jefferson, Mineral, and Monroe. Data collection methods used to identify forces occurring within this seven-month pilot project is listed here as follows: structured, semi-structured, and un-structured interviews. A total of thirty research participants, four support staff, two Extension Specialists, nine Extension Agents, two applied social science researchers, and one graduate student in applied sociology contributed to this research. The results of this study will be utilized in the development of future intervention strategies by the WVUCES. 


\section{DEDICATION}

I would like to thank Paul Joseph (P.J.) Edalgo (R.I.P. 2001), my brother, who always took the most joy in my accomplishments, no matter how small. To my father, much gratitude is given, for eagerly taking on the challenge of raising two boys through adolescence and into adulthood. To my wife (Jen) and extended family, thanks for all the love and encouragement that helped make this possible. To my Lord, who has taken my limited abilities and made them sufficient in all of my educational pursuits. 


\section{ACKNOWLEDGMENTS}

To Ronald Althouse, I have enormous gratitude for the opportunity you have given me. If it were not for you, the challenge of pursuing a degree in Applied Sociology would not have been mine to earn.

To Tom McConnell, I am thankful for your willingness to seek funding that positively impacts so many lives in West Virginia, myself included.

To Jim Nolan, thank you for adding this project to your already busy schedule. The expertise you gave in reference to Action Research was invaluable to me.

To Harry Schwarzweller, an interim professor at WVU during the first difficult months of my thesis, I am very grateful. Through your guidance I was able to find my research bearings and lay the foundation from which the rest of my work was based.

To Nancy White, thank you for providing this project with your editorial skills that have been hewed over thirty plus years of practice. The tireless work you so freely gave in the areas of grammar and presentation taught me about professionalism.

To Jeff Himes, thank you for your friendship, mentorship and opportunities you provided me. Your friendship will be carried with me wherever this life takes me.

I would also like to thank WVU Extension Agents, Melissa Latimer, PhD, Loretta Price, Amy White, Barbara Long, my classmates, and the farmers of West Virginia all of which helped in their own special ways with this thesis. 


\section{LIST OF TABLES}

Table 1.1 The National Commodity Rankings for West Virginia

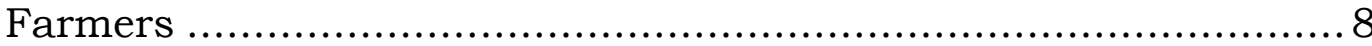

Table 1.2 West Virginia vs. National Computer Adoption......................... 9

Table 1.3 Characteristics of Innovation ......................................... 20

Table 1.4 Farm Activity by Enterprise Proportions Among DEDCMSI

Project Counties ......................................................... 36

Table 1.5 Operations System Checklist........................................... 38

Table 1.6 Data Collection Achieved in Study ...................................... 43

Table 1.7 Restraining Forces Identified by Farmers as Negatively Affecting Their Participation .............................................. 52

Table 1.8 Driving Forces Identified by Farmers as Positively Affective Their Participation.......................................................... 74

Table 1.9 Restraining and Driving Forces Identified by Extension As Affecting Farmer Participation 


\section{LIST OF FIGURES}

Figure 1 The Action Research Spiral Process Model ............................. 31

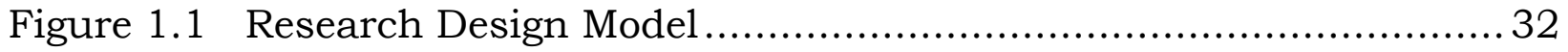

Figure 1.2 Farmer Education Obtainment ........................................ 34

Figure 1.3 Farmer Education Obtainment ....................................... 37

Figure 1.4 Data Collection From February to June 2005........................ 40

Figure 1.5 Data Collection from July 2005...................................... 42

Figure 1.6 Procedures of the Research Design for Pre-Experimental

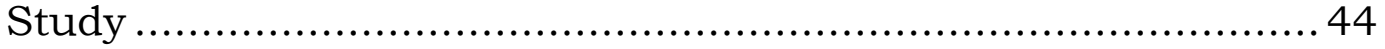

Figure 1.8 Amount of Time Spent by Respondents Recordkeeping

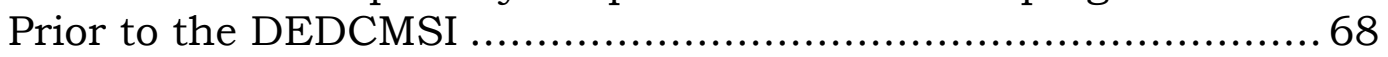




\section{TABLE OF CONTENTS}

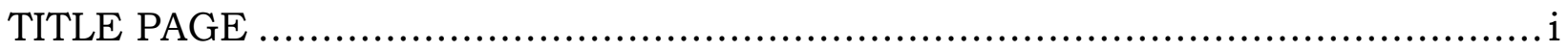

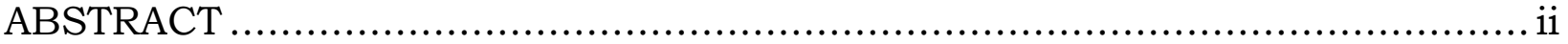

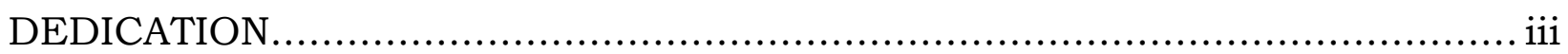

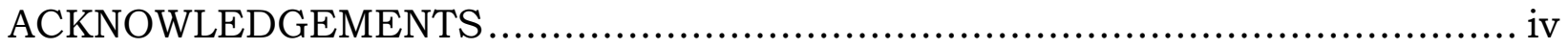

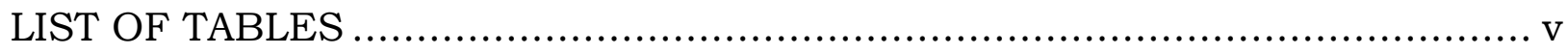

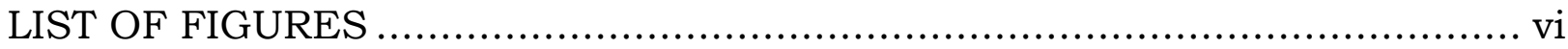

CHAPTER 1. THE PROBLEM

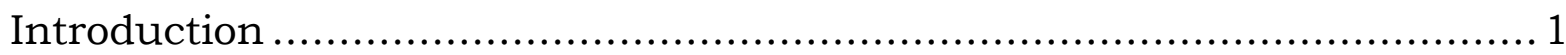

Research Problem.....................................................................

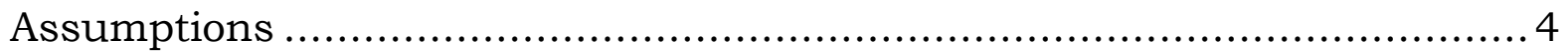

Research Question ............................................................... 5

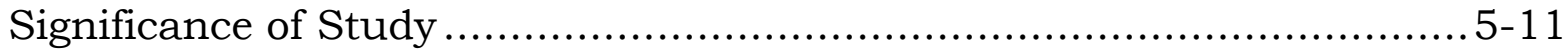

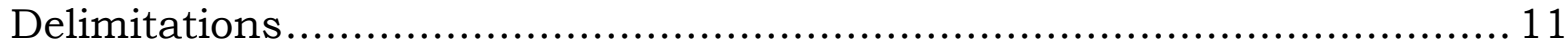

Definitions and Operational Terms ....................................... 12-14

CHAPTER II. REVIEW OF LITERATURE

General Background Information............................................. 15

Computers in Agriculture Research .......................................... 15

Personal Digital Assistant................................................... 16-18

Diffusion of Innovation ...................................................... 18-21

Action Research ............................................................... 21-23

Democratic Approach to Research ..........................................23-25

Theoretical Perspective ......................................................... 25-26

Review of Literature on Instruments .......................................27-29

CHAPTER III. PROCEDURES

Research Design ...................................................................

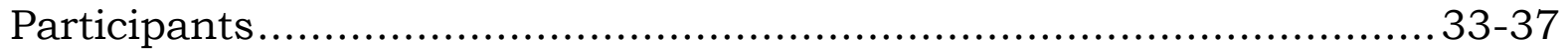

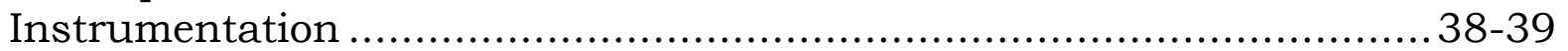

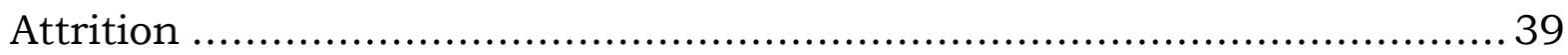

Data Collection................................................................. $39-45$

Statistical Treatment ............................................................. 46-47

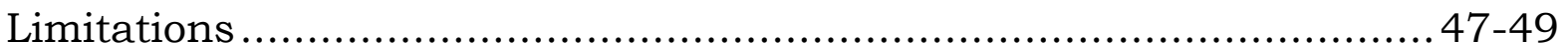


CHAPTER IV. RESULTS

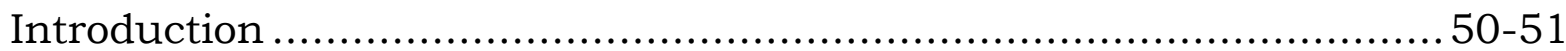

Farmer Identified Restraining Forces - Table 1.7 ............................. 52

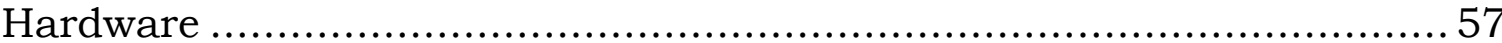

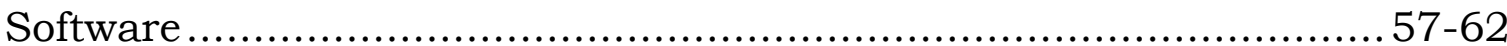

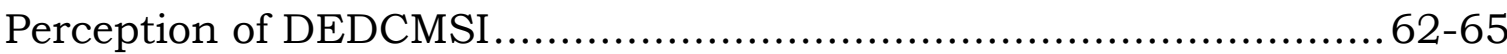

Perception of Technology …............................................... 65-70

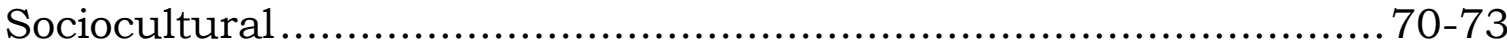

Farmer Identified Driving Forces - Table 1.8 ................................ 74

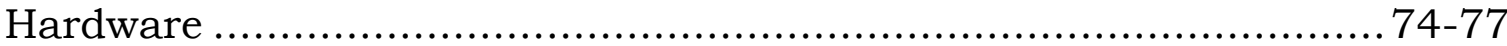

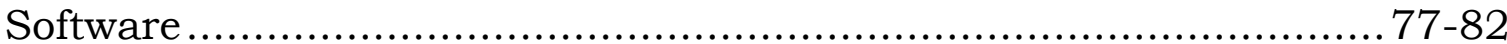

Perception of DEDCMSI................................................... 82-86

Perception of Technology .................................................. 87-90

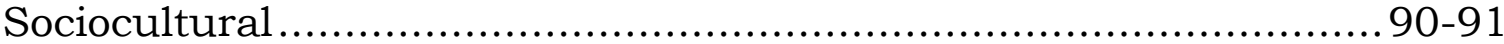

Extension Introduction ........................................................ 91-92

Extension Identified Restraining and Driving Forces - Table 1.9 ............. 92

Hardware ..................................................................... 93-94

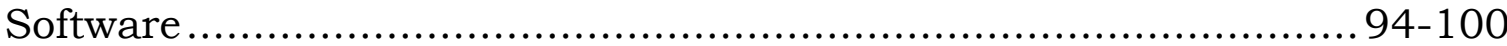

Perception of DEDCMSI............................................... 100-102

Perception of Technology ................................................... 103-104

CHAPTER V. SUMMARY, DISCUSSION AND CONCLUSION

Project Category Summaries ................................................ 105-106

Positionality .................................................................. 106-107

Critical Reflexivity ........................................................ 107-108

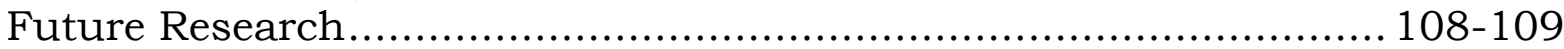

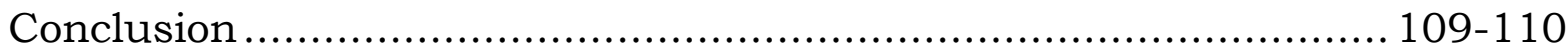

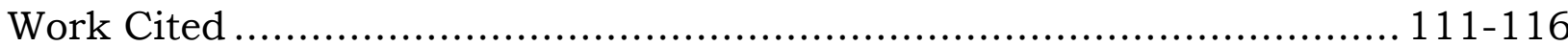




\section{APPENDICES}

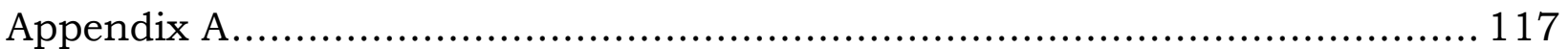

Farm Family Survey …...................................................... 118-131

IRB Approval Letter ............................................................... 132

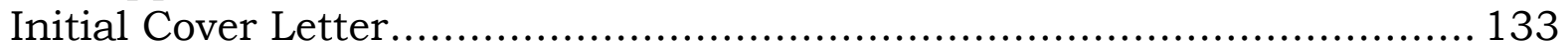

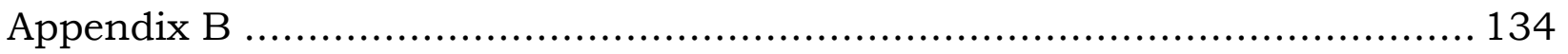

Executive Summary ......................................................... 135-138

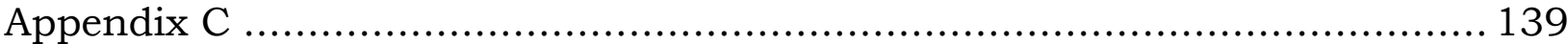

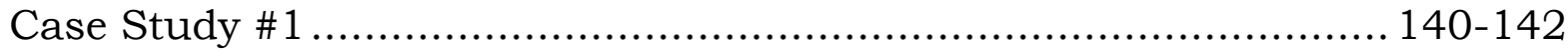

Case Study \#2 ............................................................... 143-148

Case Study \#3 ................................................................... 149-150

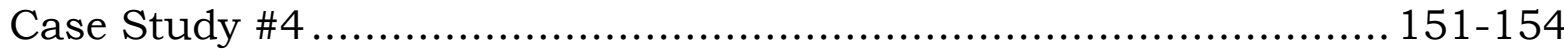

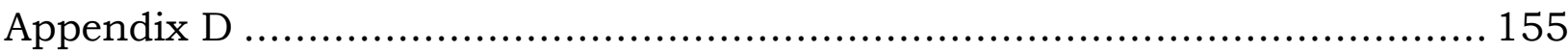

Basic Skills Training Manual ..................................................... 156

Table of Contents ................................................................. 157

Book 1. Battery Basics ................................................... 158-161

Book 2. Security ......................................................... 162-164

Book 3. Maintenance of Axim .......................................... 165-173

Book 4. ActiveSync ...................................................... 174-179

Book 5. Data Management ............................................. 180-186

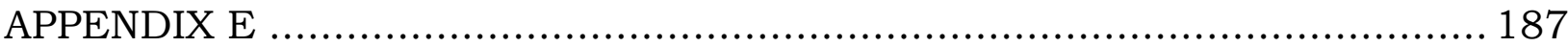

Operational System Checklist ............................................... 188-189

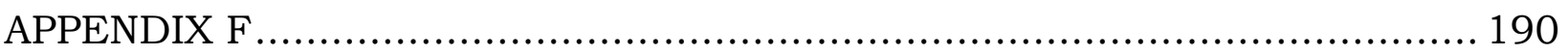

Geographical Information System Project Maps .............................. 191 


\section{Chapter I - The Problem}

Introduction

This study seeks to compile information collected from farmers and extension personnel participating in the pilot phase of the Decision Enabling Data Collection Management System Initiative (DEDCMSI) intended to enhance farmer's recordkeeping abilities. The DEDCMSI Program was created and implemented by West Virginia Cooperative Extension Service (WVUCES). The relative utility of the Dell Axim X5 and X50 (handheld computers) was identified by the Extension Service as the technological center piece of the initiative, and as a result will be a major area of concern for this study. Equally important to the success of the initiative, says Tom McConnell, an Extension Specialist of 31 years, "is the farmer feedback in relation to key aspects of the DEDCMSI educational materials" (McConnell, 2005). In this study Action Research (AR) principles are utilized to insure West Virginia farmers were involved in the planning and implementation related to the research. This research is applied research. The results that come from this study will be of immediate use to the West Virginia Cooperative Extension Service as well as farmers participating in this initiative.

The ultimate goal of DEDCMSI is to give farm families the opportunity to compile desired records on various aspects of their farming enterprises in the most efficient way possible. The WVUCES's initiative seeks to increase recordkeeping ability on the farms of West Virginia through the collective benefits of farm finance groups as well as possible advantages gained from handheld 
computer technology. More specific descriptions of the initiatives goals and objectives can be found in Appendix B - Executive Summary.

Research Problem

Extension specialists have identified the lack of recordkeeping practices as a serious problem affecting the profitability of West Virginia family farms. Research done by Thompson and Gwynn (1989) surveyed a total of fifty deans from agricultural schools throughout the United States, and found that over half of those located in the Northeast Region (West Virginia) suggested that more research on farm finance would improve the effectiveness of the extension's efforts. Fifty-two percent of the deans said that more social awareness in research would also help Land Grant institutions meet the greater need of their clientele. Extension professionals want to investigate how handheld computer technology can serve West Virginia farmers desiring more accurate and portable data on their farm. A study that identified factors contributing to the success of small farm operations in Tennessee stated that, "The most important need in research was marketing, followed by production and assessment of technology" (Muhammad, Tegegne, and Ekanem, 2004; p. 6).

This initiative addresses the perceived need for recordkeeping education on West Virginia farms through the diffusion of handheld computers and related lesson plans. The home computer has been identified as, "a major technology invading the clientele of Extension professionals today..." (Hall, Dunkeberger and Ferreira, 2003; p. 2). The idea that farmers ultimately will gain more control over 
their farm management decisions/operation is at the root of this intervention (Jarvis, 1990). The four characteristics of action research are listed here as follows: collaboration between researcher and practitioner, solution of practical problems, change in practice and development of theory (Holter and Schwartz, 1993). Each of these research measures will aid in the identification of the problem to be studied or solved. In this study we will identify suggestions or changes for the West Virginia University Cooperative Extension Service (WVUCES).

The research problem reads as follows:

\section{Research Problem: To develop a research methodology that will adequately identify encouraging and discouraging factors affecting farmer participation in the DEDCMSI; using Lewin's Field Theory.}

"Participation" in this project is defined as any farmer who utilizes the handheld computer as well as DEDCMSI educational materials for recordkeeping on his/her farm. In a study focusing on improving access to the internet in rural communities inhibiting factors (forces) were also identified in relation to successful use of the internet (Samson, 1998). Our research seeks to identify those factors that if addressed by the Extension Service, can be transformed into a driving force for change. It is our desire to give the proper understanding of the social fields of their participants so the social change desired by the agency is achieved. 


\section{Assumptions}

The assumptions in this study revolve around in institutionalized research, as well as a desire to produce the most efficient intervention programs skill and resources will allow. The first assumption is related to the democratic research approach utilized in this pilot study. It is assumed that the farmer participants and communities of interest will receive the greatest benefit by taking active roles in setting research objectives as well as evaluation of existing project characteristics.

Secondly, it was assumed that the handheld computers, Dell Axim X5 and X50, purchased for farmers in this project are efficient and equal, if not superior to their competitors in performance. Further, the assumption was made, based 100 years of Cooperative Extension experience and previously cited literature that recordkeeping on West Virginia farms is a pressing need that, if sufficiently met, could help WV farmers make better management decisions. It is also assumed that the Applied Sociological research methodologies utilized in this study are adequate.

Finally, it is assumed that there is a disproportional percentage of progressive (early adopter) farmers participating in this, the first stage of the project. This assumption is made because the sample in this study was one based on Cooperative Extension project goals related to human capital generation and sustainability. 


\section{General Research Questions}

The problem to be addressed by this research is specific to WVUCES educational programming needs. In the same manner the research question is intended to give the change agency directional input into the factors that are working for or against their efforts in the DEDCMSI.

The research question reads:

Research Question: Which variables should WVUCES include in a survey instrument designed to identify the extent to which encouraging and discouraging forces are present on an individual farm and DEDCMSI group levels?

This research question will allow the change agency to focus their efforts in the program areas of greatest need. It could be that the inhibiting factors identified in these first seven months of the program will be minor and easily solved by subtle changes. WVUCES will know which forces they should focus on as they move the initiative forward in the second phase of the initiative.

Significance of Study

"Burn down your cities and leave our farms, and your cities will spring up again as if by magic; but destroy our farms and the grass will grow in the streets of every city in the country..." These words were spoken by William Jennings Bryan at the Democratic Convention 109 years ago, but still ring true today (Bryan 1896). The grass is not growing in America's streets today, yet the seeds of destruction are sewn. Small family farms comprise $90 \%$ of the total farms in 
America; however, they produced only $28 \%$ of the total output in America during 2001 (Banker and MacDonald, 2005).

There are many justifications for actively promoting small family farms in America today. Societal benefits come from the generation of biodiversity through seed sharing programs and conservation of vital wildlife habitat through small land holdings. The plant and animal species often promoted by the small farm are drastically being replaced by commercial farms which is often synonymous with monocultures as far as the eye can see. Put differently, small farms are able to increase native plant and animal diversity through the smaller fields, once typical in America's landscape. Today larger commercial farm operations with many thousands of contiguous tracks of land maintained year after year for one crop (monoculture) common place. Additional benefits resulting from small family farms include supplementing your family's income, sustainability in our nation's food system through moving away from a globalized economy and toward a local one, and diversification of agricultural commodities grown in a given area, to name just a few.

Today there are roughly two million farms in America. When the two million farmers of today are compared to the 6.8 million farmers of 1935, a drastic decrease of 4.7 million farmers is evident (Banker et al, 2005). One can not contribute this decrease exclusively to the depression nor the farm crisis of the 1980's. Many farmers cite low prices for the agricultural products they produce as well as an ever shrinking producer's share of the retail market. Over the past century, technological advances and low prices have demanded farming 
operations increase inputs (acres farmed, fertilizers, irrigation and pesticides) to be competitive (Shildgen, 2004). As fewer farmers were inclined to take on large loans to acquire needed equipment, etc., the number of American farms in 1940 began to drop. With the increased efficiency on farms, production has become concentrated on large farms that have the equipment and technology to increase yields on fewer and fewer acres (Banker et al, 2005). When the aforementioned farming characteristics are considered, it is evident that the family farm has been under attack from rising land prices, commercial farming, and high interest rates on even higher machinery costs (Diaz, 2003).

If one believes in preserving the family farm, in America, West Virginia should be a serious concern. Of West Virginia's 20,812 farms, 95\% of them are considered small and family/individual ran operations (NASS, 2004). Since 1997, West Virginia has lost 144 farms per year resulting in a 3\% decrease (NASS, 2004). In a state that is under severe economic strain, with $32 \%$ of West Virginia families in 2000, making less than or equal to $\$ 24,999.00$ in 1999 (U.S. Census, 2000). The $1,808,344$ people in West Virginia can ill afford to loose the \$423.4 million dollars generated from all agricultural commodities in 2004 (King, 2005). Some of the most successful agricultural commodities in West Virginia as compared to the rest of the nation are broilers, turkeys, tobacco and apples as shown in Table 1.1. 
TABLE 1.1

The National Commodity Rankings for West Virginia Farmers

\begin{tabular}{|l|c|c|}
\hline \multicolumn{1}{|c|}{ Product } & $\begin{array}{c}\text { National Rank } \\
\text { Among States }\end{array}$ & $\begin{array}{c}\text { Value of Production } \\
\text { In Dollars (Annual) }\end{array}$ \\
\hline Broilers & 16 & $\$ 121,550,000.00$ \\
\hline Turkeys & 14 & $\$ 33,127,000.00$ \\
\hline Tobacco & 15 & $\$ 3,065,000.00$ \\
\hline Apples & 10 & $\$ 8,100,000.00$ \\
\hline
\end{tabular}

*All data gotten from 2004 WV-NASS Bulletin No. 35

As we move further into the future of modern farming, food producers are faced with more management decisions than ever. How large should we expand our farming enterprise? Should we produce our product cooperatively with large agribusinesses or collectively with other farmers? Would our family be better off if we took advantage of the higher real estate prices and just sold the family farm? Questions like these are asked by more and more non-commercial farming operators everyday. Some have chosen farm consolidation and contract farming as ways to offset risk often common on the small family farm today. The rate of technological capabilities and the ability for these innovations to positively impact small non-commercial farms is also growing at a rapid rate. Although, a relatively small amount of direction and applicable literature can be found in reference to handheld computers (PDA's).

The computer revolution began showing up in the early 1980's, the infancy of microcomputer research in agriculture. Most of the literature in the early eighties predicted adoption rates of the microcomputer in agriculture as high as 80\% (Schmidt, Rockwell, Bitney, and Sarno, 1994). This optimism was short 
lived because soon farmers would have to face over-priced hardware costs and very little software applications related to farming.

These barriers to computer adoption would not last through the next ten to fifteen years. In 1999, Rosenberg noticed this upturn in computer excitement and predicted $90 \%$ of U.S. households would be online by 2005 . The most recent data compiled in 2005 by the National Agriculture Statistics Service (NASS) showed that $51 \%$ of the farms in the United States had internet access, up from 48\% in 2003 (NASS, 2003 and 2005). This analysis also showed an impressive $60 \%$ of farms had access to computers in 2003, a number that fell $7 \%$ in 2005. Most scholars say that 2005 computer adoption rates show a leveling off, suggesting that the computer has reached its highest level of adoption at present (Farmer Computer Usage and Ownership, 2003). Further, there is little doubt that, of those computer owning farmers in West Virginia, a significant number do not use their computer for farming purposes. Of the $51 \%$ of farms that own or leased a home computer in $2005,31 \%$ actually use their computers in the perspective farming operation both on a National and a West Virginia state level (NASS, 2005).

TABLE 1.2

West Virginia vs. National Computer Adoption

[CUFB = Computer Use for Farm Business; IA = Internet Access; NA = Not Available $]$

\begin{tabular}{|l|c|c|c|c|c|}
\hline \multicolumn{1}{|c|}{ Category } & $\begin{array}{c}\text { ON WV } \\
\text { Farms - 1997 }\end{array}$ & $\begin{array}{c}\text { ON WV } \\
\text { Farms - 2002 }\end{array}$ & $\begin{array}{c}\text { On WV } \\
\text { Farms - 2003 }\end{array}$ & $\begin{array}{c}\text { On WV } \\
\text { Farms - 2005 }\end{array}$ & $\begin{array}{c}\text { National \% of } \\
\text { Farmers 2005 }\end{array}$ \\
\hline CUFB & NA & NA & $19 \%$ & $31 \%$ & $31 \%$ \\
\hline E-Mail & NA & NA & NA & NA & $46 \%$ \\
\hline IA & NA & NA & $55 \%$ & $51 \%$ & $35 \%$ \\
\hline
\end{tabular}

*All data gotten from NASS Farm Computer Usage and Ownership, 2005 
As shown by the above table, the number of agricultural operations using computers has increased $12 \%$ in two years. What are the other $69 \%$ of the farmers not using computers on their farms scared of? If relevant research were available, it would allow farmers interested in applying computing to their management practices access to early adopters' successes and failures. In this manner the risk associated with new innovations is diminished and certain amount of technological evaluation is achieved before initial investments are made. Surprisingly, after twenty-five years of steady research related to farming and the microcomputer, few examples can be applied to the small family farm, much less handheld computers. Potential need for computer technology on farms exist in the areas of; environmental regulation governing fertilizer concentrations in the soil, bio-solid application, and farm animal identification program requirements. O'Brien (1998) stated in a literature review on (AR), "...that most research on group support systems to date has been in short-term, experimental situations using quantitative methods. "There are a few examples... of those that did use action research; none studied the use and effects of communication systems in groups and organizations" (O'Brien, 1998). Technological research in agriculture is commonly performed on larger farms due to the increased probability of finding more early adopters of technology in this arena of farming. Larger farms often have the ability to afford new technologies resulting in wider profit margins that allow for the risk associated with innovation. This lack of knowledge is further demonstrated by the fact that the state of West 
Virginia only has two years of technology data related to computers on farms versus the four years that $83 \%$ of the rest of the nation has (NASS, 2005).

\section{Delimitations}

There is some project characteristics that are best described under the delimitation subheading. For instance, the target population for this research was not selected using a randomly selected representative sample. The sample was obtained through the County Agents' ability to select the best candidate for the job. Those farmers with the most exposure and technological ability related computers are overrepresented in this study, a characteristic believed to help the initiative achieve sustainability in the farm finance groups. For these reasons the results will not be generalized to the larger population of farmers in West Virginia. The forces impacting these farmers will be identified, however, with the intent that the change agency will increase the effectiveness of their efforts.

The project was also limited by the time of year data collection was undertaken. Due to vegetable harvest and market selling activities reaching a pinnacle in the months of July and August, the post survey response rate suffered at $6 \%$. The pre-survey, however, experienced higher than normal response rates in May at $90 \%$. Finally the small number of farmers participating in the pilot study was an intentional limitation. The pilot study is intended to identify and eliminate problem areas before the intervention is taken on a larger sampling size. 
Definitions and Operational Terms

Action Research Terms

Action Research: "is social research carried out by a team encompassing a professional action researcher and member of an organization or community seeking to improve their situation" (Greenwood and Levin, 1998).

Applied Social Science: A field of Sociology using sociological concepts, principles, and insight to deal with practical real world decisions and problems (Johnson, 1995).

Force: " ...Power to influence, affect, or control (esp. men in their actions, sentiments, etc.)...(Oxford English Dictionary, 1989)."

Restraining Forces: Any factor identified by farmers or Cooperative Extension personnel as negatively affecting participation with the DEDCMSI.

Driving Forces: Any factor identified by farmers or Cooperative Extension personnel as promoting participation with the DEDCMSI.

\section{$\underline{\text { Technical Terms }}$}

Outlook 2003: "The new version of Microsoft's popular personal information manager (PIM)" (Habraken, 2003;p.79).

WVU Template: A Microsoft Access database that was created by WVU Cooperative Extension specifically for the DEDCMSI.

DEDCMSI Pilot Study: A Sustainable Agriculture Research and Education grant funded initiative intended to increase the data collection and use on West Virginia farms through the use of handheld computer technology. The pilot study is the precursor to the year long initiative that will start beginning January 1, 2006.

Microsoft ActiveSync: Software that synchronizes information on computer with information on your device (PDA) and also transfers information on your device to the home computer (Dell Corp., 2003).

PDA: “...a device intended for organizational purposes (clock, date book, addresses and tasks list) but evolved into the more advanced Pocket PC (Microsoft Operating Systems like Word, Excel and Access)" (historymanina.com, 2005).

Pocket PC (PPC): “...a hand held computer that runs many of the same Microsoft applications as the home computer" ( historymainia.com 2005). 
Dell Axim X5: The first PPC to hit the market. It has $400 \mathrm{MHz}$ processor (Ries and Mino, 2003).

Dell Axim X50: One of three PPCs that Dell manufactured with the X5O logo. The X50 went on sale to the public October 12, 2004 (Rojas, 2004).

Bluetooth: "A wireless technology standard for short-range" (User's Guide, 2003).

Microsoft Access database: "A collection of data related to a particular subject or purpose. Within a database, information about a particular entity, such as an employee or order, is categorized into tables, records, and fields (Microsoft Corporation, 2005).

USB (Universal Serial Bus): "A hardware interface for a low speed device such as a USB-compatible keyboard, mouse, joystick, scanner, set of speakers..." (User's Guide, 2003).

Letter Recognizer: "allows you to use your stylus to write letters on the screen as you would on paper" (User's Guide, 2003).

RAM (Random Access Memory): "The primary temporary storage area for program instruction and data. Any information stored in RAM is lost when you perform a hard reset" (User's Guide, 2003).

\section{Diffusion of Innovation Terms}

Diffusions: "is the process by which an innovation is communicated through certain channels over time among the members of a social system" (Rogers, 1983).

Change Agency: "is an individual who influences clients' innovation decisions in a direction deemed desirable by a change agency" (Rogers, 1983). Synonyms: Intervention agency

Social System: a set of interdependent parts that can be thought of as a whole (Johnson, 1995).

Innovation: "is an idea, practice, or object that is perceived as new by an individual or other unit of adoption (Rogers, 1983). Synonyms: Technology

Opinion Leaders: "is the degree to which an individual is able to influence other individuals' attitudes or overt behavior informally in a desired way with relative frequency" (Rogers, 1983). 


\section{DEDCMSI Terms}

Small Farm: "is any farm that comprises of 179 acres or less, or that grosses $\$ 50,000$ or less per year. Small farms are usually family farms but may or may not be sustainable" (Macher, 1999; p.6)

Family Farm: "is any size farm-small, medium, or large in which family members supply the majority of needed farm labor. A family farm is not necessarily sustainable" (Macher, 1999; p.6)

Farmer: defined by the (USDA) United States Department of Agriculture as any individual that sells $\$ 1,000.00$ worth of agricultural goods/year (Macher, 1999; $p$. 7). Synonyms: Participant

Farm Operator: "A person who operates the farm either through doing the work or making the decision related to planting harvesting feeding and marketing" (NASS, 2002).

Market Value of Production: "The gross market value before taxes and production expenses of all agricultural products sold or removed from the place in 2002 regardless of who received the payment. It is equivalent to total sales. Figure does not typically include monies from Federal Farm Programs" (NASS, 2002). Synonyms: MVP

Cooperative Extension Agency: A land-grant governmental agency intended to help people identify and solve problems through technology and other information obtained through the university and USDA (Extension Report, 1988). Synonyms: Change Agency, WVUCEA, and intervention agency

Advisory Committee: This committee consisted of farmers, Extension Agents/Specialist, support staff, and Information Technology specialist. The committee set target objectives and evaluated ideas in reference to the DEDCMSI pilot group.

Real-time Recordkeeping: Terminology used in the initiative to define the elimination of a double entry recordkeeping pen/computer system to the single entry system the based on ActiveSync software utilized on the PPC.

Single Entry Recordkeeping System: In this project, the use of the handheld computer's sync ability will allow the farmer to collect information in the field once and sync it to the larger data base on the home computer.

Data-on-the-Run: Is software that enables Pocket PC users to create Access spreadsheets and have them sync with Microsoft Access on the home computer. 


\title{
Chapter II - Review Of The Literature
}

\author{
General Background Information
}

The literature review primarily deals with data based studies related to general topic of technology as well as some background on democratically organized research, a fundamental principal utilized in many action research studies. Currently, due to the inability to find handheld computer diffusion research related to recordkeeping, literature reviews on precision farming and farmer computer use has been included. This study seeks to fill the void in existing literature by dealing with the following three areas: small farm perceptions of record keeping, potential utility related to handheld PC technology and small family farms, and how the work done in this thesis relates to diffusion of innovation research.

\section{Computers in Agriculture Research}

Current work related to computers and agriculture began in the late 1980's with Putler and Zilberman's study. The important finding in this study was, "that basic introductory educational programs about computers may need to be targeted toward small farmers, while more advanced computer-oriented programs should be targeted toward large farms and well educated farm operators" (Putler and Zilberman, 1988: 800). Many studies have identified farm size and education as being positively related to computer adoption/usefulness and age as being negatively related to computer adoption (Batte, Jones, 
Schnitkey, 1990; Amponsah, 1995). Additional research on computer adoption by Jarvis (1990) found the complexity of the farming operation and the farm size to be positively related to computer adoption for Texas rice farmers. Jarvis went on to state that if Extension's goal is to increase adoption of computers, 'encouraging computer users' groups among producers could increase the visibility of returns associated with computer use" (1990:1393). In 1997, at a conference for information technology in agriculture, Peter L. Nuthall identified farmer involvement as being a major factor contributing to computer adoption in the following quotation:

"Despite the vast investment that occurred, the uptake rate of both computerized and non-computerized systems has been very much less than what the protagonists would have liked. This is due to many reasons, but a major one is that the developers have not worked sufficiently with potential users to assess requirements" (Nuthall, 1997: p. 15).

\section{Personal Digital Assistant}

The technological centerpiece for this project is the Personal Digital Assistant (PDA), manufactured by Dell and marketed as the Axim X5 and X50's. Other names commonly used to refer to the PDA are the handheld computer, the palm pilot and the Pocket PC. The Microsoft Corporation refers to the Pocket PC as a Windows mobile device (Hall, Ball and Shilmover, 2004). This definition of Microsoft is extremely accurate and speaks to the mobility of data identified by farmers later in the thesis. Other terminology related to the handheld computer can be found under Definitions and Terms section in Chapter I. This technology was chosen by DEMSI for its ActiveSync capabilities in data management. Extension specialists identified the potential for single-entry recordkeeping 
capabilities as being beneficial to its clientele. Existing research also showed that "PDA units won't be replaced, but enhanced" (Gonzalez-Castano, ValesAlonso, Costa-Montenegro, Livy and Anido-Rifon, 2003: p. 18).

The Dell Axim X5 used in this study was primarily equipped with Windows Mobile 2003 for Pocket PC which is listed on the units as 'Pocket PC 2003'. The unit operates programs and stores the data it generates with 64 megabytes (MB) of RAM. Any Pocket PC software added by farmers after units are issued is stored here. An additional $48 \mathrm{MB}$ of flash RAM is used by the $\mathrm{X} 5$ for storing programs associated with Pocket PC 2003 (Pocket Word, Excel, and Outlook) installed by the Microsoft Corporation (Hall et al, 2004). The processor for the X5 is Intel XScale with a $400 \mathrm{MHz}$ processor. Hall et al. (2004; p. 11) describes the processor as, "...the brains of the computer-the small chip deep inside the Axim."

The PDA has basically been defined and assessed "...in three distinct periods. In the first period the problem was to create a pen based computer that would provide tremendous ease of use... In the second period, the problem was to create devices that could communicate, particularly over wireless networks. In the third period, the problem was, "to create a device that would synchronize with other computers" (Allen, 1998; p. 7). Seven years after Allen published his historical account of the PDA, the agricultural community has barely scratched the surface of handheld PC research. Precision farming remains the only area where research is being done into the utility of the handheld PC related to agricultural enterprises (Swinton and Lowenberg-DeBoer, 1998; Atherton, Morgan, Shearer, Stombaugh, and Ward, 1999; Batte and Arnholt, 2003; Hoag, 
James, and Frasier, 1999). This research will be the first study looking into the utility of the handheld PC in relation to recordkeeping in farm management.

\section{Diffusion of Innovation}

The diffusion model began in American agriculture in the 1950's (Rogers, 2004). Most of the work at this time was done by rural sociologist investigating Extension problems. The corn study of Ryan and Gross (1943) provided the foundation from which Everett Rogers and others would develop the diffusion model. This type of research has grown into many different fields among those listed by Rothman et al. (1976) in his book, Promoting Innovation and Change In Organizations and Communities A Planning Manual are anthropology, medical sociology, education, and industry. Perhaps the most comprehensive work done on diffusion of innovation is Everett Roger's many revisions of the book entitled Diffusion of Innovation (1962). The last publication of this book was in 2001. By 2004, diffusion related research numbered in the 5000 range (Rogers, 2004). Rogers defines diffusion research as, "the process by which an innovation is communicated through certain channels over time among the members of a social system" (Rogers, 1983). Diffusion research is frequently a long process that, "require a lengthy period, often of some years, from the time when they become available to the time when they are widely adopted" (Rogers, 1983). Due to the longitudinal nature of most diffusion research, this study will not attempt to assess the level of adoption experienced by farmers. Rather this work focuses on the social system described in Rogers (1983) definition of diffusion 
research. In 1983, Dickerson and Gentry analyzed all innovation studies dealing with innovators and came to the following conclusion, "Given the failure to find empirical support for a concept of "innovativeness" that is generalizable over wide range of products, it is not surprising that differing profiles of consumer innovators would be found for different types of products" (1983). As for this study, the concept of diffusion of innovation will be outlined in the literature review, but the findings will not attempt to address the level of diffusion accomplished by the program.

The field of forces communicated by Extension Personnel were placed in the recommendation section of the thesis to facilitate communication. It is highly likely that many concerns and successes would be lost if they were not logged in this study. Further, by providing the comments of Extension Agents in print, personnel will be heard without anyone having to take ownership of a possible rebuttal.

The research methodologies used in this study identified several driving and restraining forces farmers identified as impacting participation in the DEDCMSI. This research uses a multimodal data collection method to identify the variables impacting recordkeeping with technology. Everett Rogers said, "The characteristics of innovations, as perceived by individuals, help to explain their different rate of adoption" (Rogers, 1983). Rogers goes on to describe five characteristics of innovation that, as previously stated, if identified can help explain the phenomenon of adoption. These characteristics are paraphrased in Table 1.3 on the following page. 


\section{Table 1.3 Characteristics of Innovation}

- Relative advantage: the extent to which a particular idea is viewed as better than the idea it came before

- Compatibility: the extent to which a particular innovation is viewed as being consistent with the adopters values, past experiences and needs.

- Complexity: the extent to which a particular innovation is viewed as hard to comprehend and operate.

- Trialability: the extent to which participants can evaluate the innovation with little to no permanent risk incurred.

- Observability: the extent to which the benefits of a particular innovation is comprehended by potential adopters

Relative advantage, "may be measures in economic terms, but ...convenience, and satisfaction are also often important components" (Rogers, 1983). The forces classified under this innovation characteristic will give the change agency some idea into the potential for adoption through the farmer's level of satisfaction.

The level of compatibility experienced between the farmers and the DEDCMSI and its technology in the pilot study will be outlined in the results. The social forces related to, "existing values, experiences, and needs of potential adopters" all will give insight into the level of compatibility existing in the pilot study. Those individuals who are highly incompatible with the initiative and its corresponding technologies and educational materials would have to undergo entirely new value system.

The level of difficulty experienced by the participants in the pilot study will be addressed in the Complexity section of the results. In this research it is believed that as complexity increases the potential for adoption decreases. This 
study identifies the field of forces that are communicated as being particularly complex by farmers in hopes of decreasing the amount of complexity experienced by farmers in the second phase of the initiative.

The amount of trialability experienced by farmers participating in the pilot study also will have a direct impact on the level of adoption achieved. Any driving or restraining forces mentioned in regards to the level of risk or cost they perceive as being associated with their involvement in the DEDCMSI. It is highly possible due to the free costs associated with the Dell Axim and program provided software, the amount of trialability will be extremely high.

Most things that people do, they want to be able to see and feel the results of their labor. Potential adopters of technology are no different. Rogers (1983) states, "The easier it is for individuals to see the results of an innovation the more likely they are to adopt." This innovation characteristic, Rogers calls observability, speaks to the usefulness of the innovations in the DEDCMSI.

\section{Action Research}

There are three elements that must be present if the investigator's efforts are to be considered action research (AR). The essential elements are classified under the following terms: research, action and participation (Greenwood and Levin, 1998; p. 6). Berg (2001) takes the aforementioned elements a step further and identifies two tasks that mainly occur in the approach: (1) Action research intent should be to discover or generate information that will be of immediate use to a group of people, and (2) The information is intended to empower 
participants, motivating them to take action $(p, 179)$. Kurt Lewin, a psychologist who fled Germany in 1933, is most commonly known as the person who coined the phrase action research (Greenwood and Levin, 1998). Lewin also would later develop the theoretical perspective known as field theory which is used in this study. However, John Collier, a commissioner of American Indian Affairs, was also doing similar work at the same time as Lewin, and is thought to have at least partial claim to the now widely known term, action research (Pasmore, $2001 ;$ p. 38). Both of these researchers believed in the idea of involving participants in the identification of research objectives and solutions. In Collier's words, "only participative approach to research could create the conditions under which authentic improvements in race relations..." (Pasmore, 2001; p. 38). Lewin also saw, "democracy and more specifically...action research as a tool that could advance science while dealing with social issues" (Pasmore, 2001; p. 38). Research that can be classified as "Action Research" typically shares the following characteristics: (a) Action research involves people in every step of research development, and (b) The research being done takes place in the real world and the findings have applied implications (O'Brien, 1998; Berg, 2001; p. 179, Greenwood and Levin, 1998; p.19). At the core of this research is the idea that behavior is dictated by different environmental forces and situations in time. Numerous scholars describe action research as cyclical in design. While scholars vary in the exact terminology, action researchers typically come back to the same concepts (O'Brien, 1998; Berg, 2001). According to Greenwood and Levin 
(1998), "a good sign of the learning taking place in an AR project is when the initial questions are reshaped to include newly discovered dimensions."

Due to the research taking place in the pilot stage of DEDCMSI, the research team felt that it was not feasible to approach this phase of research as evaluation research. Evaluation research is often associated with completion of a particular project, a goal that is outside the scope of the seven-month pilot project. Rossi, et al. (1999:1991) describes evaluation research in the following quote, "Program monitoring is usually directed at one or more of three key questions: (a) whether a program is reaching the appropriate target population, (b) whether its service delivery and support functions are consistent... with appropriate standards, and (c) whether positive change appears among program participants." Unlike action research which ask the researcher to produce meaningful results with applied applications, evaluation research ask whether positive change occurred, a question that will be best answered at the end of the second phase of this project.

\section{Democratic Approach to Research}

At the core of this action research is the initiative's ability to ascertain participants' input within every stage of the research. By using an open approach to research, farmers will enjoy a directional influence on the project. In agriculture related research, who better to identify the potential negatives and positives associated with the performance of a program and its corresponding 
technology, than the farmer to whom all findings will pertain? Middendorf and Busch (1996) state the following:

"Based on evidence from the experience of these institutions, we argue that a closer approximation of the 'public good' can be achieved by encouraging the participation to the fullest range possible of constituents as a integral part of the process of setting research priorities" (pps. 45-57).

The institutions that Middendorf and Busch (1996) refer to are the research designs used to achieve democratic participation by the lay public within scientific pursuits. Land Grant University policies typically have not achieved the level of farmer participatory research that this initiative is designed to accomplish. The focus on farmer knowledge and influence rests in a democratized theory of participation. This is what signifies a move away from exclusively elite influence of research towards the citizens' ability to make decisions regarding technology and research (Barber, 1984; Peterson, 1984; Scolve and Scammell, 1995). However, participatory approaches to research do not go unchallenged by the scientific community (Greenwood and Levin, 1998; p. 109). Stevenson and Klemme (1992) state that "democratizing science.... is ultimately unattainable because the public is unable to participate in highly technical decisions" (pp. 111-117). The following reasons for Stevenson and Klemme's (1992) populist views on democratic research are numbered as follows:

1. The subject matter is highly technical, beyond the point of being intelligible to the lay public.

2. The lay public lacks the skills and information (and the time to acquire them) to participate in decision-making.

3. Public decision-making impedes the...decision making process (p. 114). 
These views are justifiable concerns that do not represent insurmountable barriers to this study. Most would agree that farmers do not classify as being in the lay sector of society when it comes to agriculture. There is no greater insight to be offered than that of the farmer who operates within the subject matter every day of his/her working life. Skelton (2001) offers the following in terms of participants' knowledge in qualitative research:

"...I have assured people that what they lack in formal education is more than compensated for by their depth of knowledge and their skill in articulating that knowledge" (p. 112).

From the technological standpoint, the farming public oftentimes will fall into the lay (untrained) classification. However, without the farmer's working knowledge of his/her needs on the farm substantial setbacks will most likely be experienced by any research seeking to identify the farming needs of the twentyfirst century. In some ways, farmers' needs are dictated by their adequacies and inadequacies in relation to technology.

Theory

The theoretical perspective of this research is derived from Kurt Lewin's Field Theory. Field theories origins are in early twentieth century psychology and later in democratic approaches to industries throughout the world. Lewin states that, "Field Theory is best described as a method: namely, a method of analyzing causal relations and of building scientific constructs" (Lewin, 1945). This idea of identifying constructs that prohibit and encourage the use of handheld computers speaks to the research problem in this study. Through mathematical 
representations of the field, Lewin has been able to predict individual action as well as to explain situations with greater clarity. The researcher is urged by field theory to look at a given situation as a whole, taking all the constructs into consideration first, with the closer analysis of individual variables to follow (Lewin 1945; p. 63 and Mey 1965; p. 19). As previously stated, this study focuses on the technological/program characteristics that could be causal variables promoting or prohibiting participation in the DEDCMSI. Through the use of two primary assumptions, field theory constructs can be identified as directional in a given field.

The two assumptions are: (1) "Social phenomenon...can only be fully understood by examining them together in the social field and not as isolated part," and (2) "Within a social field there are counteracting forces at work, both internal and external forces, that affect behavior" (Nolan and Akiyama, 1999; $p$. 101).

The constructs identified by farm families in this study will be compiled and analyzed collectively as suggested by the first assumption previously mentioned in regards to field theory. This first assumption can also be referred to as interdependency. Interdependency, "is the basic assumption of field theory ... that the various parts of a given life space are to some degree interdependent" (Lewin, 1945; p. XII). Most action researchers believe that theory is best understood when it is put to action or practice (Gustaven, 2001; p. 18). It is well within this theoretical perspective selected for this study to identify the field of forces impacting participation in DEDCMI. 
Review of Literature on Instruments

We utilized the transformative strategy of inquiry common to mixed method research designs. The procedures utilizes, "a theoretical lens as an overarching perspective with a design that contains both quantitative and qualitative data" (Creswell, 2003; p. 16). The data collection strategy used within the transformative approach was concurrent. Concurrent data collection uses quantitative and qualitative data to analyze research problem. Usually one form of data is shown within another larger form of data collection (Creswell, 2003). In this study, the qualitative face-to-face interview represents the most significant area of data collection and the survey will be used to define the farmers participating in the study. Further, the use of mixed methods will help relate the voice of the participant. A desire to achieve a democratic approach to research was identified as paramount by West Virginia Extension personnel.

The existing literature in related areas used many of the same sampling methods. Dickerson and Gentry (1983) due to low ownership of the home computer, at the time of their study, chose not to seek the large random sample necessary to achieve representation. "Instead of obtaining a large random sample, we obtained two mailing lists, one from a home computer manufacturer and the second from a popular magazine" (Dickerson and Gentry, 1983). Samson (1998) also identified barriers encountered by Extension clientele in reference to Information Technology. The use of mixed methods in research is "relatively new to social and human science as a distinct research approach" 
(Creswell, 2003; p. 209). The mixed method approach to research is defined as a blend of techniques used to investigate a research question (Hay, 2000). Research methods like quantitative and qualitative approaches are often times mixed so that data generated in one method can be compared/contrasted with data collected in the other. It is important to note that mixing research methods could take place over time, as in lateral studies or in several studies. In this research, however, both quantitative and qualitative research methods will be used within the same study at different points in time. This research project will utilize mixed methods to achieve the following ends: (1) increased flexibility in data collection, (2) maximized response rates, and (3) better understanding of the research question (Groves, Fowler, Couper, Lepkowski, Singer, and Tourangeau, 2004).

While there are many benefits to be gained from using a multimodal approach to research, there are some challenges that were seriously considered before accepting the use of the quantitative surveys and the qualitative face-toface interviews in this research project. Some of the drawbacks associated with using mixed methods in this research are as follows: (1) the time demands place on research related to the collection and analysis of both numerical and text data, (2) increased demand on available resources/funding, and (3) added complexity to research design (Creswell, 2003). The type of mixed method design chosen for this research is pre-experimental. In pre-experimental design, "the researcher studies a single group and provides and intervention during the experiment 
(Creswell, 2003; p. 167)." We utilized four sub-groups, one in each of the four project counties, to make up the one pre-experimental group. 


\section{Chapter III - Procedures}

\section{Research Design}

The overall research design used in this study is grounded in action research. The research problem in action research is explained in terms of a specific situation and setting (Holter and Schwartz-Barcott, 1993). Taking into consideration that the findings in this research would primarily be specific to the practitioners soliciting the study, action research methodology was perceived to be the best fit. It was understood early on by researchers and practitioners alike that the research method would evolve overtime in cooperation with participants (Holter and Schwartz-Barcott, 1993).

Rossi, Freeman and Lipsey (1999: 240) in their book Evaluation: $A$ Systematic Approach states, "...the evaluator should choose the best possible design from a methodological standpoint after having taken into account the potential importance of the result, the practicality and feasibility of each design, and probability that the design chosen will produce credible results....." This research utilizes a basic action research design. The approach stresses four component parts to scientific inquiries and are listed as follows: (1) identifying the research question, (2) gathering the information to answer, (3) analyzing and interpreting the information, and (4) sharing the results with the participants (Berg, 2001; p. 180). Berg goes on to show these component parts of the action research design as a spiral process as shown in the following model on the following page. 
Figure 1: The Action Research Spiral Process Model

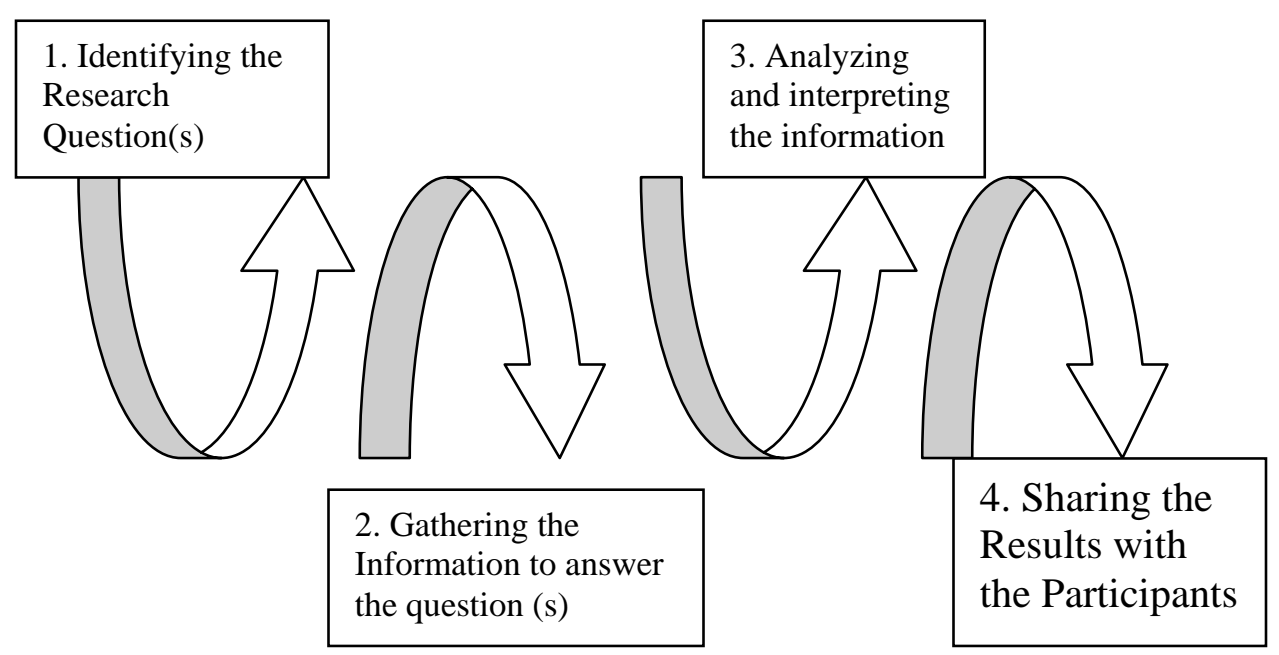

Cite: Berg (2001; p. 181) Figure 7.1

The 'Action Research Spiral Model' will be used in this research by first establishing the problem and then through the help of participants, the research question. Through a process described in the 'Instrumentation' section of the thesis, information will be gathered to answer the research question. After all data has been compiled and analyzed, it will then be shared with the participants. We think that by sharing the findings with farmers before the second phase of the DEDCMSI begins, they will be better able to assess the extent to which the identified forces are present on their farms. Our research design is shown with all the stake holders in the following figure, on the following page. 
Figure 1.1 Research Design Model

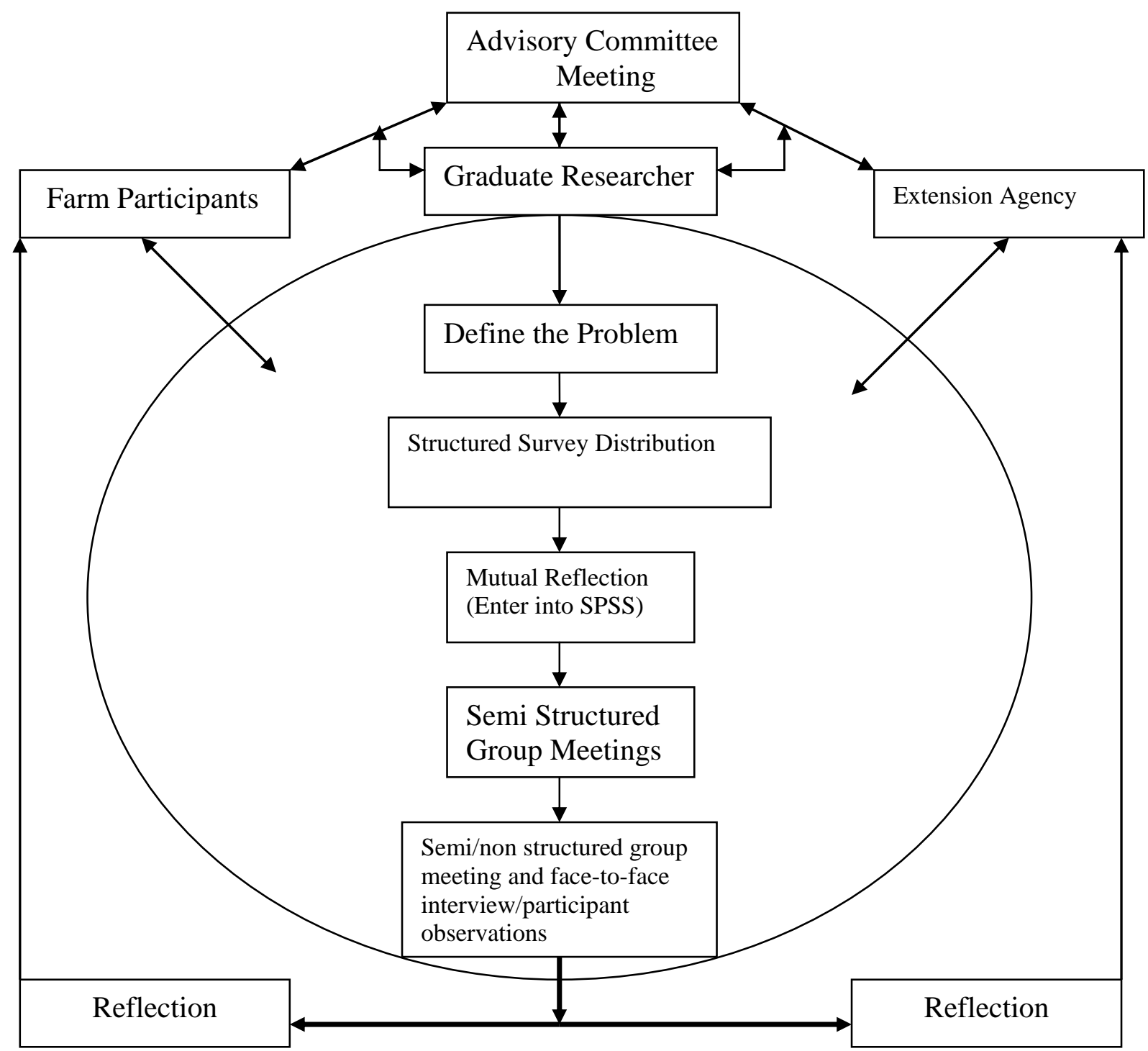

Figure 7.1 of Greenwood and Levin's Introduction to Action Research was the inspiration for this model

In the first stage of this action research the Advisory Committee helped establish the research objectives for the pilot stage of the DEDCMSI. After the research question was established the survey instrument was designed. Over time the questionnaire was evaluated by farmers and Extension Personnel 
serving on the advisory committee. Once the survey was approved by the committee and the Internal Review Board (I.R.B.) the second phase of the action research design was began, the collection of information to answer the research question.

Step three of the research design took place through the data collection. Survey responses came in at the same time group meetings were being implemented. Face-to-face interviews and dictation was also going on in certain counties while still others were meeting in their groups for the first time.

\section{Participants}

In theory those individuals that Extension Agents perceived as being most likely to become early adaptors of the DEDCMSI were selected. The selection of farmers participating in this program was primarily the county agent's responsibility. The issue of selecting participants for Cooperative Extension programs was addressed by Philip Selznick (1948) in his book TVA and the Grass Roots. Selznick (1948; p. 122) contends, "the tendency of the county agent to deal with relatively more prosperous farmers" as an unavoidable fact of

grass roots organization. He goes on to say that, "As educators, the agents have been under pressure to make a good showing so that they often turned to the more well-to-do farm families who might be used to advantage in reporting accomplishments (Selznick, 1948; p.123). Note the following excerpts from Selznick's work subtitled "A Study of the Sociology of Formal Organization":

"Extension must render reasonable service to those progressive people who already have the desire for information." 
In this study the progressive farmers will be a strategic part in reaching the larger, more representative population of West Virginia farmers.

This research was done in conjunction with thirty farmers of a variety of different agricultural enterprises in the following four West Virginia counties: Jefferson, Ohio, Mineral, and Monroe. Of the thirty total farm participants, 27 filled out the pre-survey, which resulted in a $90 \%$ response rate. In this program, $74 \%$ were male and $26 \%$ were female. Farm participants most frequently had 30 to 35 years of farm experience representing $26 \%$ of the total number of participants and 15 to 20 years of experience representing $15 \%$ of the population. Those farmers with ten years or less farm experience comprised $22 \%$ of the participants. In the area of education, $44 \%$ of all participants were college graduates.

\section{Figure 1.2: Farmer Education Obtainment}

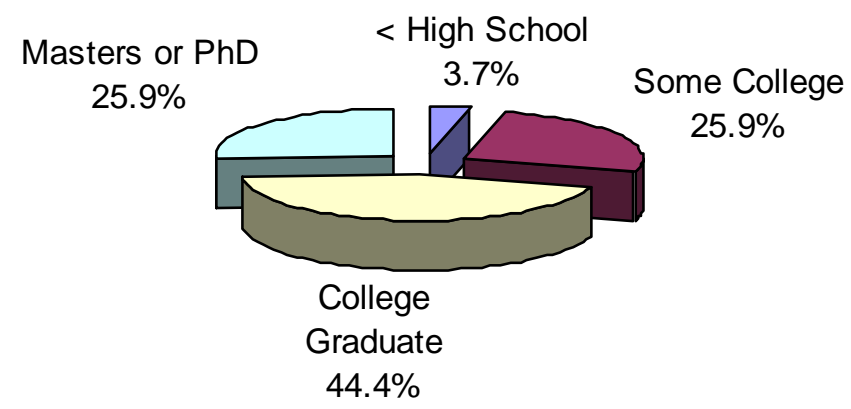


Previous computer training by participants mirrored the cumulative percentage of $70 \%$ related to those participants that have graduated from college or achieved Masters/PhDs. The remaining $30 \%$ of the participants started only had their personal experiences to draw from when it came to utilizing the technology in DEDCMSI. The most common age class of participants was 47 to 52 at $18.5 \%$ of the total population. The second highest concentrations of participants were in the age classes of 37 to 41 , at $15 \%$, and 58 to 62 , at $15 \%$. The last age class with better than ten percent of the farmers - it was ages 32 to 36 , at $11 \%$. The maximum age of a participant in DEDMSI was 81 years of age and the minimum was 21 years of age.

\section{Farm Characteristics of Participants.}

Participants owned an average 156 acres of land and $6 \%$ of farmers did not own any land. Of the respondents that returned the survey, $4 \%$ did not answer the question of acres owned. Approximately $99 \%$ of the participants were involved with livestock in some form. Grain production was part of $53 \%$ of the farms operations in this study. The last two agriculture enterprise categories worth noting were $56 \%$ of the participants involved in vegetable production and $40 \%$ in fruit production. The total farm sales were diverse and spread out over the entire continuum. For a closer look into enterprise characteristics within counties see Table 1.4 below. 
Table 1.4: Farm Activity by Enterprise Proportions Among DEDCMSI

(NASS 2002)

\begin{tabular}{|l|c|l|l|l|l|c|c|}
\hline $\begin{array}{c}\text { Project } \\
\text { Counties }\end{array}$ & $\begin{array}{c}\text { No. of } \\
\text { Farmers }\end{array}$ & $\begin{array}{c}\text { Percent in } \\
\text { Livestock }\end{array}$ & $\begin{array}{c}\text { Percent in } \\
\text { Veg/Fruit }\end{array}$ & $\begin{array}{c}\text { Highest } \\
\text { State Rank } \\
\text { By County }\end{array}$ & $\begin{array}{c}\text { \%ot MVP } \\
\text { Total } \\
\text { MVP }\end{array}$ & $\begin{array}{c}\% \text { of MVP } \\
\text { i } \\
\text { County } \\
\text { Vegetable/ } \\
\text { County }\end{array}$ \\
\hline Jefferson & 13 & $80 \%$ & $20 \%$ & $\# 1^{*}$ Grains & $\$ 17,341,000$ & $59 \%$ & $24 \%$ \\
\hline Ohio & 7 & $67 \%$ & $33 \%$ & $\# 8^{*}$ Milk & $\$ 1,744,000$ & $77 \%$ & $23 \%$ \\
\hline Mineral & 3 & $50 \%$ & $50 \%$ & $\# 2^{*}$ Vegetable & $\$ 14,195,000$ & $93 \%$ & $7 \%$ \\
\hline Monroe & 7 & $100 \%$ & $0 \%$ & $\begin{array}{l}\# 2 \\
\text { Cattle/Calves }\end{array}$ & $\$ 17,236,000$ & $94 \%$ & $5 \%$ \\
\hline
\end{tabular}

Ls* $=$ Livestock

$\# 1^{*}$ grains, oilseed, dry beans, and dry peas

$\# 8^{*}$ milk and other dairy products from cows

$\# 2^{*}$ vegetables, melons, potatoes and sweet potatoes

MVP* For all agricultural products sold in each county for the year 2002

The amount of total farm sales with the highest concentration of farmers was $\$ 100,000.00$ or more pertaining (10\%) of the participants. The second highest concentrations were located in the lowest total farm sales, less than $\$ 1,000.00$, with $7.5 \%$ of farmers, an additional $7.5 \%$ were located in the $\$ 90,000.00$ to $\$ 94,999.00$ sales class. Half of the participants $(51.9 \%)$ had a total combined household income of less than or equal to $\$ 59,999.00$. Only $20 \%$ of the farmers in the four project counties admitted to having experienced anxiety related to computers. Of the respondents, $44 \%$ believed that the computer at least had a chance to increase farm profits. The majority of participants (82\%) had web access either at the farm or in their home.

Participants in this study were West Virginia farmers primarily recruited through a bi-monthly Extension farm newsletter. Advertisements for the DEDCMSI were posted in three of the four participating counties and participants were chosen from those farmers who responded. Consistent with Extension's 
policy in this initiative, a conscious effort was made to include early adopters in the pilot study. The total number of participants in this study were 30 as shown below:

Figure 1.3

\section{Participants Per County}

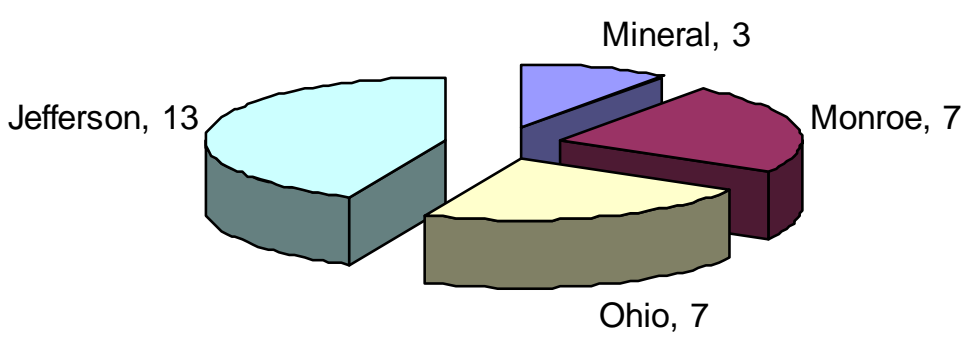

A total of 25 respondents (97\%) found out about this project through the Extension Service. A questionnaire was distributed to each of the four project counties, providing adequate background information on the farmers and the enterprises they dedicate themselves to. Two farm families, however, were chosen by a single agent, in a single county. All participants sampled were done so based on agents' ability to select those farmers who are most likely to help the initiative achieve its goal of sustainability. The agents were only bound by the Operational Systems Checklists (OPS). The OPS checklist is directly related to the participants' home computer and includes the following requirements: 


\section{Table 1.5: Operation Systems Checklist}

- 128 MG of RAM (or greater)

- Windows 98 - Second Edition (or greater)

- Computer less than 5 years old

\section{Instrumentation}

Each instrument developed for the pilot study underwent Internal Review Board approval and were given clearance for distribution by the Advisory Committee. The first of the structured interviews, the pre-survey, provided much needed background information on participating farmers as well as their corresponding agricultural enterprises. The primary areas of this survey are as follows: background (farm/farmer), prior recordkeeping practices, computer use/knowledge, and group cohesion.

The second survey, the comparison group survey intent was to randomly sample the forces/factors driving or inhibiting handheld computer use of farmers that have been randomly selected. This information was collected at the Hardy County Farm Fair. The information collected in this county provided additional insight into the general population of farmers' perceptions of technology. The final surveys intent was designed to ascertain how farmers felt at the end of the pilot study.

Considering that this research has little literature associated with it, it was felt that our ability to custom fit questions to our research purpose would far exceed any pre-existing instruments intended for another information technology. 
Survey structure was gleaned, however, from the Farm Family Survey Department of Sociology at Michigan State University. As previously stated in the justification section of the thesis, handheld computers have a limited field of knowledge in agriculture. It is important to note, however, that the external and internal forces identified in the pilot study will be examined and ultimately used develop a survey instrument for the second phase of the initiative (Newman et al., 1997).

\section{Attrition}

The attrition experienced in the pilot study in reference to the post survey is largely a result of time and timeliness. The first survey process was started by Monroe County in April and completed by the last county no later than June. The timing/timeliness was excellent and the response was 90\%. The post survey, however, did not enjoy the same success. This survey was distributed at the end of the pilot study which was in August. Farmers were under considerable harvest pressure and as a result surveys did not get returned which equated to a response rate of $6 \%$. It is believed that this rate of response will increase as winter approaches and farmers find more time to complete the surveys.

\section{Data Collection}

The data collection approach is the pre-experimental strategy of inquiry (Creswell, 2003: 215). Our effort primarily relied on qualitative data (face-to-face interviews, offset by some participant observations) and to lesser extent, self 
administered surveys all of which are consistent with previous action research methods (Argyris and Puntnam, 1985). Mixed methods will be used in hopes of providing a richer understanding of project and family farm dynamics which contribute/inhibit assimilation into the project. Today an ever growing number of research studies are using mixed methods, "to expand an understanding from one method to another, to converge or confirm findings from different data sources" (Creswell, 2003:15). All forces identified within the social fields of farmers are verified through one of the following; face-to-face interviews, participant observation, group meetings, and telephone conversations.

Data collection activity was initiated in February 2005 and continued through August 2005 as shown in the following figure:

\section{Figure 1.4: Data Collection from February-June 2005}

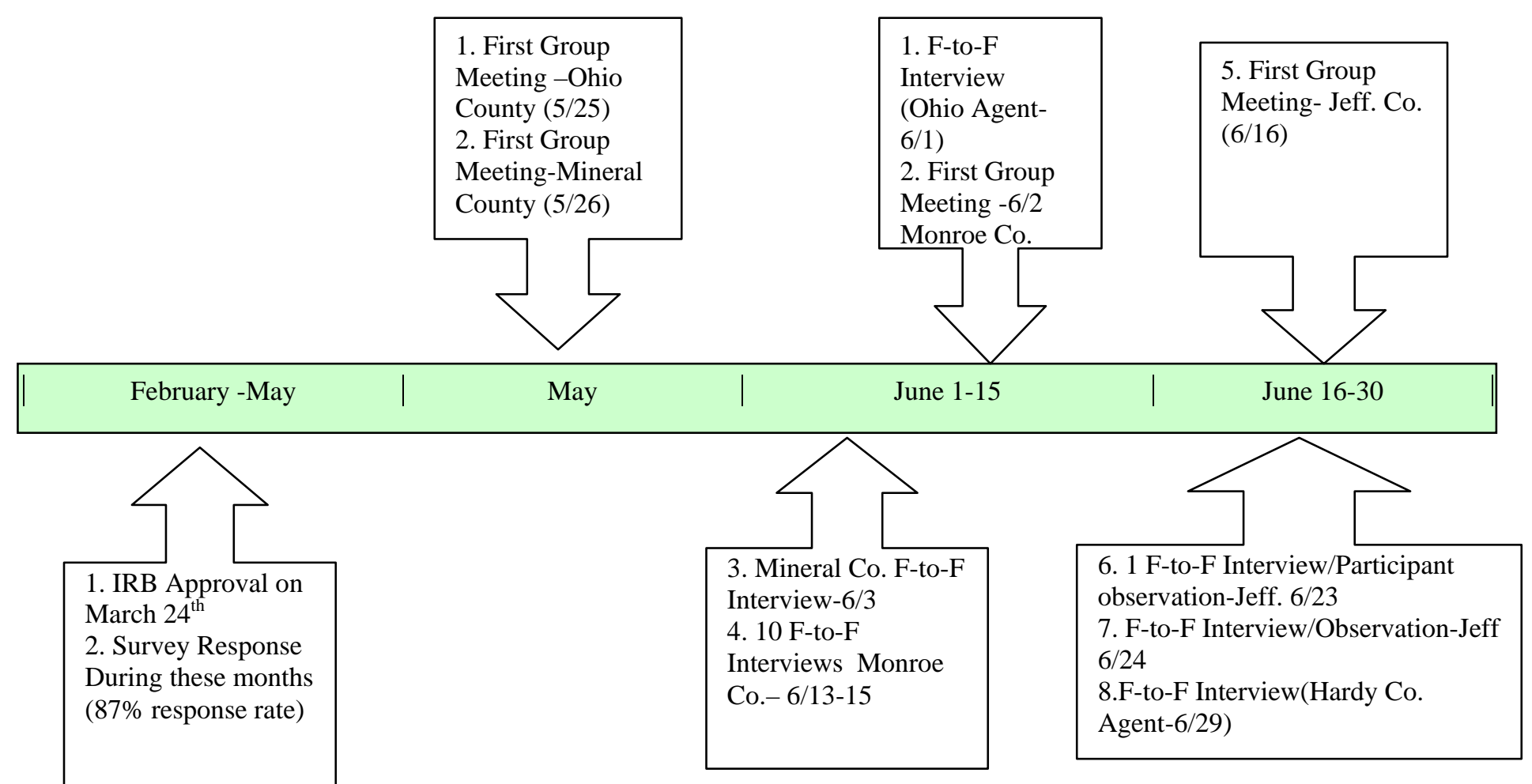


The information collected was intended to either give voice to farmer participants to both their feelings regarding the technological center peace of the study as well as specific project areas needing addressed by extension before the second phase of the DEDCMSI. Each respondent was a West Virginia Farmer in one of the following counties: Jefferson, Hardy, Ohio, Mineral, and Monroe. Before any data was collected the Advisory Committee met two times. In these meetings Extension Professionals, farmers, support staff and information technology representatives all discussed the pilot project's objectives. After these meetings a survey instrument was developed and evaluated by WVU Extension personnel as well as farmers participating in the Advisory Committee.

July would mark the beginning of the halfway point of the field season for field data collection that began in May. During the period depicted in Figure 1.6 those project counties that would have two group meetings started their second. Face-to-face interviews/observations continued through this period as well, with the primary focus being on Monroe and Ohio counties. It is important to note that due to increased activity on many farms during August the previously agreed upon post-survey was discontinued. 
Figure 1.5: Data Collection from July 2005

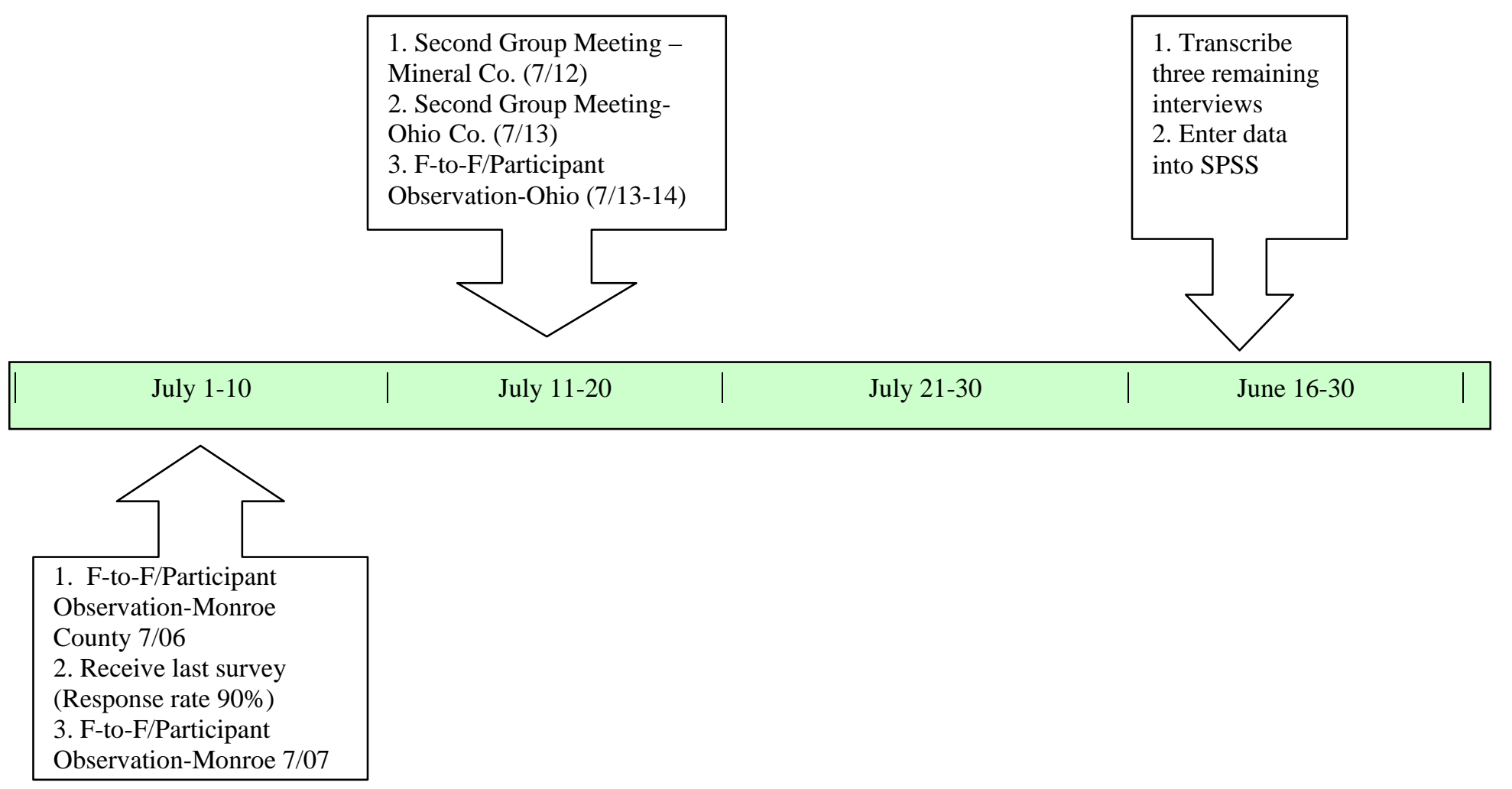

The three types of data collected are listed as follows: structured (questionnaire), semi-structured (group meetings), and un-structured (face-toface/telephone interviews). The total number of interviews and farmers included are shown in the following table on the following page. 
Table 1.6: Data Collection Achieved in Study

\begin{tabular}{|c|c|c|c|c|c|c|}
\hline $\begin{array}{c}\text { Type of } \\
\text { Interview }\end{array}$ & $\begin{array}{l}\text { Mineral } \\
\text { County }\end{array}$ & $\begin{array}{l}\text { Monroe } \\
\text { County }\end{array}$ & $\begin{array}{c}\text { Jefferson } \\
\text { County }\end{array}$ & $\begin{array}{c}\text { Ohio } \\
\text { County }\end{array}$ & $\begin{array}{c}\text { Total \# of } \\
\text { Interviews }\end{array}$ & $\begin{array}{l}\text { Avg. Time } \\
\text { of } \\
\text { Interviews }\end{array}$ \\
\hline Questionnaire & 2 & 8 & 10 & 6 & $26 *$ & NA \\
\hline $\begin{array}{l}\text { Group } \\
\text { Meetings }\end{array}$ & 2 & 2 & 1 & 2 & 7 & 2.5 hours \\
\hline $\begin{array}{l}\text { Face-to-Face } \\
\text { Interviews }\end{array}$ & 4 & 9 & 3 & 4 & $20 *$ & 2.25 hours \\
\hline $\begin{array}{l}\text { Telephone } \\
\text { Interviews }\end{array}$ & 3 & 9 & 2 & 1 & $15 *$ & $1 / 2$ hour \\
\hline Case Studies & 1 & 2 & 2 & 1 & 6 & NA \\
\hline $\begin{array}{l}\text { Participant } \\
\text { Observation(s) }\end{array}$ & 1 & 2 & 1 & 1 & 5 & 4.2 hours \\
\hline
\end{tabular}

*Additional data exist with persons outside of the aforementioned counties.

These semi-structured interviews are described by lain Hay (2003), as being "organized around ordered, but flexible questions." Topics that will guide the semi-structured interviews are provided in the Appendices of this proposal. The results from both of the methods, quantitative and qualitative, will be combined during the data compilation portion of the study.

The Decision Enabling Data Collection and Management System Initiative's data collection procedures established community groups (farm finance groups) in the following four counties of West Virginia: Ohio, Jefferson, Monroe, and Mineral. The pilot project consisted of thirty farm families. Data was collected in the following ways: post surveys, semi-structured farm finance groups meetings, unstructured face-to-face interviews, participant observations as well as phone/e-mail correspondences. A diagram of the sequence is indicated in Figure 1.6: 
Figure 1.6: Procedures of the Research Design for Pre-experimental Strategy

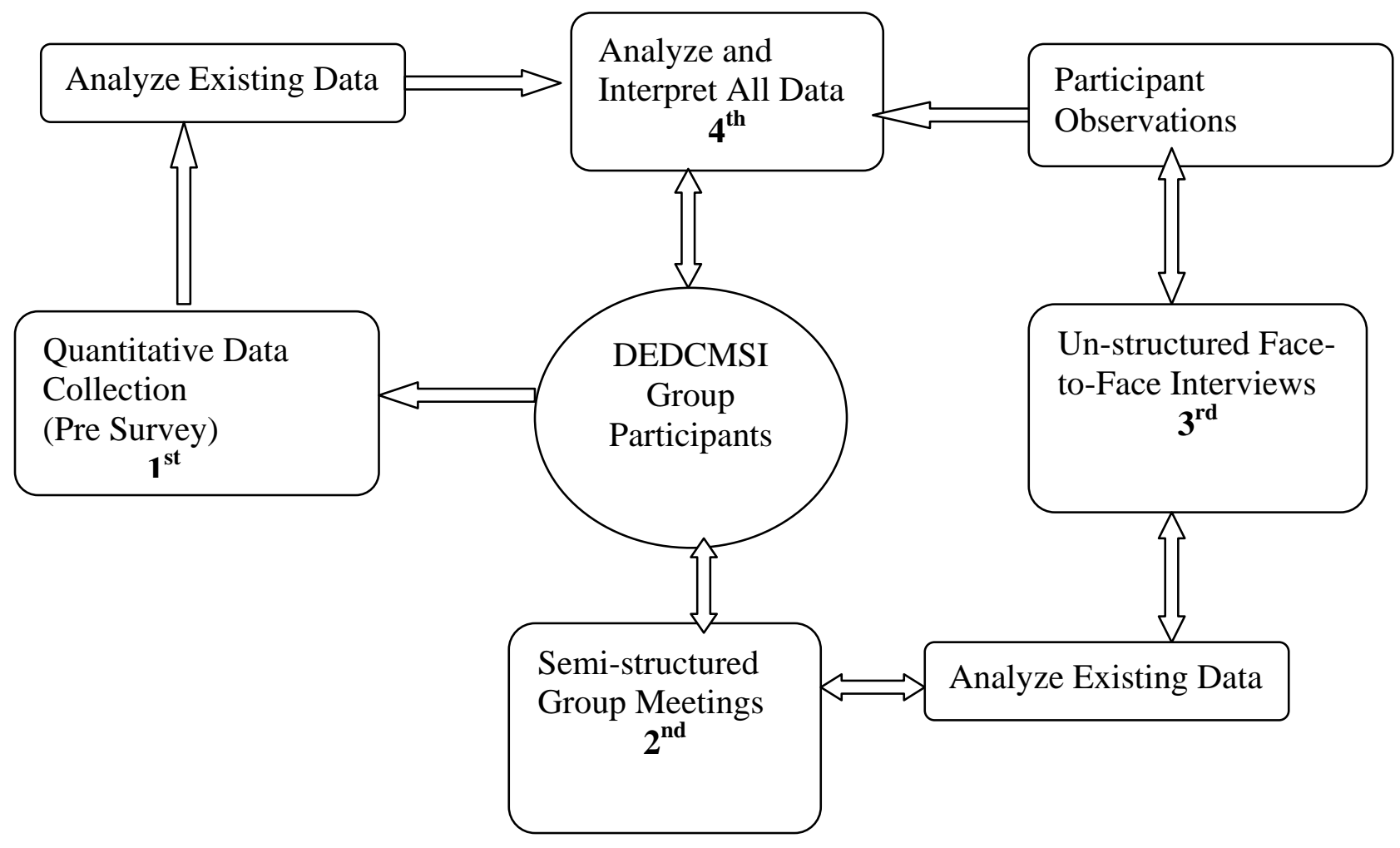

The data was first collected through a survey intended to provide the study with more information on the 30 participants. This survey received a $90 \%$ response rate with 27 of the 30 total farmers returning completed copies. From this point forward all data collection measures were to be various qualitative techniques designed to increase our understanding of participants in this study.

The first qualitative technique used in the research was data collected from semi-structured farm finance group meetings which were held in each county. The content for these meetings were prepared ahead of time by the 
county agent in most cases and by the researchers in a few isolated cases. After one group meeting was complete, in each county, unstructured face-to-face interviews were undertaken. In these interviews it was our intention to allow the participants to control the direction of the content when possible. The researcher started with a general understanding of key themes that were mentioned in the farm finance meetings and used this information as a general guide during the question answer process. These face-to-face interviews were initiated in the following ways: contacts made at meetings, on farm technical assistance and face-to-face interviews done before or after farm finance meetings. Participant observations usually occurred as a direct result from a face-to-face interview. To increase our understanding of farmers' natural setting and how the projects ambitions fit into it, participant observations were used. After talking with farmers for a time they would usually make a reference to some tasks that needed their attention and at that point the offer would be made by the interviewer to help. Other participant observations were planned over a time for specific tasks and times. Finally telephone and e-mail communications were constantly coming and going throughout the pilot study. This type of communication was purely random in nature and the data primarily used to increase the researchers understanding of various problems and successes experienced by farmers (Adler and Clark, 2003). 


\section{Statistical Treatment}

Descriptive statistics will primarily come from the pre-survey and be represented through the use of frequencies and means. When necessary the non-response for figures listed in the text will be given. Due to the small sample size, non-response was observed infrequently in surveyed variables. The textual data collected in this research will be analyzed for the number of reoccurring themes that respondents report. Additional analysis was undertaken in relation to the visual text observed through participant observations. An example of a visual text in this project would be the handheld computer observed in use by a participant on his/her farm. The validation aspects of the mixed method approach will also guard against a Type 1 error when performing data analysis. Rossi et al. (1999: 245) describes a Type 1 error as "concluding that a program has an effect when it actually does not." In the book subtitled, "A Study in the Sociology of Formal Organization" Selznick (1949; p. 250) states, "A careful investigator can minimize error by such means as checking verbal statements...appraising the consistency of information supplied to him, and avoiding reliance on any single source."

The validity of the data previously described is very important if the integrity of the results is to be protected. This research does have potential characteristics that could be disruptive to the integrity of the data if not identified. When dealing with human subjects, sociological variations can arise in the results produced within different modes of data collection. Another drawback 
from multimodal data collections mentioned by Dillman (2000) comes from psychological undertones that exist within different modes of surveillance. Telephone and mail surveys were shown to have substantial differences in results, a combination that will not be used in this research. Every possibility for uniformity within the surveys will be sought. However, as previously mentioned, real time uniformity will not exist between project counties. While a mixed method approach presents some obstacles to the integrity of the data, it is small in comparison to the possibilities of improving response rates and decreasing non-response (Dillman, 2000). This approach will also help reduce the amount of bias interjected into the data collection producer. By utilizing two approaches to data collection, the bias preferences in one method can be offset by the other (Creswell, 2003:15).

\section{Limitations}

It is not within the scope of this study to quantitatively define the extent to which driving and restricting forces were present in the research. We will seek to identify the forces communicated to us by farmers in face-to-face interviews and semi-structured group meetings. Participants were sampled based on fundamental policy decisions within the DEDCMSI. Due to the lack of random sampling in this study a limitation exists in our ability to generalize results across farming communities in the state of West Virginia. Extension professionals throughout the Nation as well as other outreach organizations could benefit from the work done however. This method of sampling is not uncommon in diffusion 
research, which commonly focuses on early adopters in the beginning stages of a study (Rogers, 1983).

This study will utilize the United States Department of Agriculture, National Agriculture Statistics Service (NASS) for the mathematical indicators needed to assess West Virginia counties participating in this initiative. In 1997, NASS was charged with organizing and implementing the agricultural census for the U.S. Government by way of the Appropriations Act of 1997. For the first time in 156 years, the U.S. Department of Commerce, a division of the Bureau of Census would not be responsible for the agricultural part of the census.

A limitation placed on this study, and others like it, is that the statistical methodology was changed by NASS upon receiving responsibility for the agriculture census (2002 Census of Agriculture: WV-Geographic Area Series). The timing of this research creates a significant limitation in relation to statistical indicators and statistical comparisons for all years preceding 1997. A personal interview with Radley Edwards, Deputy Director of the USDA-NASS West Virginia Statistical Office, revealed that in the census of agriculture it was clear that "NASS did not enter into the decision of changing the data collection methodology lightly" (Radley, 2005). Today it is apparent to anyone in the nation taking a closer look into agricultural statistics that NASS representatives chose the integrity and validity of the data over the ability to make historical comparisons pre-1997. Mr. Radley confirmed that "once the decision was made to change existing methodologies of sampling, the ability to make present day comparisons against the historical data collected prior to 1997 was 
compromised" (Radley, 2005). In light of the aforementioned situation, some studies have chosen to ignore the change in census of agriculture methodology and compare historical data across the board (Jung, 2002). Many studies simply worked with the adjusted figures in 1997 without mentioning the issue (Batte, 2004). In this research, historical comparisons based on West Virginia's statistical indicators will be held to the 1997 adjusted figures and those tabulations compiled after 1997. Terminology will be based, to a large extent, on the Census of Agriculture definitions and will be listed in Table 1.3. For example, NASS defines a farm as any business in which $\$ 1,000$ or more agricultural products were sold in one census year. This definition has been in use since 1975 in agricultural data collection and will be used in this research with others mentioned in the Terminology Table. The theoretical perspective that provided the content from which the survey was developed rest in action research. 


\section{Chapter IV - Results}

Introduction

The findings in this study were placed under one of two forces: Driving and Restraining. Factors promoting or inhibiting participation in the DEDCMSI were identified by farmers and Cooperative Extension personnel participating in DEDCMSI. West Virginia Farmers identified 59 variables that they believe impact their participation. Of these variables, 25 were identified as restraining forces, and 15 were driving forces. For organizational purposes all forces were listed under the following project categories: Hardware, Software, Perception of Technology, Perception of DEDMSI and Sociocultural. These categories should help the change agency place farmer concerns and successes in the context of the Extension initiative. Much emphasis was placed on farmers' points of view due to the inclusionary approach desired by Cooperative Extension professional in relation to farmers.

Names, livestock units and in some cases agricultural enterprises have been changed to protect participants. All farmer quotations are in italicized format and have brackets for inserted or replaced text by researcher for clarification or participant protection. Pseudonyms were also used in some excerpts and case studies. When multiple quotes are used to give voice to farmers, a pseudonym will be attached or a generic title will be used, for example Farmer A, B, C. These measures are taken to ensure that participants are not identified. Each individual force has a specific sequence of dialogue. With each new force, under a project category, the letters start over with no relation to 
preceding quotes. Some farmers are used more than once but is far more likely that each new quote is from different individuals. The Dell Axim X5 and X50 were the handheld computers used in this study. Considering $6 \%$ of the farmers had X5 handheld computers, distinctions will be made between the two units in regards to farmer identified restraining and driving forces, when necessary. The two units had far more similarities than differences. 
Restraining Forces

\section{Table 1.7: Restraining Forces Identified by Farmers as affecting their Participation}

\author{
Hardware \\ Home computer hardware Issues \\ Virus potential for home computers with \\ internet access \\ Subscriptions to dial-up Internet Service \\ Providers (ISP) \\ Dell Axim design limitations \\ Reoccurring backup battery power \\ fluctuations/failure for the Dell Axim X5 \\ Software \\ Software installation needs of participants \\ Lack of knowledge related to excel \\ Complexity of Microsoft Access \\ WVU Template problems \\ Data-on-the Run software problems \\ Limitations related to Pocket Outlook's \\ calendar \\ ActiveSync problems
}

Perceptions of DEDCMSI

Training manuals inadequacies

The lack of group agreed target objectives for data entry

Farmer Perceptions' Dictate whether the Innovation will be Applied

\author{
Perception of Technology \\ Fear of data loss \\ Fear of rapidly changing technology \\ The belief that "we are not children of \\ technology" \\ Frustration related to technology \\ Lack of a good place to carry the handheld \\ Fear of breaking the Pocket PC \\ Belief that poor hand writing is the reason that \\ PDA does not register entries in scriber \\ Sociocultural \\ The lack of time \\ Perception that PDA will eliminate/reduce \\ face-to-face communication on the farm \\ Old Habits
}




\section{Hardware}

- Home Computer Hardware Issues

In this study the operating systems of both the home computer and the handheld computer were areas farmers identified as problematic. As previously mentioned in the 'Participant' section of the thesis the selection criteria for the Operational Systems of family farms was the only official elimination criteria used in the study. This criteria of Windows 98 ( $2^{\text {nd }}$ Edition), 256 Megs of RAM, and a home computer no more than five years old was made mandatory. Any version of Microsoft Windows owned by participants more recent than Windows $98,2^{\text {nd }}$ Edition was acceptable. It was noted, however, that some computers with adequate versions of Windows did not have Microsoft Office installed. In many cases farmers needed Microsoft Excel and Access and therefore expressed the absence as an external force restraining participation in the DEDCMSI. Software needs were addressed in the pilot study. Resources put into this problem added to $\$ 1,000.00$. This amount was split between providing Excel and Access to farmers, PDA specific software and mass media software that will be used to increase farmer accessibility to project information. Hardware deficiencies related to the home computers of participants almost did not exist, or at least were not communicated. Farmers were expected to handle all costs associated with hardware acquisitions and for that reason, the amount of communication in this area would have been kept to a minimum. The one farmer that did communicate a concern with the restraining force relating to hardware had USB ports that were malfunctioning. Any problem related to the computers ability to 
read or pick up the Pocket PC is extremely crippling to any participant in this project. This farmer had a professional repair the problem.

- Virus Potential for Home Computers with Internet Access -Subscription to Dial-up Internet Service Providers

The lack of virus protection was an area identified by some farmers as possibly causing operating problems on home computers. This comes to no surprise when you consider that $81.5 \%$ of the participants had internet access. Specifically the number of cookies on the hard drive of some participant's home computers were particularly problematic. Internet access was not the same for every farmer in the project, however. Somewhat of a digital divide existed among those farm families that had high-speed internet access and those with dial-up services. Slow internet prevented farmers from downloading project software in an efficient manner. In some cases it took participants as much as two hours to download software. For those farmers that do have dial-up internet service, DEDCMSI may have to purchase software like Data-On-the-Run and distribute it on disc to those needing said software. In this manner, prolonged time investments could be avoided by participants and compensation, if needed, could be paid directly to the change agency during distribution.

-Dell Axim Design Limitations

Design constraints of both the Dell Axim X5 and X50 were communicated by farmers. One design constraint pointed out by farmers related to the Dell Axim X50 was the Bluetooth button placement on the side of the unit. More specifically the 'Bluetooth' button on the upper left side of the X50 is located 
exactly where one's hand can hit it when the unit is grasped. Farmers were constantly having to turn the Bluetooth wireless feature back off after accidentally initiating the handheld computer to search for wireless networks.

Farmer: "The Bluetooth button on the side of the X50 is a problem. It comes on when we hold it, there needs to be a way to cut it all the way off."

Currently no command has been found on the Dell Axim X50 that will disable the Bluetooth capabilities of the unit and prevent its accidental activation during normal use. Another limitation identified by farmers was the lighting problems related to the user interface when outside. One farmer, in particular, gave good insight into his experience using the handheld computer outside with the following statement:

Farmer: "I can't see the screen on sunny days!"

The problem of PDA screen lighting was common on both of the X5 and X50 and could be easily fixed by navigating to the System features on the unit. The power level is decreased or increased through a slide bar. Axim X5 users can also adjust screen illumination by pressing in the scroll dial while moving the screen up or down. It should be known, however, that the higher the brightness setting the more battery power needed to operate the handheld computer. Note the following excerpt from Hall et al. (2004; p. 23) concerning screen brightness:

“...turn brightness up when you are outdoors or in a location where you need more brightness and turn it down when you don't, in order to conserve battery power."

The user interface viewing limitations in regards to Excel was seen as a limitation. This limitation in Excel basically comes down to columns and rows. You can view twelve rows and three columns on a given spreadsheet in the Dell 
Axims. This limited view does not provide a clear view of the data. Instead the user is forced to frequently navigate within the spreadsheet. Further limitation exists in the total number of columns and rows with 256 columns and 16,384 rows being the maximums (Hall, et al, 2004). Any files farmer wish to move larger than this will be automatically reduced to fit. Pocket Excel is discussed further in farmer identified Driving Forces and Extension identified Restraining and Driving forces.

-Backup Battery Fluctuations/Failures for the Dell Axim X5

The concern for backup power loss was communicated by farmers in group meetings as well as face-to-face interviews, the largest concentration of problems took place primarily in one county. Farmers in this county all had Dell Axim X5s. Differences in battery performance between the Dell Axim X5 and the X50 were evident. The $10 \%$ of the farmers who were operating the X5 Pocket PC experienced backup battery fluctuation levels frequently. Soft resets fixed the problem for a short time, but the issue for $\mathrm{X} 5$ owners reoccurred throughout the pilot study. It is important to note that those individuals who let their main batteries fall below $70 \%$ of a full charge experienced more problems with the backup battery. Most problems could be traced back to the participant's charging practices. Battery manufactures testify that a fully charged lithium battery can provide anywhere from four to eight hours of uninterrupted use (Hall, et al, 2004). Handheld computer users do have the option of purchasing high capacity batteries (3400mAh) lithium ion removable batteries with manufactory proclaimed 
increased longevity. It should be noted that the small percentage of farmers using the older Dell Axim X5s viewed their units as inferior to the newer X50.

Software

-Software Installation Needs of Participants

Unfortunately Pocket PC versions of Windows could not be interchanged with the various versions of Microsoft Windows downloadable on the home computer (Hall, et al, 2004). For this reason dispersing handheld computers with Pocket PC versions of Word and Excel pre-installed did not equate to meeting farmer's software needs on the home computer. While the handheld computers came with Pocket Excel many farmers have it on their personal computers. In the initial stages of the pilot study, some participants did not have a Microsoft Office package on their home computers. Therefore, this was communicated as a restraining force. Over time, Microsoft XP Suite was provided making Access, Excel, PowerPoint, Word, etc. available to many participants.

- Lack of Knowledge Related to Excel

Many farmers were interested in learning more about Excel. In the pre-survey, only $15 \%$ said they used it more frequently than other programs. Of the 27 farmers that filled out the survey, $48 \%$ said they currently use the computer to keep records. This number is $17 \%$ higher than state and national averages, which suggest the target population was captured. It should be said, however, that more positives were identified than negatives related to Excel spreadsheets. 
There is no question that ActiveSync capabilities worked with greater ease and certainty when communicating with Excel and Pocket Excel documents. The real-time capabilities of the single entry recordkeeping practices on farmers were best realized through these two programs due to the efficiency and ease in which they communicated.

\section{〜Complexity of Microsoft Access}

Farmers also described Microsoft Access as being complex and less than user friendly. This restraining factor will strike few in Cooperative Extension as a surprise. Steps were taken at the beginning of this pilot study to harness the power of the Access program, while at the same time minimize the complexity often associated with it. Out of the aforementioned statement came the creation of the WVU Template database which was constructed in Access. Successes of the template are addressed in the Driving Force section of results.

-WVU Template Problems

The WVU template is a series of Access spreadsheets that is intended to address the recordkeeping needs of farmers participating in this project. Farmers identified the WVU Template as a restraining force for several different reasons. Many farmers simply wanted to wait until the database reached $100 \%$ operational capacity before they committed their valuable time entering data into the template. The following comment is from a farmer pondering whether to use the existing template:

Farmer A: "I will wait until he has the other one...I will just wait." 
This type of participant apprehension can be expected due to the problems identified in the recordkeeping database. The aspects of the template cited as being especially problematic are as follows: Field Records, Expense Form, and Cow Table. Field records, as pointed out by farmers, did not have a category for chemical application history.

Farmer B: "..you need to know application date."

While the 'Expense Form' in the WVU Template showed the most promise in meeting farmers' needs in the shortest amount of time, concerns were identified. The primary farmer concern in this part of the Access database was related to the programs inability to calculate the 'Schedule F' totals automatically. Currently farmers who enter expenses in the Schedule F categories have to manually total them and enter the sum into a total field. This act was seen as a major restraining force for those farmers who expected the program to perform addition and subtraction. In the Cow Herd Records, farmers were not allowed to type in the Calving Problem field. It is believed that this field was designated as numerical during the programming process and should have been designated a text field. Considering $98 \%$ of the farmers in this study participate in some form of husbandry it comes to no surprise that health record needs was seen as extremely important and needing immediate attention. It is important to mention that the WVU Template is also listed as a driving force due the potential (Observability) that most farmers saw in it. 
-Data-on- the- Run Software Problems

Data-on-the-Run software makes Microsoft Access viewable on the handheld computer and helped reduce the usual complexity related to the database program. In the DEDCMSI, the act of installing the software Data-on-the-Run was absolutely imperative if the farmers were to evaluate the WVU Template in relation to the handheld. Data-on-the-Run enables Pocket PC users to create and view Access databases in the handheld computer. If Data-on-the-Run was successfully installed, farmers could create Access data bases with greater ease specific to their own farming operations. One barrier identified by a farmer was the mistake of entering and re-entering the wrong Data-on-the-Run site license password in the handheld.

Farmer A: "I got Data-on-the-Run on my computer, but I could not get it to come up on my handheld."

This password problem was solved on the phone with the farmer. Failure to enter the correct password was not a wide spread problem due to on-site download assistance provided to many farmers by Cooperative Extension. As previously mentioned the installation process was often complicated due to slow dial-up internet capabilities. Other farmers with high speed internet downloaded the software in a matter of minutes. There was one isolated instance were a farm family had experienced available memory fluctuations in the Dell Axim X5. Over a span of about two months this problem came and went. Eventually the County Extension Agent removed the Data-on-the-Run software and the problem subsided. 
- Limitations Related to Pocket Outlooks Calendar

Outlooks inability to print full copies of a farmer's calendar was found to be restraining for some participants. The handheld computer was also scrutinized for the inability to beam over seven dates to another handheld computer. Seven dates could be beamed by PDAs only if they were consecutive appointments (days) in the calendar month. For those farms with two Dell Axims and a desire to communicate events in a matter of seconds, this was seen as a major limitation.

-ActiveSync Problems

There were multiple issues raised by farmers concerning the syncing capabilities of the handheld computer with the home computer or desktop computer. Many of these issues were minor and could be fixed by selecting the proper icon in the installation process. For example, if a farmer wanted to sync Microsoft Word with Pocket PC Word, the icon 'Files' must be selected in the ActiveSync Installation process. Other concerns were related to the ActiveSync icon changing colors from green to orange as the software searched for files that had been modified on the handheld and home computers. This problem was communicated in group meetings as well as face-to-face interviews. As it turns out this, "had no technical implication whatsoever" (Dell Corporation Personal Communication, 2005). The color changing ActiveSync icons was simply how the software was designed. 
Other problems related to ActiveSync came from those farmers who had two handheld computers on a single desktop computer. Many unanswered questions were generated as a direct result of syncing two Dell Axim X5s with Microsoft Windows XP 2003 operating systems. Some of the questions are listed here as follows:

1. How should two handheld machines be installed on versions of Microsoft Windows when guest status does not apply to either of the users?

2. Should two user accounts be set up on the desktop, one for each PDA?

3. How can each PDA user navigate their Outlook information in their perspective accounts?

4. What would cause a 'Pocket PC My Documents folder' to be placed on the hard drive without the ability to remove it?

There is no question that the level of comprehension by participant as to how to import and export specific handheld documents in Microsoft software programs on the desktop was not at acceptable levels. To achieve real-time data management the procedures related to synchronization of documents must be understood by all. The presence of confusion comes to no surprise due to the software and hardware providers' inability to provide efficient literature in the process.

\section{Perception of DEDCMSI}

-Training Manual Inadequacies

Farmers identified the Basic Skills Lesson Plan as a restraining force negatively impacting their participation in DEDCMSI. Concern was voiced regarding the computer reading level or complexity of the materials. The following statements 
address the concerns by those farmers who did feel like more detail was needed in the training manuals:

Farmer: "I have some experience with a computer, but I am no genius. If you could have given me a step-by-step direction on how to do this, it would have been much better than to look and try to figure it out."

The education materials for the DEDCMSI were prepared at the beginning of the pilot study and with the understanding that the Dell Axim X5 would be the technological center piece of the initiative. To WVUCES's surprise, Dell stopped the production of the $X 5$ in favor of three versions of the $X 50$. Unfortunately all educational materials had been prepared using the Dell Axim X5. A total of $90 \%$ of participants in the project received Dell Axim X50's. Understandably the educational materials that preceded the handheld devices created a lot of confusion among farmers.

Farmer: "...the book is ok, but it needs improvements. For example import and export information. This book leaves a lot to be desired. It is not a step-by-step outline. There should be a lot more instruction besides just the screens."

Some farmers simply wanted to have every aspect of critical concepts outlined with more detail. Those farmers with past computer experience or additional avenues of computer assistance within their family did not struggle as much. Additional comments related to the training manual were as follows:

Farmer: "My feeling is that a glossary would help as well. For example, when you started talking about icons and desktop, I didn't know what that stuff was initially. Is desktop that screen that I get first? ...definitions and terms would have helped me and I could say, oh yeah, that is that screen when I first turn my computer on, something that jogs your memory." 
-The Lack of Group Agreed Target Objectives

Group restraining forces did not exist in any great number and as a result was not noticeably duplicated in multiple interviews. However, group-related forces was identified by the farmer participants in this study, and therefore, demands elaboration. Note the following statement from a farmer in a group meeting:

Farmer: "Well I still think that we should set some kind of date to have data entered into two of these access data bases."

Group involvement in setting objectives is also listed as a driving force in Table 1.8.

-Farmer Perceptions' Dictate whether the Innovation will be Applied

A belief that enterprise management can not be improved by transitioning from a memorized recordkeeping system. It is important to mention here that this belief was not a reoccurring belief at all. In fact, when it did occur the desire to keep digitized records in another area of the farm seemed to always accompany it. The use of the technology and ultimately the initiative seemed to be based on where the farm member participating in the program spent most of his or her time.

Farmer A: "This technology would be more crucial in my other enterprises than in the Dairy. In some ways it would be nice for the Dairy, but as far as the summer goes, I am in there a very little amount."

-Fear of Data Loss

The fear of data loss was communicated as a phobia rather than primarily technical concerns. It is interesting that while some farmers were apprehensive and feared data loss the fear did not equate into data backup measures. The 
following farmer's statement was altered, as indicated by the only non italicized word in the statement to protect the identity of the participant:

Farmer A: "I did work the livestock and put more data on the PDA a weekend ago and two weeks before that, but I have not synced It."

\section{Perception of Technology}

In the aforementioned farmer quote, the farmer is actively using the technology; however, the fact that the unit has not been synced shows a disregard for data preservation through backup measures. Memory capabilities for the handheld computer as perceived by users were also expressed as a restraining force during the pilot study.

Farmer B: "To try and fit everything we have going on that handheld...I mean I don't know how much memory that thing has, but it seems like it would be too much stuff."

It may be possible after prolonged participation in the initiative to dispel the feeling that the size of the technology is directly related to the capabilities of the unit. The comment also speaks to the training need of what the computer should be used for and where the handheld fits into recordkeeping on the farm. Too many participants thought the handheld was to take the primary computer's place. By incorporating these concerns into the training manuals of the future farmers will be more comfortable with the unit and how it operates. One key point related to memory is the fact that Pocket Word and Excel saves documents automatically when users exit the document screen through the OK button. If farmers know that the machine saves in this manner perhaps some concerns can be put to rest. The automatic save by the PDA does not in any way replace the need for syncing the device which will result in backing the data up. 
It should be mentioned that memory is often added through storage cards by Pocket PC users. User manuals that are shipped with the Dell Axims, after purchase, indicate where extra hardware can be added in storage cards slots. The two different expansion slots located on the Axims are referred to as Secure Digital (SD) and Compact Flash (CF). The compact flash has the ability to hold 4GB and is the location where GPS (Appendix C-Case Study \#4) and other accessories are added. The SD now can be found with up to $1 \mathrm{~GB}$ of available memory and is primarily used for extra storage memories. It is recommended that every use of the technology that is encouraged through educational materials or lesson plans should have equally in-depth directions on how to back the data up.

Fear of Rapidly Changing Technology

Some farmers had previously experienced the rapidly changing nature of technology, and as a result, they were skeptical. The following statements in relation to technology's rapidly changing nature recorded at a group meeting:

Farmer B: "Well my accountant... was using an entirely different program and I would send him my files and great golly he had a $\$ 30,000.00$ program that he no longer uses. I was using Simon and he said he stopped using Simon 10 years ago."

This farmer was pointing out that he had a working recordkeeping software program that he was familiar with, and all of a sudden, his accountant stopped using the sister program that allowed him to share records. Initial investments of time and money can be too high when software changes so rapidly. There is a legitimate fear that technological changes and software companies are here one moment and gone the next, leaving the consumer paying the price. This 
restraining force helps point out numerous implications for DEDCMSI. A few of these forces are indicated by the following three questions:

Question 1: What is the level of involvement for accountants when farmers have achieved an adequate system of recordkeeping?

Question 2: Should farmers make sure that their databases are compatible with a prospective financial consultant's tax preparation program or software (what are the pros and cons)?

Question 3: How often do accountants and others change software?

Due to software issues raised it may be beneficial to train participants in making basic spreadsheet in Excel and Data-on-the-Run. In this way they have the ability to address recordkeeping needs on a task by task basis using technology that is backed by the largest software company in the world, The Microsoft Corporation.

Not Children of Technology

There were also those farmers who considered themselves not to be of the technology generation. This perception was not entirely unwarranted with the most common age class participating in the initiative 47 to 52 years of age.

Farmer: "The thing you have to remember, too, is that, I don't know what our ages are in this room, but we're not children of technology. You know? It is not like I had this in high school, middle school, elementary school or anything else. You look at it this way, this came along for me maybe 8 or 9 years ago. Technology proceeds a lot quicker today. Children in elementary school can do a power point where, as with me, I struggle."

It should be noted however, that few participants in this age class saw themselves as 'technology-type people'; the self-perception did not keep them from participating in the project, nor did it keep them from using their computers. Of the participants in this pilot study, $48 \%$ reported they used their computers for recordkeeping before this program. This amount is slightly higher than the West Virginia state percentage of $31 \%$. The amount of time spent by respondents' 
recordkeeping prior to this program is shown in the following figure on the following page.

Figure 1.8: Amount of time spent by respondent's recordkeeping prior to the DEDCMSI

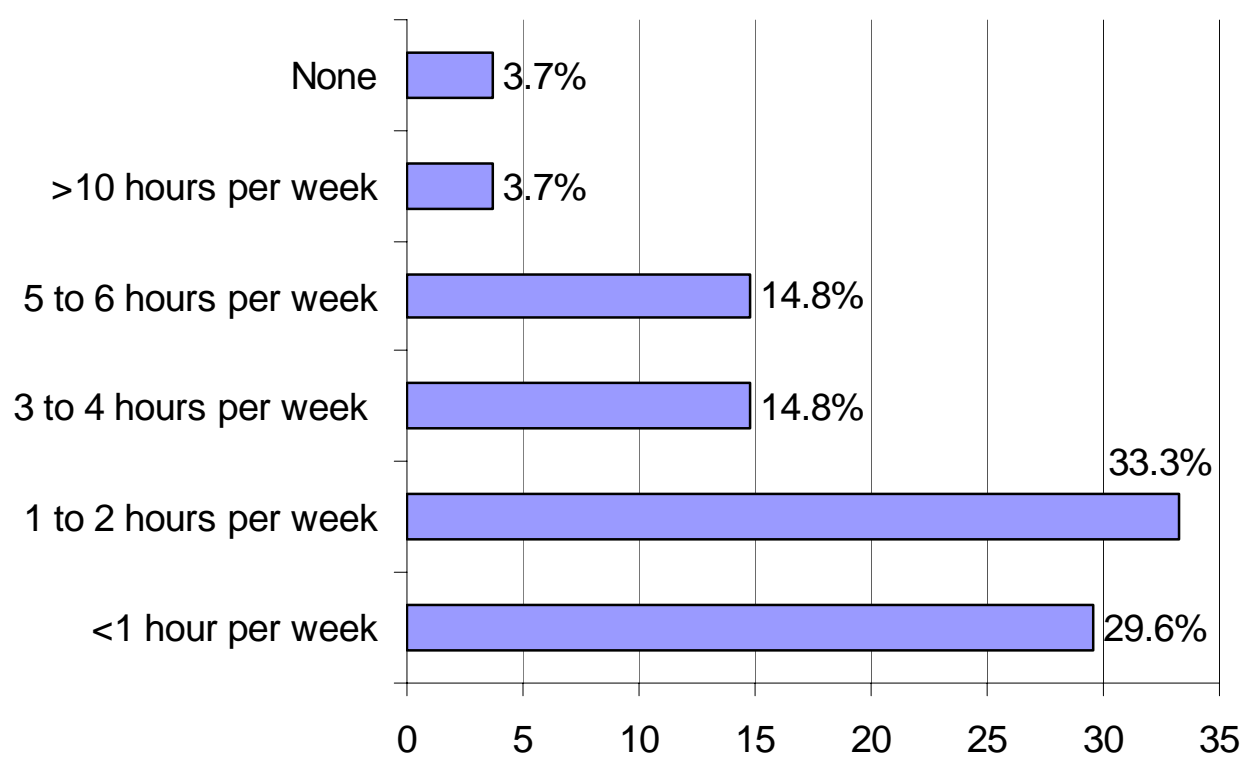

- Letter Recognizer Data Entry

Farmers identified the letter recognizer feature as a restraining force. This feature represents one of the three ways users used the stylus to enter data. The other two methods are known as Block Recognizer and Transcriber. There is no question the restraining force related to handwriting recognition could be reduced with more training and practice related to the operation of the letter recognizer. The unit's failure to acknowledge stylus strokes has more to do with the farmer not knowing which character strokes the handheld computers recognize and less to do with the unit not knowing users' handwriting. The letter recognizer is also listed as a driving force in Table 1.9. 
-Frustration Related to Technology

The previously mentioned point of view related to technology probably is tied to the restraining force 'frustration' that comes from working with the unit.

Farmer E: "Sometimes I get frustrated when working with the Axim, and before I know It, I have to go on to something else."

Given that $20 \%$ of the farmers entered the program having had experienced some level of computer anxiety the aforementioned statement comes to no surprise.

- Lack of a Good Place to Carry the PDA

This force was placed under the project category of 'Perception of Technology' potential variability among farmers and this force we felt was better classified as a perception. While many farmers like the mobility of data, the handheld offers the issue of where to carry the unit was widely discussed and ultimately came down as a restraining force. The fear of breaking the unit, was perceived to be directly related to a lack of a convenient place to carry the unit. It is important to note here that differences between the X5 and X50 exist in structure, a fact that could have a bearing on the 'I may break it' perception. The $X 5$ is not nearly as sleek and is intended to be carried on one side. The X50 is about the diameter of a calculator and easily fits in the farmers' front pocket. The following are some comments by $\mathrm{X} 50$-owning farmers related to this issue:

Farmer A: "I use a Hewlet Packard case... This is handy when I get in and out of the tractor. When I enter things in the field, it doesn't come loose from my belt. One thing I have found you do have to stretch the strap before you can get it to fit the X50".

Farmer B: "I tried the Hewlet Packard case... that thing drove me crazy. I couldn't get it to buckle. When the unit was less than three weeks old, it almost went into a fire from a $2 X 4$ sticking the unit on my side...It didn't go into the fire, but it went directly in the mud, buried! I found one (a case) with the belt loop...it's secure. Hopefully it will drag me before I drag it off". 
-Fear of Breaking the Pocket PC

A small minority of the farmers actually admitted that they were concerned about breaking the handheld computer. The following comment was made by a daughter who was participating in the program with her father:

Farmer A: "I have been around these guys all my life, they bust stuff."

The durability was tested in this project in relation to the task of cutting hay. No problems occurred with the unit in relation to hanging it on the tractor, etc. The only barrier that was identified was related to dirty hands. A hydraulic line had to be replaced on the tractor which greased up the hands in the process. Other farmers were not so apprehensive with their perception of durability related to the Dell Axim.

Researcher: "See some people have been apprehensive about carrying this (handheld computer) in the field. I see that you're not because you have hay field dust on it."

Farmer B: "If you're going to use it, use it!"

Researcher: "That's right, that's what I say, and if it breaks, it breaks".

Farmer B: "Well, I am not going to break it now...take care of it. You can use It, but don't abuse it though."

\section{Sociocultural}

\section{$\sim$ Perceptions of Time}

Time, and the lack of it, was identified as a force inhibiting farmers from using the technology and therefore participating in the DEDCMSI. Farmers cited the lack of time as a restraining force for different reasons. The following excerpts are some of the most common:

Farmer A: "I have hay/beans in the field, two markets I sell at, and a possible third to be added. Time is the biggest thing keeping me from using the darn thing." 
Farmer B: "I have put just over 600 square bails in the barn since you were here last. I haven't had time to do anything with the unit or records..."

Farmer C: "I wish I had time to play with this. It seems endless what it will do."

There is no question that farming is a very busy profession often with no days off just time in between tasks. Small children, not of school age, was identified as a restraining force keeping some farm managers from having more time to utilize the technology. Ironically older children can be a driving force as we will see in Table 1.8. In this case however, children were scene as a primary reason for not entering data or spending time learning the ends and outs of the handheld computer. The following are one farmer's statement related to small children:

Farmer: "But the last six to twelve months I have actually been able to sit down at the computer by myself without ten or twenty extra fingers to help me out. So I am hoping that now that the boys are getting bigger I will get back into it a little bit".

- Desire to Preserve Face-to-Face Communication on the Farm

Another area of concern pointed out was communication on the farm. One

farmer, when asked if he thought having two handheld computers would help him become more efficient in communicating tasks and priorities to farm employees (brother in-law) he replied:

Farmer: "That would be good on a dairy farm because they have employees. I am sure you will talk to someone about that. But that would be very good, I would think, because they do have a large operation and a lot of things going on all the time.

Researcher: "But as for your operation it's not..."

Farmer: "It's not - I mean I enjoy conversing with my brother in-law. I don't mind talking to him. It would be good in my office."

Researcher: "Well that point you made is a good point because that is the social element of it."

Farmer: "That's the fun part of farming, the family, the brother in-law, communicating with my brother-in-law. Definitely we could be spending more time watching the stock market making more money, ha-ha. But it's the other stuff that we do that makes it more enjoyable, being able to live out here and not in town." 
The aforementioned scenario is perhaps the best example in this pilot study of a farmer knowing what he wants from the technology and perhaps more importantly what he doesn't want.

\section{Old Habits}

Agatha Christie, an English mystery writer, wrote, "Curious things, habits.

People never knew they had them." (Moncur, 2005) Farmer's habits were cited by some as a barrier restraining use of the technology/ data entry.

Farmer A: "It is hard to change his habits of keeping everything in his head."

In the aforementioned quote, the transition from a vegetable farmer who has always done calculation is his head to a recordkeeping system that calculated sales, etc. is pointed out by a family member. Many farmers are good at calculations and may have to adjust to the idea of allowing spreadsheets to automatically tally every entry. This particular farmer, however, started using his technology in an extremely efficient manner (Appendix C-Case Study \#1). Other habit related forces identified by farmers were related to the e-mail client in Microsoft XP, called Outlook. Some farmers simply did not want to give up their paper calendar for the electronically managed version. No matter what the potential benefit might be for having events, etc. digitized, the habit of the hard copy was stronger. The following quote is from a farmer with similar internal concerns:

Researcher: "I was seeing if you had Outlook on your computer. Okay you have it..." Farmer B: "I really don't care to use it. Yes, paper and pencil and I get along just fine." 
This farmer was among the exception in the project. Most participants identified Outlook as the most useful thing on the Axim. Calendar, coupled with tasks were the PDA features that farmers used most often in the DEDCMSI pilot study. The farmers essentially had seven months to evaluate the project and the technology to see which components would be most useful to them. It is expected; however, that as more experienced is gained the added exposure will result in farmers using more complex features of the technology for recordkeeping. There may be some benefit in starting participants out with lessons that help them take gradual steps in, "adopting a mobile lifestyle (Hall, et al, 2004; p. 15)." Equally important could be the transition from paper to digital records. Granted this transition is harder for some than others. Most would agree, however, the frustration of not understanding is far greater than the discomfort of moving a little slower in group meetings than one would prefer. The following are habit changing suggestions derived form Hall et al. (2004; p. 15) 'Seven Tips to Help You Adopt a Mobile Lifestyle':

- Don't put off the task of data entry

- Avoid using paper (hard copies). You may want to print hard copies after you have entered the information into the handheld computer, but don't choose to write the information on a piece of paper with the intent on entering into the handheld later.

- Enter expenses as they occur or at the end of each day

- Look for opportunities to make life easier/more efficient through records and the mobile technology

- Keep the unit with you at all times. If you don't have it, you certainly can't use it 


\section{Driving Forces}

Table 1.8 Driving Forces Identified by Farmers as Affecting their Participation

\author{
Hardware \\ Farm access to high-speed internet \\ Pocket Excel operating features \\ The Dell Axims' boot-up speed \\ Letter recognizer date entry on the Pocket PC
}

\section{Software}

Participants building their own spreadsheets

A desire to have a digital calendar

WVU Template's Future Potential

WVU Immediate Benefit

\author{
Perception of DEDCMSI \\ Successful Training Manual Format \\ Farmer initiated target objectives \\ Perceived benefit from participation in the \\ DEDCMSI \\ Communication among farmers outside of \\ meetings
}

\section{Perception of Technology}

$A$ belief that the PDA will be useful

\begin{abstract}
A belief that the PDA is useful
Sociocultural

Reliance on technological savvy family member
\end{abstract}

\section{Hardware}

\section{-Farm Access to High Speed Internet}

Just as the lack of high-speed internet was identified by farmers as being a restraining force, the reverse, high-speed internet, is a driving force promoting participation in the DEDCMSI. Those farmers with high-speed internet access enjoyed extremely quick software and page downloads. The time investments were extremely different between those farms with high-speed internet capabilities and those without. Verizon and City Net were two common ISP providers in this project, especially in the area of the Outlook e-mail client. It is important to mention here that ISPs were responsible for a lot of technical 
assistance in this project, making it even more important that farmers do business with reputable companies.

-Pocket Excel Operating Features

Some farmers found features specific to Pocket Excel allowed for more efficient navigation within spreadsheets. For example, by freezing the pane in the Excel document, a livestock number could be viewed while looking at the corresponding weight several columns to the left. By splitting the spreadsheet of interest into two panes farmers were allowed to see columns not normally in the user interface. This is done by selecting the cell where the split is desired and then selecting split from the View Menu. Freeze panes also allows more of the spreadsheet to be viewed, the difference is that when the column is froze it will not allow for side-to-side navigation. This feature is selected in the same way Split screen is selected. Note the following excerpt from a face-to-face interview.

Farmer: I like that little bar. It helps me in to view the spreadsheets. For instance, if I can see the numbers of the females and then five columns over you can see what percent of breeding they are, but with this view bar it holds one column while splitting the screen and making row five viewable with 1. I needed their number, but I also wanted to view the \% information so instead of trying to remember which line they are on..."

\section{-The Dell Axims' Boot-up Speed}

One operational feature within the Dell Axim that promoted the use of handheld records and data entry was the fast boot-up speed. The speed in which the handheld computer could be activated when powering the device up was expressed as a driving force. Unlike home computers, the handheld computers did not go through prolonged booting up times when powered on. Farmers also viewed the PDA's operating system as less likely to crash or freeze up as compared to their home computers. Note the following correspondence between two farmer participants:

Farmer A: "One thing about these things that I have found that when everybody says when you learn to use a computer you can't break it. Believe me I have been cursed out 
by my daughters, couple of times, for breaking it. They really get mad. This thing I can't break."

Farmer B: "I found out if you don't know what the little dialogue box is asking for, it is better not to do anything."

Farmer A: "Yes, I have crashed a computer a couple of times."

It is important to note here that the word, 'break' used by Farmer A is referring to computers freezing, and the processor, no longer accomplishes or accesses the last commands it was referred to by this farmer as 'breaking' the unit. Farmer A was pointing out that he feels more comfortable accessing and using programs on the handheld computer than he does the home computer.

- Letter Recognizer Data Entry on Pocket PC

A program deemed useful by the farmers once the unit was on was that of the Letter Recognizer feature. A farmer with sustained success in relation to the Letter Recognizer Program is quoted as follows:

Farmer: "I can write on this thing even as sloppy as my hand writing is. My daughter is amazed at how my writing is picked up and a few choice words when it doesn't for hers. I was told it has a program for klutzes. It has worked great, and we used it several times".

To see how this farmer used the technology in the context of his vegetable farm see (Appendix C-Case Study \#1). In order for farmers to successfully input data into the Axims they have to master the soft input panel (SIP). This panel is where users write the various letters to make up the words, numbers and symbols they wish to enter. This panel is split into three sections with very distinct purposes. Farmers in the project must realize that the far left of the SIP is for capital letters only. The middle one-third of the SIP is for lowercase letters and the far right section only reads numbers. No lowercase letter should be written above the 
dashed line and never entirely between the dashed line and the bottom most line of the SIP. The Axims also allow users to change some features of the Letter Recognizer by selecting Options in the Input pop-up menu (Hall et al., 2004). The Transcriber features also have the ability to learn a users handwriting through Letter Shapes Selector. It is apparent from this pilot study that either all three methods of handwriting recognition be addressed in training materials or one method recommended and promoted through educational materials. It is recommended that the Letter Recognizer be used over the two other methods of handwriting recognition.

\section{Software}

-Participants Building Their Own Spreadsheets Many farmers in this initiative found it within themselves to create their own spreadsheets using both the desktop PC and the Pocket PC. These farmers identified their recordkeeping needs and in some cases used recordkeeping concepts from the WVU Template. It should be known that many farms already had spreadsheets created before their involvement with the DEDCMSI. However, all participants keeping records prior to their participation in this initiative were doing so using a double entry system. Note the following farmer comment:

Farmer A: "I transfer all data into my computer from handwritten records in the field." 
The aforementioned farmer question is an excellent example of a double entry recordkeeping system. This farmer has kept pedigree records on his herd since 1997. There is little question that a person of this type who has a long history of keeping records will be more likely to participate in the DEDCMSI and utilize the technology. There is also little doubt that this type of participant stands a good chance of being an opinion leader in the initiative. Farmer creativity was in its highest concentration within this section of the research. Those farmers that looked to spreadsheet production as being beneficial to the well being of their farm were glad to show off their work, a fact that resulted in much qualitative documentation. There is a real potential to drive the project on the successes farmers have had in creating their own spreadsheets in Excel. Many farmers created their own spreadsheets specific to their farming operations and needs. The following goat farmer describes her Excel spreadsheet as:

Farmer B: "This is our base herd records. It has their number, gender, heritage, birth weight, birth dates, and their breeding percent (boar versus the cow). So all of our basic stuff."

Beef cattle farmers kept similar information on their handheld computer. It was not uncommon for one spreadsheet to have column headings indicating Cow ID, Calf ID, Birth Date, Birth Weight, Sex, Calving Ease, Weaning Weight, Cow Rating and Cow Age.

$\sim$ A Desire to use a Digital Calendar As previously mentioned the e-mail client Outlook did have some limitations and therefore has been as a restraining force by farmers and is listed in Table 1.7. 
Most farmers were interested in communicating their schedules to employees,

family members, etc. Beaming calendars were appealing to participants as well,

even though the limitations in how much of a person's calendar could be

transferred to other PDA users ended up as a restraining force. The following is

an excerpt from Case Study \#3 in Appendix C.

"John also serves on the Soil Conservation District, is the President of The County Chamber of Commerce, and remains engaged in other civic activities. Teresa points out, "You only have about 50 meetings a week"! The Hopkins family believes that Outlook's (Microsoft e-mail client) compatibility with the handheld computer and home computer offer schedule management features that will be useful. By syncing the hand held computer in the afternoon when John gets home from work, all of his appointments go into the Outlook calendar on the home computer making all of his appointments available in two places simultaneously. In this way Teresa can access John's calendar without him being present, and the reverse is true for John (Case Study \#3; p. 149-154)."

Other farmers that found the Outlook software useful had ambitions of increasing their familiarity with their clientele through the Outlook address book and the Business Contact Manager, an extension of the Outlook software. Case Study \#1 (Appendix C) shows one farm family's idea of creating pictures in Business Contact Manager to create a connection and shopping history with customers. Through the Business Contact Manager, farmers can rate customers financial status, payment status, and list the customers preferred method of communication (Habraken 2004). Another farmer saw an opportunity to use Outlook and Pocket Outlook as a way to organize his spray schedules. His methodology is described here in his own words:

Farmer: "I drew a picture of sweet corn crops and what I was doing is a lot better of drawing on paper. I was trying to figure out which fields I had sprayed, applied chemicals to, which ones I had to re-spray that sort of thing. What I do need to figure out is how to put in square footage. I have the spray schedule on these and that is handy that keeps us update on what we need to spray all in notation form. What I do is spray fields and enter them on the calendar. There is a 14 day window that you can spray on the fruit and what I do is go 10 days and mark it on the calendar as a reminder which gives me a 4 day grace period to get it done in case it is too windy." 
-WVU Template's Future Potential

The WVU Template was seen by many participants as having enormous potential for the future. As previously stated in restraining forces, however, the WVU Template was not without problems. These problems did not keep the farmers from viewing the recordkeeping software as a driving force encouraging participation. The template represented all the things most recordkeeping software companies fail to do; provide a product with in-state technical support, attempt to make the product better through farmer suggestions, the ability to attach a face with the software, and finally the peace of mind that comes with not having spent hundreds of dollars on the program. At the moment anyway the hope that the template will meet their needs in future was enough to list the template as a driving force, note the following two examples:

Farmer A: "We would like to enter the cows we buy and sell all in one place." Farmer B: "I currently keep the kind of records in the WVU template and the thought of having all those fields right there with you in the handheld is great!"

Farmer B, a dairy farmer, desires a recordkeeping package that will allow her to transform her paper and pencil recordkeeping system into a single entry digitized system. This farmer knows exactly what information is important to her dairy; she desires help in utilizing the technology to make the current recordkeeping system more efficient. Farmers saw the WVU Template's potential to track herd health information as particularly appealing. One progressive dairy farmer who was already using a PDA for herd health checks liked the WVU Template's program related to individual cow health concepts. The Palm VX was the PDA 
technology she first attempted to keep health records with it is described by her as follows:

Farmer C: "This thing is slow, I've got a vet who I pay by the hour and this thing won't come up!"

This farmer sees the value of keeping the health records listed in the 'Cow Herd Record' table of the WVU Template. The 'Cow Herd Record' major malfunction was that it did not allow participants to make entries in the calving problem field. These minor issues were counter productive in creating farmer confidence in the system. Farmer C's method of keeping herd health records, etc. is done in the following three categories: Herd Record (Tag \#, Date of Purchase, purchased from, freshening date, monthly herd health notes, selling date and price, death notes), Herd Daily Health Notes (Tag \#, freshening date, gestation in days, previous/current month herd health notes) and Production Sheet (Production Sheet: month, Day, Tank Wt.). Currently Farmer C prints blank spreadsheets in Excel and fills in the aforementioned information. Farmer $\mathrm{C}$ desires to make her Vet visits more efficient through the utilization of the technology in her own words:

Farmer C: "The vet wants to know herd health notes from last month and make notes of what he tells you. He usually tells you the same thing, it's just a different month. The thought of having all that information right their in one place is great!"

The 'Expense Table' with its Schedule $\mathrm{F}$ tax categories drew positive responses as well. Note the following two potential uses identified by these farmers:

Farmer D: "See if one vendor offers a better deal on a specific item than what you paid last week at a different vendor."

Farmer E: "You would know in December if you need to buy something before taxes." 
Farmer D's statement speaks to the mobility of data. Farmer E addresses data analysis and its impact on farm management. As previously mentioned, however, the fields in the 'Expense Table' would not tally entries automatically and therefore kept the participants from realizing the immediate potential.

-Immediate WVU Template Benefit

This template's immediate utility should not be identified solely on the level of operation at the time of the pilot study. There is something to be said for the template's ability to stimulate conversation in regards to the recordkeeping concepts it addresses. The machinery inventory was the one aspect of the program utilized in the pilot study by a number of participates. The farmers who used this form had an Access field to enter in the following; Model Number, Manufacturer, Serial Number, etc. Purchase date and price of a machine are two more categories that will eventually become important as more farmers begin their data to make management decisions.

\section{Perception of DEDCMSI}

-Successful Training Manual Format

Certain aspects of the training manual were seen as extremely beneficial to the farmer. For example, Chapter 5.2 of the training manual had information in it that was seen as beneficial for farmers just starting the program.

Farmer: "The piece that I liked was the Ch 5.2. You had little diagrams, and they were circled. That was very, very helpful." 
This farmer points out the visual imagery in the training manual chapter allowed for more efficient navigation through the written material as well as the tasks of putting that knowledge into practice. Additional farmer input in relation to training materials can be found in the restraining forces section of results (Table 1.7).

\section{-Farmer Initiated Target Objectives}

The farmer's suggestion of setting group agreed recordkeeping target objectives is extremely insightful and shows a farmer who is taking the initiative within the group. Extension Personnel are very committed to making this project sustainable and comments like this are a noticeable step in the right direction. The ideas that each individual agrees to have a certain amount of data (records) entered by an agreed upon date would help motivate farm managers to spend time with the technology and do data entry. This type of farmer motivation should be encouraged! The DEDCMSI is grounded in sustainability. If Cooperative Extension is to meet their goal of creating peer facilitated farm finance groups, the driving force of 'Farmer Initiated Target Objectives' should be increased. The lack of this force, was listed as a restraining factor limiting participation in the DEDCMSI. It is our belief that if this initiative is to enjoy sustained success, participants must demonstrate this type of self-motivation.

-Perceived Utility of the DEDCMSI

As one might expect the presence of perceived DEDCMSI utility among farmers was an enormous motivator for participation in the initiative. Farmers perceived the program useful for a variety of reasons. For example, farmers wanted to 
keep purchase history records, as well as price justification. A strong desire to provide clientele with price justification records through the use of DEDCMSI technology was also observed. This perceived utility was documented in Case Study \#1 (Appendix C). Many vegetable farmers seemed to be driven by the feeling that physical/financial records will give one an opportunity to become a price maker and not a price taker.

Farmer A: The ultimate for me is to identify what my price per unit of production is for my crops and ultimately compare that to the different leased properties as far as fertility and performance. I just want to know the actual cost it took me to produce a basket of fruit

Security through documentation in husbandry operations was communicated as a motivator for participation. The belief that current Premise Identification program will eventually be made mandatory created a since of urgency among some farmers. There were also those farmers (primarily beef enterprises) that wanted to increase the amount of records they keep per production unit in hopes that the hard data could serve as a form of insurance-protecting the rest of the herd from possible extermination in the event of disease, like Bovine Spongiform Encephalopathy.

Farmer B: Wants to track calves from the time it's born to the time it's sold (Wt., weaning, and sell)

The desire to become more efficient in farm operations through other participants' management practices was also identified as a driving force in group meetings. Participants easily could see the benefit from learning how other farms classify and enter records.

Farmer C: Obtain a level of recordkeeping practices that will allow a farm manager to incorporate records into the decision making process

Farmer D: So I want to be able to access a database through the does so that I can track her history and make management decisions based on those records. If the kid has a 
high birth weight great, but if it doesn't put it on, it doesn't matter. Like we had one little kid born at 5 pounds (smallest ever), but she had better weight gain than everybody else out there. So I don't care about birth weight so much so long as they had the gain. So to be able to pull that up through a database is important.

It was apparent that many farmers participating in this program kept detail records in certain aspects of their agricultural enterprises. This fact considered, there is no disputing that most participants know which records they want to keep, they just lack the technological know-how to increase efficiency and application potential. Efficiency comes from making electronic records portable, data entry easier, and realizing the real-time capabilities of the technology. Most farmers communicated what they wanted from the initiative once dialogue was started. Take into consideration the following beef cattle farmer's statement: Farmer E: "I am not interested in farm finance. We use a tax consultant for the farm" It could be that this farmer will come to appreciate the benefit of keeping financial records through the eyes of his peers who found farm finance as a major area of concern. Until that point, however, the initiative will need to meet some of this farmer's specific needs, which were communicated as follows:

Farmer F: "I need the program to have chemical template resident times built into entries. So if I administer a shot I know by the date and automatic calculation when it is safe to eat."

Other records desired by Farmer $\mathrm{F}$ were in the area of dams and sire pedigree information as well as Al (Artificial Insemination) inventory. The important point here is that the DEDCMSI have the capacity to meet the participant where they are at in relation to understanding and perceived use. In the area of hardware, however, requirements can not be relaxed, in fact they may need to be tightened. Farms with multiple stakeholders involved were seen as a driving force. A few farmers co-owned or participated in cooperation with other operations which 
complicated inventory overhead cost allocations and profit distributions. This phenomenon was identified as a reason for participation in DEDCMSI. A strong desire to organize each farm's investment was evident. This same motivator was communicated by those farmers participating in calf pools.

A desire to make better management decisions through directed recordkeeping was also communicated by participants. The farmer highlighted in Case Study \#1 (Appendix C) in particular, realized his current methods of recordkeeping, in his head, was not accurate enough to meet the farms needs. Consistency was the motivator driving his participation. Other examples of forces driving farmer participation in DEDCMSI are listed here as follows:

Farmer G: "As a maximum I would like to be able to demonstrate that people who are half way intelligent and want to work can be in the pluses instead of the minus as far as the economics in farming. Well I would like to be a demonstration for people that wanted to do this sort of thing. Currently we haven't focused our attention on profitability instead we have focused on being an organically grown and sold farming operation."

Farmer H: "Identify the best organic sellers and begin gardening with tenacity!"

〜Communication among farmers outside of meetings

Some farmers pointed to communication among group members outside of meetings as a driving force. This force primarily refers to the interaction at farmers markets where most of the vegetable growers in DEDCMSI. There is a high potential for this group dynamic to facilitate learning. 
Perception of Technology

$\sim$ A Belief the PDA will be Useful

This is the category with the largest response by farmers during the face-to-face interviews and participant observations. Most farmers demonstrated a degree of observability during the seven month pilot study. The belief that the PDA was useful manifested itself in many different ways. The following excerpts are two examples of how farm families plan on using the Pocket PC in their perspective enterprises:

Farmer A: "this will be good to track what farm they (cows) came from cause that is going to be real important soon with the Cow ID."

Farmer B: It would be a major, major thing for us to know how to do stuff like cutting a maize with handheld."

As previously mentioned in $\sim$ Farmer Identified Target Objectives by produce stand operators desiring information that can provide on site price justification to their customers. This potential utility was discussed in Case Study \#1 (Appendix C). County groups also expressed the need to communicate schedules, calendars, etc. One farmer's idea in reference to communication facilitated by the handheld computer is shown in the following excerpt:

Farmer C: "I get all the publications from Ohio's big dairies and they find that communication is the problem. A guy told me the other day that he is a contractor that manages two different groups of Spanish speaking people (speak differently). He could understand one, but couldn't understand the other."

During the interview with Farmer $\mathrm{C}$, it became evident that the handheld computer could serve as a potential language bridge. For example, if the farm manager types tasks with the desired information on the home computer and then changes the language to Spanish before downloading on the handheld 
computer the language barrier has been bridged. Instantly, the Spanish speaking farm manager has the day's tasks in his handheld unit and can communicate the responsibilities to the large work force.

\section{$\sim A$ Belief the PDA is Useful}

The desire to communicate with other PDA users was strongly felt among those families that were given two Pocket PC's per households. Many farmers almost immediately adapted the idea of machine inventories on their handhelds, as noted in the $\sim$ WVU Templates Immediate Potential - Participants found the Machinery Inventory in the WVU Template to be of immediate use. Conceptually speaking farmers used the template to learn what categories could be used to place enterprise data into. As far as utilizing the template in the handheld, it was problematic. Data entry into the WVU Template and the transfer of data from the handheld into the desktop computer seemed to be the largest obstacles facing the farmers. This transfer process of the Access database over to the handheld computer problems are covered in Chapter V- Summary, Future Research and Conclusion in the $\sim$ Areas of Active Sync Not Clarified section. During a participant observation the actual moment of observability in reference to machine inventories was recorded; as shown in the following correspondence. The names have been replaced with generic terms or pseudonyms to protect the identity of the participants:

Farmer Worker: "That is not the right belt for this mower. This is the right belt." Farm Manager (Rich): "That's the right belt?" Machine Worker (Jake): "That will sure make a difference in the way..." 
Farm Manager: "Well then how did you end up getting the right belt and the belt we had wasn't right."

Farm Worker: "Rich!"

Farm Manager: "You told them what we needed?"

Farm Worker: "Yea, well I always do that. You have to take the model number and stuff you know and get a... belt."

Farm Manager: "You just can't buy a belt that looks similar to what you already have."

Farm Worker: "No, you can't go down to the farm supply and match it up, that doesn't work."

Farm Manager: "Doesn't work? Ok! Well we have a way of learning things the hard way around here Jake."

See Case Study \#2 (Appendix C) for more information concerning the above farm. The correspondence between the Farm Manager and worker shows how this particular farmer came to the realization that by keeping his machinery serial numbers and corresponding model numbers on his handheld computer mistakes like buying the wrong mower belt could be avoided. This mistake of purchasing the wrong part basically comes down to serial number breaks. A farmer described the utility of a portable machinery inventory in the following interview excerpt:

Farmer A: "Let's take this for example the John Deere Tractor 2555. They made this tractor for probably 8 years, but the serial numbers breaks. They made different type of parts for this tractor depending on when it was built during that 8 year span. So the serial numbers are very important. So at lunch I will put in 2555 and the 13 digit serial number and that will tell me what fuel pump I need."

Knowing how a mistake can occur, it becomes easy to see how this problem can be compounded for those farmers who live long distances from the nearest parts store. Note Farmer A's experience:

Farmer A: "...you drive 40 miles to the parts store and the guy asks, "What is your serial number?" Well I have no idea and there is three oil filters depending on when it breaks. So a machinery inventory will eliminate a lot of problems. Like a young parts manager that don't know what he is talking about." 
This perceived utility also speaks to the portability of data by the handheld computer. In the twenty-first century much attention has been given to the accessibility of information. The handheld computer is seen by farmers as being useful in specific information available. Through the increased mobility the Pocket PC offers farmers can analyze data on the go not being tied to the hardcopies in the office. Some farmers actually viewed the Pocket PC as being more user friendly in setting up spreadsheets than home computers as shown by the following dialogue:

Farmer C: "In a year or so after we have been using this thing for a while we want create documents on here as much. But I can guarantee you for the next couple of years we're going to creating things on here (The PDA)".

Researcher: "You don't think you would create it the night before. You wouldn't know what the document looked like?"

Farmer C: "That's part of it. Like right now we have our little farm and we are pretty well in a routine. But just this year he started fencing in other people's properties. So we need records on different bands of goats on different properties and we want to know what we need in the document until we go there. So we will do more creating on here (PDA) than we will be on there (Home Computer)."

\section{Sociocultural}

-The Family Factor

Some family farms enjoyed an added advantage in the initiative due to technological savvy family members or friends. More times than not the participant fortunate to have such a person usually had them in their immediate or extended family. One example of a daughter helping her father realized the potential of DEDCMSI's technology is found in Case Study \#1 (Appendix C). In fact, children as young as eleven were seen as positively impacting participation in DEDCMSI and ultimately the utilization of handheld technology. 
Special interest in specific capabilities of the Pocket PC also motivated farmers to participate in the study. One farmer in particular, wanted to learn more about the handheld computer in hopes of achieving independence in an area of his agro-tourism business that currently is done by a family friend. The area of concern for this farmer, as shown in Case \#3 (Appendix C), is a corn maize. The participant would like to learn more about Geographical Information Systems on the Pocket PC and saw the DEDCMSI, which uses the same technology, as a good place to start.

\section{Extension Restraining and Driving Forces Introduction}

The driving forces identified in this study can not always be juxtaposed to a competing restraining force, meaning some variables only exist as a driving or restraining factor, not both. Recommendations will be offered, however, in regards to the direction these variables should go if participation is to be maximized by the agency.

The intervention agency in this study is seeking information that will give farmers the resources (training, hardware, software, etc.) they need to achieve their recordkeeping goals. The forces identified in this section of the study were either identified during data collection or by County Extension Agents working with farmers in project counties. Comments communicated by Extension personnel in relation to the initiative were combined with research observations to generate the list of forces in Table 1.9. Project categories that these variables 
fit under are listed as follows: Hardware, Software, Perception of DEDCMSI, Perception of Technology, and Sociocultural.

To eliminate unnecessary duplication topics covered in detail in the previous two sections of the Results will not be listed in this section for a second time. Those forces that are duplicated in both sections were done so due to the importance of the concepts and extra space needed to describe the phenomenon from the change agency's prospective.

Table 1.9: Restraining and Driving Forces Identified By Extension As Affecting Participation

\section{Restraining Forces \\ Hardware \\ Lack of cradles for every farmer \\ Inability to hook up system correctly}

\section{Software}

Data-on-the-Run

Variability in Operating Systems

Recordkeeping in Microsoft Word

Inconsistency in the versions of Microsoft Office used to create the WVU Template

Areas of ActiveSync that were not clarified

\section{Perception of DEDCMSI}

Lack of technical support provided by dell

Neglecting to communicate participants' role as opinion leaders in the county groups

Malfunctioning e-mail addresses

Perception of Technology

Keeping up with changing technology in training materials and beyond

\section{Hardware}

\section{Driving Forces}

Owning a cradle

Clear understanding of the role of the PDA and home computer

\section{Software}

Free visual display software

Software discounts given by manufactures

Excel's supreme ability to achieve real-time recordkeeping

\section{Perception of DEDCMSI}

The Utilization of farm successes for educational materials

\section{Perception of Technology}

Project website

Rapidly Changing Technology 
Hardware

-The Cradle

The importance of the cradle to the user was not realized by the Dell Corporation until 2003. During this year the X5 started coming with a USB cradle and based on our observations, this was a good idea. Everything about the cradle promotes better charging by handheld users and consequently better performance. The cradle has an extra slot which is designed for an extra battery to be placed until needed. Farmers also have a convenient place to set the unit after a hard day in the field. If there is no substantial holder for the PDA and farmers are asked to use a USB synchronization cable and a separate cord for AC adaptor, the chances are far less that they will take the time to look for the extra wires that probably have fallen down behind the desk. Few will dispute that if the technology does not have a dependable power source the chances of it being useful is diminished. For this reason, cradle ownership is listed as both a restraining and driving force. Note the following quotation in reference to battery charging habits:

"The most common usage scenario is to drop your Pocket PC into the data/charging cradle while you are... at home at the end of the day. In most cases you will not have to deal with low battery" (Hall, et al, 2004).

-Inability to Hookup Systems Correctly

This restraining force did not exist on a noticeably large scale during the pilot study. The fact that insurmountable problems arise when participants hook up the Dell Axim wrong demands that more instruction be given in the future on this 
topic. If farmers know what a USB port is and manage to hook up the unit at the correct time during the ActiveSync installation procedure but fail to connect the cradle cord with an adequate power source, charging problems will ensue and confidence in the technology will suffer.

\section{Software}

$\sim$ Variability in Operating Procedures

As previously mentioned, the selection criteria related to participant's Operating Systems on their home computers was set at a liberal Windows $98,2^{\text {nd }}$ Edition. This selection criterion created a pilot study with a large amount of variability concerning operating systems. Initially our concern was primarily related to the participants' computer and their machines ability to load needed software as well as operate under increased memory demands. After completion of this seven month pilot study there is no question that future selection criteria should be uniform with all participants having the same version of Windows. Technical assistance effectiveness is simply compromised when farmers, owning Microsoft

Windows $98,2^{\text {nd }}$ Edition, encounter technical issues and all training manuals and Extension experience in place to help them is related to Microsoft XP. Note the following comment by an Advisory Committee Member serving as aN Information Technology consultant to the initiative:

IT Staff: "I am telling you different versions of Office will make technical support almost impossible."

This statement could not have been truer during the seven month pilot. With limited resources to put toward direct technical assistance on the farm or even 
the phone it makes good sense that solutions and work underwent to achieve them could be better magnified if all farms participating in the initiative are on the same page.

-Recordkeeping in Microsoft Word

Many farmers began working with the handheld computers as soon as they received the units. This type of excitement should be encouraged, but it is our intention to illustrate here the potential dangers of large amounts of data entry in Microsoft Word and the corresponding Pocket Word on the PDA. Information like farmers' machinery inventory in Word limits the efficiency in which the data can be used. Without columns attaching numbers to notation and organizing numerical entries the user has placed his or herself at a disadvantage. Note the following farmer quotation:

Farmer: "I also have some poultry sitting on eggs, and hatching dates, and planting dates on plot \#1,2,3 beans etc. all in notation form."

The records mentioned in the above quotation preceded any instruction in Excel and therefore was done in notation format using Microsoft Word and Pocket PC Word. We believe that many farmers getting a jump on the program entered data into the note feature in the Pocket PC as well. Those participants that use the aforementioned programs as oppose to Microsoft Excel and Pocket Excel may have to re-enter data after they learn the power sacrificed from the use of programs intended for dictation. 
- Version of Microsoft Office used to Create the WVU Template

It was apparent that the WVU Template could be created using multiple versions of Access databases. The two most commonly discussed during the course of the pilot study were Access 2002 and 2003. The newest version of Access, 2003, was distributed to participants in this project through the DEDCMSI. There were, however, some 2002 versions of Access being used by participants and Agents alike. The Microsoft Corporation says the following about Access database compatibility:

"In most cases, you'll want to convert a previous version to Access 2000 file format if all users have upgraded to Access 2000 or later, and you'll want to convert to Access 2002 - 2003 file format if all users have upgraded to Access 2002 or later. In Access 2002 or later, you can modify data and make design changes to an Access 2000 file."

For simplicity sake, it is recommended that the second phase of this project choose one version of Access to meet database needs on the farm. For those individuals who don't possess that agreed upon version of Access, site license should be purchased."

-Areas of ActiveSync that were not Clarified

The User's Guide (2003, p. 68) that comes with the Dell Axim gives this brief introduction about ActiveSync:

"You can synchronize the information on your computer with the information on your device with ActiveSync. Synchronization compares the data on your device with the data on your computer and updates both with the most recent information." 
This statement is followed by a couple of basic examples related to Outlook in the User's Manual. Nothing is mentioned by the Dell Corporation about how different operating systems (Microsoft Office or XP) demand different steps before they can be linked to the handheld computer or Axim. For example, the typical procedure used in the pilot study for synchronizing Access files was to drag the file from the desktop to the mobile device icon. This was an uncommon procedure when syncing files. Microsoft Excel and Word document could be linked with Pocket PC by placing files in the Pocket-PC My Documents Folder. This folder is created automatically after successful installation of ActiveSync software. If Microsoft Access documents were not placed in the Mobile Device icon the real-time capabilities could not be realized. Further, spreadsheets created in Pocket Excel and not the desktop version of Excel failed to accomplish synchronization and therefore real-time recordkeeping was not a possibility for these types of documents. As previously stated, however, Excel spreadsheets created on the desktop computer proved to be the most reliable spreadsheet program for ActiveSync purposes during the pilot study. It is possible that this fact could change as Cooperative Extension personnel and farmers learn more about Microsoft Access capabilities on the Pocket PC.

-Free Visual Display Software

Visual Display Software was found by a County Agent participating in the program. This software allowed users to view the Dell Axim screen on the desktop PC. Once the user interface of the handheld computer was transposed 
on the home computer screen data entry could be accomplished through the use of the desktop keyboard and mouse. It is easy to see how a program that transposes the PDA screen on the desktop screen could be useful in group meeting demonstrations. The software also allowed more efficient use of the Data-On-the-Run software. This software allows Microsoft Access spreadsheets to be viewed and created on the handheld computer. This was important because Access as viewed through Data-On-the-Run was seen as being less complex.

-Software Discounts

Software discounts given by manufacturers refers to the ability to obtain substantial cost reductions from software providers. One such discount in the pilot study came from a Colorado based software provider of Solstice. Solstice was manufactured for handheld computer users who wanted to access the power of Quicken recordkeeping software on the PDA. A discount of $\$ 100.00$ and one year of free technical service was obtained for all farmers in the DEDCMSI. In the future, Cooperative Extension personnel will need to make contact with other Quicken compatibility providers at the following websites: www.landware.com and www.spbsoftwarehouse.com

- Excel's Consistency in Achieving Real-time Synchronization Microsoft Office Excel's ability to synchronize with spreadsheets on the home computer was a driving force. It is mentioned here again to address the potential 
role of Excel versus Access in the second phase of this project. There is little doubt that farmers using Pocket Excel enjoyed more successes than those trying to achieve the real-time data entry and syncing through Access programs. The Pocket Excel program allowed farmers to view and manufacture spreadsheets tailored superficially to their operations with the greatest ease during the pilot study. The documents have one of the following extensions: .pal for workbooks and .pat for templates (Hall et al. 2004). If the Cooperative Extension Agency chooses to meet farmers' needs in the DEDCMSI by utilizing the Pocket Excel and Microsoft Excel spreadsheets the compatibility limitations should be well understood. Hall, et al. (2004; p. 83) gives the following list of Pocket Excel supported functions of Microsoft Excel:

- Standard text formatting bold, italics etc.

- Fonts by default: Courier New, Tahoma, Bookings and Frutiger Linotype

- The following Cell formats: general, number, currency, accounting, date time percentage, fraction, scientific and text

- The following Alignments: horizontal, vertical, word wrap

- Row heights and column widths

Those Microsoft Excel features that Pocket Excel does not support are listed as follows by Hall et al. (2004):

- Formulas with arrays will be converted to text in Pocket excel

- Functions are limited (select tools menu then insert function command to see a list)

1. pivot tables

2. borders with more than single lines

3. vertical text

4. hidden names

5. passwords

- Settings that will be restored

1. Graphics of any kind 
2. Auto filter: allow the spreadsheet to only show the data of interest

3. Add-inns

8. Scenarios

4. Data validation

9. Text boxes

5. Cell notes

10. Hyperlinks

6. cell patterns

7. Cell \& sheet protections

11. VBA scripting

Some alternatives do exist for PDA users wanting to focus on elaborate spreadsheets.

Software is available to allow the viewing of full Excel documents at www.westtek.com, but editing is not an option yet (Hall, 2004).

\section{Perception of DEDCMSI}

-Lack of Technical Support Offered by Dell

As previously mentioned in the section of $\sim$ Areas of ActiveSync that were not Clarified there were some severe problems related to syncing files. Problems like software installation and Pocket PC operation system difficulties have also been explained in previous sections. Through these challenges the Dell Corporation refused to answer any questions related to software issues. Understandably, this comes to a big surprise considering their usual excellence in the area of technical support and the importance of software in achieving real-time data entry with the Dell Axims they sell.

Neglecting to Communicate Participants' In Sustainability Effort As previously mentioned, one of the major long-term objectives for the DEDCMSI is that the county groups become self-sustained with County Agents serving as advisors. Opinion leaders in project counties will be absolutely crucial if this objective is to be reached. Having said this, very little was mentioned to participants in reference to the participants in reference to their role as opinion leaders in the program. It is our belief 
that many farmers will eagerly take on the role of facilitator of their farm finance group. Those counties with two family members actively participating in the initiative have a higher likelihood of finding people that have time to help lead.

- The Role of the PDA and Home Computer

There seemed to be an unanswered question related to how the PDA is to be used on the farm in relation to the computer. This lack of clarity probably is in higher concentrations on the participant side of things than by Cooperative Extension personnel. It is our recommendation that the role of the PDA be more tasks specific and the demands placed on the unit be reinvented as the needs on specific farms change each day. For example, if a beef cattle farmer is working cattle on Friday, then Thursday night the beef cattle spreadsheet that developed for this activity should be placed on the handheld device. When other spreadsheets or files are needed they are added, replacing previously used spreadsheets. Memory can be added as described in The Fear of Data Loss restraining force to increase the device's capacity to carry more information as well as eliminate unnecessary file removal. In no way should the handheld computer substitute the home computer in data storage, analysis, and data entry. There were some participants who would take data down on paper and then transfer it into the Pocket PC, and finally sync it with the home computer. This is an extremely labor intensive way to enter data and should be addressed in training materials and group meetings. In fact, farmers demonstrate a lack of understanding related to the PDA and home computers. 
-Malfunctioning e-mail Addresses

During the seven month pilot study, Information Technology personnel worked with Cooperative Extension staff to create a project list serve. This list serve theoretically had all participants entered into an Extension Electronic Mailing list. Unfortunately, many emails were wrong and were left out of the loop. It is recommended that all County Agents send DEDCMSI staff copies of e-mails sent to their participants in their perspective counties. The correct e-mails then can be re-compiled with accurate accounts. This solution is recommended due to the high degree of communication among participants and County Agents maintained throughout the pilot study.

-The Utilization of farm successes for educational materials

In this project, benefits could be realized if the successes of opinion leaders/early adopters could be realized and highlighted in group meetings. Farmers will be more likely to understand the information being presented if their peers present it. Further, as previously noted one of the main goals of the DEDCMSI is that the groups be selfsustainable. Participants will be more likely to identify certain individuals within the group as leaders if opinion leaders have assisted in the educational presentations in the past. Successful application of the DEDCMSI could be found in each of the four counties. It is our belief that these successes should supplement the project lessons. 


\section{Perception of Technology}

Rapidly Changing Technology in an Atmosphere of Adult Education

This concept was previously covered under farmer identified restraining forces but due to its importance it is reiterated here from the change agency prospective. Rapidly changing technology represents a real challenge for Cooperative Extension personnel who desire to take on the monumental tasks of introducing technological innovations to farming families in West Virginia and beyond. The lesson plans that are to come from the DEDCMSI should have measures safeguarding against the passing of time and its tendency to make training materials obsolete. For this reason it is recommended that the lesson plans written at the end of the DEDCMSI be as much about delivery methodology as specific mechanics are related to the functionality of the technology.

\section{-Project Website}

The project website was an enormous driving force in the pilot study. Farmers could access the website and instantly get software links, training materials, and contact information on project affiliates. All of these benefits were realized at varying degrees during the course of the pilot study. It is our recommendation that this momentum be carried into other aspects of the project. County recognition is a virtually untapped aspect of the website that if utilized could increase excitement about recordkeeping with technology. We suggest that the case studies generated from this research be posted on the website, with the farmers' permission of course. Further group meeting pictures will also aid in generating interest. These materials should be segmented by county to ease navigation of the site. Currently the web design responsibility falls on one agent. It is our recommendation that one participant per county be given the opportunity to prepare 
materials for web postings. The materials that could be posted by the Cooperative Extension Agent are by the participant farmers/family members. True, time is an issue especially when it comes to busy farmers. However, there may be potential to incorporate a family member. In light of busy farmers, perhaps a young family member seeking to add to a high school resume could meet this project need. No matter who ultimately takes the web masters job on for a particular county it is important to create opportunities for participants to take ownership through delegation of responsibilities if the sustainable goal is to be met. 


\section{Chapter V - Summary, Discussion, and Conclusion \\ Project Category Summaries}

\section{Hardware}

In this study thirteen issues related to hardware have been identified and elaborated on. Of the thirteen hardware issues, seven were classified as restraining, and four were listed as driving forces. This information is intended to increase extension educators' knowledge about hardware topics encountered by participants as well as communicate hardware issues to other communities of interest.

\section{Software}

The project category of 'Software' had the most classification listed of any other table. A total of eighteen factors were related to software in the pilot study. Eleven of these factors were considered restraining forces and seven were listed as driving forces. It should be noted, that the project category 'Software' has the most driving forces classifications listed of all the themes identified in the research and therefore should $\mathrm{b}$ a major focal point for extension. Unlike 'Hardware', extension professionals have grant authorization to allocate resources for meeting participant software needs.

\section{Perception of DEDCMSI}

Participants' perceptions in relation to the DEDCMSI consisted of a total of ten forces. These factors were split evenly between restraining and driving forces. Each of these factors specifically related to the program in some way, regardless of whether it was identified by Cooperative Extension personnel or farmers. 


\section{Perception of Technology}

This project category also had ten forces identified as affecting farmer participation in the initiative. Eight of the ten were classified as restraining forces and the remaining two identified as driving farmer participation. This project category is unique in the sense that changes will come slower and more likely than not, one farmer at a time. The factors identified should serve those individuals whose tasks it is to prepare training materials well.

\section{Sociocultural}

The 'Sociocultural' had the fewest forces identified as affecting participation. A total of five forces were identified: three restraining and two driving participation. All of these forces were viewed as being internal to the farmer or farmer environment. It is important to note these factors typically existed before the participation in the DEDCMSI.

\section{Positionality}

In this research the lines between researcher and change agency were meshed. The role of the researcher went beyond the in-depth interviews and participant observation used to identify the driving and restraining forces that occurred in the program. There is really no way to remove the researcher from the change agency when the level of researcher involvement is considered. The researchers duties included, but were not confined to the following: write training manuals, organize advisory committee meetings, provide technical support to farmers and project affiliates, distribute target objectives decided by advisory committee, perform frequent phone calls to agents in participating counties, 
identify need in project counties, seek approval for meeting identified needs and see that it gets to desired locations, attend $100 \%$ of the group meetings and type minutes, provide instruction for some group meetings, evaluate the WVU Template and negotiate software discounts with applicable providers. For this reason, observation and data collected by the researcher in the field is meshed with those identified by the Extension agency in the results.

\section{Critical Reflexivity}

In hopes of increasing the ability of the researcher to reflect on what was done a research journal was maintained throughout the study. This journal was used to confirm dates of data collection as well as personal interpretations of what was said and observed. The democratic approach to research allowed farmers to have an active role into how the research would move forward. As previously stated, two to four farmers were present at every Advisory meeting. One point needing reflection is the potential for overwhelming farmers with technical aspects of the program. For example, database development was discussed in detail in two of the meetings and those farmers that were present were noticeably confused and as a result had little impact in the discussion. In this isolated case those farmers present probably would have been better off if they were not present. Other issues however, like survey content, training manual suggestions, and various other project critiques from a working farmer's perspective were extremely beneficial and should be duplicated in the future. Another project characteristic that was beneficial was the face-to-face technical assistance provided by the DEDCMSI. This sentiment is mirrored by the following statement from Extension Specialist Tom McConnell, “we can't just throw money and resources out there and not have a consistent 
presence helping farmers figure how to best apply the technology to their specific situation enterprises."

\section{Future Research}

This study identified factors that are driving participation and those behaviors that were restricting participation in the pilot study. The next stage of the research begins on January 1,2006 . It is our recommendation, that the 59 variables (forces) identified in the pilot study be used to develop a survey instrument. The purpose of this instrument would be to quantitatively assess the degree to which each of the 56 forces recognized, existed on participants' farms and project counties as a whole. In this manner, information that was qualitatively collected through semi-structured group meetings, un-structured face-toface interviews and participant observations serves as a basis for the survey instrument questions. By listing each force in this study as ordinal variables in this survey respondents will be given the opportunity to communicate to what extent these forces exist on their farm. Nolan and Akiyama (2002; p. 91) describe the transition from their qualitatively obtained forces in focus groups to the Likert-type five-point scale survey instrument as, "... a score of 1 indicates a low-level presence of an encouraging or discouraging force with a 5 indicates a high-level of presence of a variable." In much the same way the WVUCES will be able to break down the restraining and driving forces indicated in the pilot phase of DEDCMSI.

Once the surveys have been distributed and completed, mean scores will be generated based on respondents' answers and then compared across project counties. This information will provide insight into the field of forces that are unique to each county. In addition, factor analysis would allow the West Virginia Cooperative Extension Service 
to collapse the 59 variables, through correlations, into broad classifications; further categorizing project constructs (Nolan and Akiyama, 1999). The end result of the factorial analysis will be to confirm or dispel forces identified in the pilot study on a peer group and entire DEDCMSI levels. Cooperative Extension will know how and where to focus their future efforts. Other research opportunities exist in the following questions: (1) Would adopters of the Pocket PC mirror those farmers in diffusion of home computer innovation? (2) What differences would exist among farmers attempting to apply technology that is smaller in size and extremely more mobile?

\section{Conclusion}

Many issues that occurred in this study in relation to the handheld computer could be found in a book or prevented by more strenuous planning. Problems encountered during the pilot stage of the DEDCMSI should be eliminated with greater ease and efficiency after this study. It was amazing how small problems could stop the progress being made with technology on farm in its tracks. The more participants know and learn; the less likely simple aspects of the technology will slow progress and the greater the chance they will adopt the technology. Characteristics of innovation as stated in the literature review allow innovation researchers to assess the potential rate of adoptiontherefore identifying potential broad problem areas. Observability, trialability, complexity and compatibility all were observed as encouraging participation in the intervention project. These innovation characteristics are defined in greater detail in Chapter II in Table 1.3.

Observability by farmers was evident through their eagerness to share how they wanted to use the handheld computer and the WVU Template. The evidence that this 
characteristic of innovation existed in the pilot study can be seen through the $\sim$ Pocket $P C$ Utility in Chapter IV of the thesis. The trialability in this project is viewed by the researchers as being extremely high. The handheld computers were made available to participants free of charge. Even though participants incurred large amounts of time investments in the project, it was not believed it adversely affected trialability. Most software needs were met free of charge to farmers. The overall risk associated with participation with the project was low.

The compatibility of the innovation and the farmers participating in this project was also high. Those farmers that used their computer for recordkeeping each month consisted of $67 \%$ of the total participants in the project (five respondents did not answer this question). A total of $70 \%$ of the respondents in the project said they view the computer as improving their farm by either saving time or providing information and $63 \%$ of respondents said computers could increase their profits (five respondents skipped each of these questions). And finally $100 \%$ of all farmers participating in this project owned computers before participating in this project, a fact which further testifies that the project was not outside participants' cultural norms.

Complexity on the other hand varied among farmers. It is believed that complexity will in many ways work in conjunction with the perceived utility of the project and its technology. Currently the majority of farmers have high expectations for the project as a whole. In many ways this characteristic of innovation speaks to the educational direction the DEDCMSI will take in the future. If simple uses are incorporated with Access database building, etc. then the likelihood of seeing the initiative as useful will be high and by so doing less complex. Currently the majority of the farmers participating in this study identify with the following farmer statement:

Farmer: "Well I think it will be useful, if I didn't, I would not be here today." 


\section{Work Cited}

Adler, E. S. and R. Clark. 2003. How It's Done: an invitation to social research. Second Edition. Belmont, California. Wadsworth/Thomson Learning. Page 420.

Argyris, C., R. Puntnam and D.S. McLain. 1985. Action Science. Josses-Bass, San Francisco.

Allen, J. P. 1998. Who Shapes The Future? Problem Farming and The Development of The Handheld Computer. Computers and Society. June 1998; Pages 3-8.

Amponsah, W. A. 1995. Computer Adoption and Use of Information Services by North Carolina Commercial Farmers. Journal of Agriculture and Applied Economics. 27(2): 565576.

Atherton, B. C., M. T. Morgan, S. A. Shearer, T. S. Stombaugh and A. D. Ward. 1999. Site-Specific Farming: A Perspective on Information Needs, Benefits and Limitations. Journal of Soil and Water Conservation. Second Quarter. Pages 455-461.

Banker, D. E. and J. M. MacDonald. 2005. Structural and Financial Characteristics of U.S. Farms: 2004 Family Farm Report. United States Department of Agriculture. Agriculture Information Bulletin 797.

Barber, B.R. 1984. Strong democracy: Participatory Politics for a new age. Los Angeles: University of California Press.

Batte, M. T., E. Jones and G. D. Schnitkey. 1990. Computer Use by Ohio Commercial Farmers. American Agricultural Economics Association. Pages 935-945.

Batte, M. T. 2004. Computer Adoption and Use by Ohio Farmer. Journal of ASFMRA. Pages 110-111.

Batte, M.T. and M. W. Arnholt. 2003. Precision Farming adoption and use in Ohio: case studies of six leading-edge adopters. Computers and Electronics in Agriculture. Pages 125-139.

Berg, B.L., 2001. Qualitative Research Methods; For The Social Sciences. Fourth Ed. Needham Heights, MA. Ally and Bacon. Page 179.

Bryan, W. J. 1896. Democratic National Convention. Chicago, Illinois, July 8.

Census of Agriculture. 2002. West Virginia: State and County Data. Volume 1, Geographic Area Series; Part 48. Page VII, A-1.

Conti, N. 2002. SOCA 101; Principles Of Sociology: The Sociological Imagination. New York, McGraw Hill Custom Publishing. Page 26. 
Creswell, J.W. 2003. Qualitative, Quantitative, and Mixed Methods Approaches. Second Edition. Thousand Oaks, California. Sage Publications.

Dell Computer Corporation. 2003. Dell Axim X5: User’s Guide. Page 68, Glossary.

Dell Technical Support. 2005. Telephone conversation with operator on June 18. Communication

Diaz, H. P. 2003. Farm communities at the crossroads: challenge and resistance. Canadian Plains Research Center. University of Regina. Sakatchewa, Regina. Page 72

Dickerson, M.D. 1983. Characteristics of Adopters and Non-Adopters of Home Computers. Journal of Consumer Research. 10:225-234.

Dillman, D. A. 2000. Mail and Internet Surveys: The Tailored Design Method. Canada: Wiley \& Sons, Inc.

Farmer Computer Usage and Ownership. Agriculture Statistics Board, NASS, USDA. July 2003. Accessed on 4/10/05: http://www-nass.esda.gov.

Farmer Computer Usage and Ownership. National Agriculture Statistics Service, USDA. July 2005. Sp Sy 9 (7-05)

Greenwood, D. and Levin, M. 1998. Introduction to Action Research. Social Research for Social Change. Thousand Oaks, California. Sage Publications, Inc. Page 1 and 119.

Groves, R. M., F. J. Fowler, M. P. Couper, J. M. Lepkowski, E. Singer and R. Tourangeau. 2004. Survey Methodology. Hoboken, New Jersey. John Wiley and Sons, Inc. Page 163.

Gonzalez-Castano, F., J. Vales-Alonso, E. Costa-Montenegro, M. Livy, and L. AnidoRifon. 2003. Condor Grid Computing From Mobile Handheld Devices. Mobile Computing and Communications Review. 6(2)18-27.

Gustaven, B. 2001. Handbook of Action Research: Participative Inquiry and Practice: Theory and Practice: the Mediating Discourse. Thousand Oaks, California. Sage Publications. Ch 1, Page 18.

Habraken, J. 2004. Microsoft Office 2003. All in One. Indianapolis, Indiana. Que Publishing. Part III; Outlook

Hall, H., J. Dunkelberger, W. Ferreira, J.W. Prevatt, and N.R. Martin. 2003. Diffusion-Adoption of Personal Computers and the Internet in Farm Business Decisions: Southeastern Beef and Peanut Farmers. Journal of Extension. 41(3) 1-12. 
Hall, R., D. Ball, and B. Shilmover. 2004. How to Do Everything with your: Dell Axim Handheld. Emeryville, California. McGraw-Hill Companies.

Hay, I. 2003. Qualitative Research Methods in Human Geography. Australia: Oxford University Press.

Hoag, D.L., C. Ascough, and W.M. Fraiser. 1999. Farm Computer Adoption in the Great Plains. Southern Agriculture and Applied Economics. 31(1)57-67.

Holter. I.M. and D. Schwartz-Barcott. 1993. Action research: what is it? How has it been used and how can it be used in nursing?. Journal of Advance Nursing. 18 298-304.

Jarvis, A. M. 1990. Computer Adoption Decisions-Implication for Research and Extension: The Case of Texas Rice Producers. The American Agricultural Economic Association. December 1387-1394.

Johnson, A. G. 1995. The Blackwell Dictionary of Sociology: A User's Guide To Sociological Language. Oxford, UK. Blackwell Publishers Ltd. Pages 117, 266.

Jung, S. 2002. “The Economic Role of West Virginia’s Food Systems in a Globalized Economic Environment.” M.A. thesis, Department of Agriculture and Resource Economics, West Virginia University, West Virginia.

King, Dale. 2005. Face-to-Face Interview with Director of West Virginia Department of NASS, August 16.

Lewin, K. 1945. Field Theory in Social Science: Selected Theoretical Papers. New York. Harper and Brothers Publishers. Pages 45.

Limb, M. and C. Dwyer. 2001. Qualitative Methodologies for Geographers. New York: Oxford University Press.

Macher, R. 1999. Making Your Small Farm Profitable. North Adams, MA. Story Books Publishing. Pp. 5-7.

McConnell, T.R. 2005. Interview with author, February 10.

Mey, H. 1965. Field-Theory: a study of its application in the social science. New York, N.Y. St. Marin’s Press Company. Pages 19.

Microsoft Office.Com. 2005. http://office.microsoft.com/access Retrieved on 9/29/05.

Middendorf, G. and L. Busch. 1996. Inquiry for public good: democratic participation in agriculture research. Agriculture and Human Values. 14:45-57. 
Moncur, M. 2005. The Quotation Page.

http://www.quotationspage.com/quotes/Agatha_Christie/ Retrieved 9/12/05.

Muhammad, S., F. Tegegne, and E. Ekanem. 2004. Factors Contribution to Success of Small Farm Operations in Tennessee. Journal of Extension. 42:8.

National Agriculture Statistics Service (NASS). 2004. West Virginia Bulletin No. 35.

National Agriculture Statistics Service (NASS). 2005. Farm Computer Usage and Ownership.

Nolan, J. and Y. Akiyama. 1999. An Analysis of Factors That Affect Law Enforcement Participation In Hate Crime Reporting. Journal of Contemporary Criminal Justice, 15, 111-127.

Nolan, J. and Y. Akiyama. 2002. Assessing The Climate for Hate Crime Reporting In Law Enforcement Organizations: A Force-Field Analysis. The Justice Prfessional, 15 (2), pp. 87-103.

O’Brien, R. 1998. Um exame da abordagem metodológica da pesquisa ação [An Overview of the Methodological Approach of Action Research]. In Roberto Richardson (Ed.), Teoria e Prática da Pesquisa Ação [Theory and Practice of Action Research]. João Pessoa, Brazil: Universidade Federal da Paraíba. (English version) Available: http://www.web.ca/ robrien/ papers/arfinal.html (Accessed 20/1/2005)

Oxford English Dictionary, 1989. Oxford University Press. Retrieved on 9/20/05. http://dictionary.oed.com/entrance.dtl

Pasmore, W. 2001. Handbook of Action Research: Chapter 3; Action Research in the Workplace: the socio-technical Perspective. Thousand Oaks, California. Sage Publications. Ch. 3, Page 38.

Peterson, J. C. 1984. Citizen’s participation in science policy. Amherst: University of Massachusetts Press.

Personal Digital Assistant., American History Information Guide and Reference. Retrieved on 9/07/2005. http://www.historymainia.com/american_history/ Personal_Digital_Assistant

Pocket PC., American History Information Guide and Reference. Retrieved on 9/07/2005. http://www.historymainia.com/american_history/Pocket_PC

Putler, D. S. and D. Zilberman. 1988. Computer Use in Agriculture: Evidence from Tulare County, California. American Agricultural Economics Association. Pages 790-801.

Radley, Edwards. 2005. Telephone conversation with Deputy Director of West Virginia 
Department of NASS, April18.

Ries, U. and A. Mino. 2003. Tom's Hardware Guide Mobile Devices: Getting Organized with PDAs-Dell Axim X5. Retrieved 09/08/05. http://www.tomshardware.com/ mobile/20030613/pdas-03.html.

Rogers, E.M. 1962. Diffusion of Innovation. New York: Free Press.

Rogers, E.M. 1983. Diffusion of Innovation. Elements of Diffusion. . New York. Macmillan Publishing Co. 3rd Edition, Chapter 1, 1-37.

Rogers, E.M. 2003. Diffusion of Innovations. $5^{\text {th }}$ edition. New York: Free Press.

Rogers, E.M. 2004. A Prospective and Retrospective Look at the Diffusion Model. Journal of Health Communication. 9 13-19.

Rojas, P. 2004. Dell Axim Pocket PC goes on sale October 12. engaged. Retrieved on 9/08/2005. http://www.engadget.com/entry/5832830172883606/

Rossi, W. P. H., H. E. Freeman and M. W. Lipsey1999. Evaluation: A Systematic Approach. Sixth Edition. Thousand Oaks, California. Sage Publications, Inc. Page: 191, 244.

Rosenberg, M. 1999. Popularity of internet won't peak for years. Puget Sound Business Journal. (http://amicity.com/settle/stories/1990/05/24/focus.html).

Samson, S. 1998. Technological Issues for Improving Access to Internet Web Sites for Rural Users. Journal of Extension. 36(4) 1-4.

Selznick, P. 1949. TVA and The Grass Roots: A Study in the Sociology of Formal Organizations. Berkeley and Los Angeles, California. University of California Press. Page: 250,

Sclove, R. E., M. L. Scammell. 1995. Participation in agenda setting at Land-Grant Universities. American Journal of Alternative Agriculture 7:111-117.

Schildgen, B., 2004. Who grows your food: And why it matters. The Magazine of the Sierra Club, November/December, pp. 30-35.

Schmidt, D., S. K. Rockwell, L. Bitney and E. A. Sarno. 1994. Farmers Adopt Microcomputers in the 1980's: Educational Needs Surface for the 1990's. Journal of Extension. 32(1) 1-7.

Stevenson, G. W. and R. M. Klemme. 1992. Advisory/oversight councils: an alternative approach to farmer/citizen.

Swinton, S. M. and J. Lowenberg-DeBoer. 1998. Evaluating the Profitability of Site- 
Specific Farming. Journal Production Agriculture. 11(4) 439-446.

U.S. Census Bureau. 2000. Profile of Selected Economic Characteristics. File 3.

http://factfinder.census.gov/servlet/QTTable?_bm=n\&_lang=en\&qr_name=DEC_2000_SF

. Accessed on 8/30/05.

U.S. Department of Agriculture (USDA). 1983 - Nas. Extension In The 80's: A Perspective for the Future of the Cooperative Extension Service: A Report. Madison, Wisconsin: Cooperative Extension Service, University of Wisconsin.

\section{Work Used Not Cited In Proposal}

William, A. J., R. P. Rettig, G.M. Scott, and S. M. Garrison. 2004. The Sociology Student Writer’s Manual. Fourth Edition. Upper Saddle River, New Jersey. Pearson Prentice Hall Inc. Page 97. 
APPENDIX A 


\section{Farm Family Survey}

\author{
For The
}

\section{Decision Enabling} Data Collection And

\section{Management System Initiative}

\section{Purpose of Survey}

This survey is intended to provide a clear picture into the farming enterprises of West Virginia farmers participating in The Decision Enabling Data Collection and Management System Initiative. All data is obtained solely for the evaluation of this program and will be kept confidential.

\section{Directions}

1. Please read and answer all of the questions to the best of your ability (Ask your agent for clarification).

2. If a question does not apply to you or your family and you choose to skip the question please provide an explanation in the spaces provided.

Project County:

Your Service Tag number:

Date survey was taken:

Sex:

Omale Ofemale 


\section{Section 1A: Farmer Background}

Please fill in the selection that applies to you or your wife (other).

\begin{tabular}{|c|c|c|}
\hline OYou & & $\square$ Spouse $\bigcirc$ Other \\
\hline $\begin{array}{l}\text { O }<\text { high school } \\
\text { school } \\
\text { OSome high } \\
\text { school } \\
\text { Ohigh school } \\
\text { graduate or its } \\
\text { equivalent } \\
\text { Otrade/tech } \\
\text { school graduate } \\
\text { Osome college } \\
\text { Ocollege graduate } \\
\text { OMasters or } \\
\text { PhD }\end{array}$ & 1. What is the highest level of schooling completed? & $\begin{array}{l}\bigcirc<\text { high } \\
\text { school } \\
\square \bigcirc \text { Some high } \\
\text { school } \\
\square \bigcirc \text { high school } \\
\text { graduate or it } \\
\text { equivalent } \\
\square \bigcirc \text { trade/tech } \\
\text { school graduate } \\
\square \bigcirc \text { some college } \\
\square \bigcirc \text { college graduate } \\
\square \bigcirc \text { Masters or } \\
\text { PhD }\end{array}$ \\
\hline $\begin{array}{l}\text { O none } \\
\text { O } 1 \text { to } 5 \text { years } \\
\text { O } 5 \text { to } 10 \text { years } \\
\text { O } 10 \text { to } 15 \text { years } \\
\text { O } 15 \text { to } 20 \text { years } \\
\text { O } 20 \text { to } 25 \text { years } \\
25 \text { to } 30 \text { years } \\
\text { } 30 \text { to } 35 \text { years } \\
35 \text { to } 40 \text { years } \\
\text { O } 40 \text { to } 45 \text { years } \\
\text { O } 45 \text { to } 50 \text { years } \\
\text { over } 50 \text { years }\end{array}$ & 2. What level of farm experience do you have? & 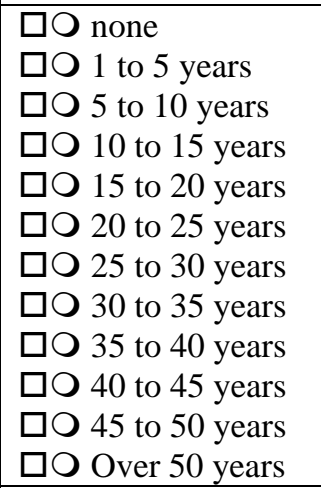 \\
\hline $\begin{array}{l}\text { Opaper/pencil } \\
\text { Ocomputer } \\
\text { (Excel, other } \\
\text { software) } \\
\text { O we keep } \\
\text { separate } \\
\text { paid } \\
\text { accounts } \\
\text { Oshoe box } \\
\text { Method } \\
\square \text { Odon’t keep } \\
\text { records }\end{array}$ & $\begin{array}{l}\text { 3. How do you keep records on the farm? } \\
\text { *If no records are kept please indicate it and skip to } \\
\text { question } 5\end{array}$ & $\begin{array}{l}\text { Opaper/pencil } \\
\square \text { Ocomputer } \\
\text { (Excel, other } \\
\text { software) } \\
\square \text { we keep } \\
\text { separate } \\
\text { paid } \\
\text { accounts } \\
\square \text { Oshoe box } \\
\text { Method } \\
\square \text { Odon’t keep } \\
\text { records }\end{array}$ \\
\hline $\begin{array}{l}\text { Odon’t keep } \\
\text { records } \\
\text { Osales in } \\
\text { dollars } \\
\text { Oyield/acre } \\
\text { O yield/sq. ft. } \\
\text { Otax purposes } \\
\text { other_ }\end{array}$ & 4. What kind of records do you keep on your farm? & $\begin{array}{l}\square \text { Odon’t keep } \\
\text { records } \\
\square \bigcirc \text { sales in } \\
\text { dollars } \\
\square \bigcirc \text { yield/acre } \\
\square \bigcirc \text { yield /sq. ft. } \\
\square \bigcirc \text { tax purposes } \\
\square \bigcirc \text { other_ }\end{array}$ \\
\hline
\end{tabular}




\begin{tabular}{|c|c|c|}
\hline OYou & $\begin{array}{l}\text { Directions: Please fill in the selection that applies to } \\
\text { you or your wife ( } \square \text { ) or other }(O) \text { individuals. }\end{array}$ & $\begin{array}{l}\square \text { Spouse } \\
\text { O Other }\end{array}$ \\
\hline $\begin{array}{l}\text { O } 21 \text { years or less } \\
\text { 2 } 22 \text { to } 26 \\
\text { 2 } 27 \text { to } 31 \\
32 \text { to } 36 \\
\text { 3 } 37 \text { to } 41 \\
42 \text { to } 46 \\
\text { O } 47 \text { to } 52 \\
53 \text { to } 57 \\
58 \text { to } 62 \\
63 \text { to } 67 \\
68 \text { to } 72 \\
73 \text { to } 77 \\
\text { o } 78 \text { years or } \\
\text { older }\end{array}$ & 5. How old are you? & $\begin{array}{l}\square \bigcirc 21 \text { years or less } \\
\square \bigcirc 22 \text { to } 26 \\
\square \bigcirc 27 \text { to } 31 \\
\square \bigcirc 32 \text { to } 36 \\
\square \bigcirc 37 \text { to } 41 \\
\square \bigcirc 42 \text { to } 46 \\
\square \bigcirc 47 \text { to } 52 \\
\square \bigcirc 53 \text { to } 57 \\
\square \bigcirc 58 \text { to } 62 \\
\square \bigcirc 63 \text { to } 67 \\
\square \bigcirc 68 \text { to } 72 \\
\square \bigcirc 73 \text { to } 77 \\
\square \bigcirc 78 \text { years or older }\end{array}$ \\
\hline $\begin{array}{l}\text { O yes } \\
\text { O no }\end{array}$ & 6. Have you ever had any computer courses? & $\begin{array}{l}\bigcirc \text { yes } \\
\square \bigcirc \text { no }\end{array}$ \\
\hline $\begin{array}{l}\text { O yes; } 40+\text { hours } \\
\text { yes; part-time } \\
\text { no }\end{array}$ & 7. Do you currently have any off farm employment? & $\begin{array}{l}\square \bigcirc \text { yes; } 40+\text { hours } \\
\square \bigcirc \text { yes; part-time } \\
\square \bigcirc \text { no }\end{array}$ \\
\hline
\end{tabular}




\section{Section 1B: The Farm}

8. How may acres of land do you currently own in the following categories?(fill in all those that apply)

O timber:

O improved pasture:

O swamp:

O crop land:

O other:

9. Do you currently rent or lease any farmland?

a. yes: amount

b. no

*If you answered no to question number 9 skip to 11.

10. How many acres do you lease to others?

11. How many total acres did you farm last year? (Omit land that is leased to others and acres that are not farmable)

12. How much of the land listed in question number ten was in your family or your spouse's family before you took over?

13. What year did you or your spouse first acquire controlling interest over this farm
a. 19
b. 20
c. not yet

14. What was the size of your farm enterprise (in acres) that first year?

O 0 to 5 acres

O 6 to 10 acres

O 11 to 15 acres

O 16 to 20 acres

O 21 to 25 acres

O 26 to 30 acres

O 31 to 35 acres

O 41 to 45 acres

O 46 to 50 acres

O 51 to 55 acres

O 56 to 60 acres

O 61 to 65 acres

O 66 to 70 acres

O 71 to 75 acres

O 76 to 80 acres

O 81 to 85 acres

O 86 to 90 acres

O 91 to 95 acres

O 96 to 100 acres

O 101 to 200 acres

O 300 to 400 acres

O 500 to 600 acres

O 700 to 800 acres

O 900 to 1000 acres

O Above 1000 acres

O don't know

15. Have you sold any land in the last 10 years?

no (skip to next page)

yes (go to question 16)

16. If you answered yes to question 15 please indicate the year and amount of acres sold.
O 1995:
O 1996:
O 1997:
O 1998:
O 1999:
O 2000:
O 2001:
O 2002:
O 2003:
O 2004:
O 2005: 


\section{Your Farming Enterprise}

17. Please select the different production units that apply to your farming enterprise (please rank in order of importance, when 1 equals most important and 5 equals least important).

*each one of the categories pertaining to your operation has its own ranking.

Livestock:

$\begin{array}{ll}\text { beef cows } & \text { _ goats } \\ \text { dairy cows } & \text { sheep } \\ \text { swine } & \text { _other: } \\ \text { Grain Production: } & \\ \text { barley } & \text { _oats } \\ \text { wheat } & \text { sorghum } \\ \text { buckwheat } & \text { _ other: } \\ \text { corn } & \end{array}$

Vegetable Production: broccoli

_summer squash green cabbage potatoes staked tomatoes

others not mentioned:
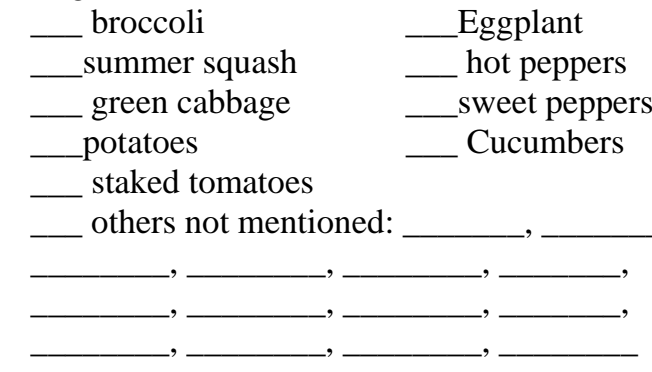

Fruits:

_blackberries

_blueberries

_raspberries

_plums watermelon pawpaw

Tree Fruits:

_ apples

_ others not mentioned:
18. What category best represents your total farm sales in 2004?
$O$ under $\$ 1,000$
O $\$ 1,000$ to $\$ 4,999$
O $\$ 5,000$ to $\$ 9,999$
O $\$ 10,000$ to $\$ 14,999$
O $\$ 15,000$ to $\$ 19,999$
O $\$ 20,000$ to $\$ 24,999$
O $\$ 25,000$ to $\$ 29,999$
O $\$ 30,000$ to $\$ 34,999$
O $\$ 35,000$ to $\$ 39,999$
O $\$ 40,000$ to $\$ 44,999$
O $\$ 45,000$ to $\$ 49,999$
O $\$ 50,000$ to 54,999
O $\$ 55,000$ to 59,999
O $\$ 60,000$ to 64,999
O $\$ 65,000$ to 69,999
O $\$ 70,000$ to 74,999
O $\$ 75,000$ to 79,999
O $\$ 80,000$ to 84,999
O $\$ 85,000$ to 89,999
O $\$ 90,000$ to 94,999
O $\$ 95,000$ to 99,999
O $\$ 100,000$ or more

19. Do you have a business partner outside your immediate family (persons living in household or mother and father) who co-owns your farm?

O yes, I co-own my farm business with my extended family

O yes, I co-own this farm business with a person not related to me in any way.

O no; I am the sole proprietor

20. Do you currently participate in any form of contract farming?

$\mathrm{O}$ Yes

O No

21. At anytime during the year do you utilize hired help on the farm?

O no (please skip 22-23)

$O$ yes 
22. If you answered yes to question 21, please list what times of the year

additional help is used on the farm.

$\begin{array}{ll}\text { year round } & \\ \text { Jan. } & \text { Apr. } \\ \text { Jul. } & \text { Oct. } \\ \text { Feb. } & \text { May } \\ \text { Aug. } & \text { Nov. } \\ \text { Mar. } & \text { Jun. } \\ \text { Sept. } & \quad \text { Dec. }\end{array}$

23. If less than one month how long is this additional help needed on the farm for the busiest month indicated in 21?

$\mathrm{O}$ days; amount

Weeks; amount 
Directions: Circle or check the best selection.

\begin{tabular}{|c|c|c|c|c|c|c|c|c|}
\hline \multicolumn{9}{|c|}{ Who Normally Does These Tasks? } \\
\hline Farm Tasks & $\begin{array}{l}\text { Task } \\
\text { not } \\
\text { done } \\
\text { on my } \\
\text { farm }\end{array}$ & $\begin{array}{l}\frac{}{\bar{\sigma}} \\
\frac{\pi}{0} \\
\frac{0}{0} \\
\frac{0}{2}\end{array}$ & $\stackrel{0}{*}$ & 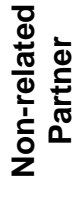 & 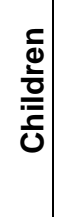 & $\begin{array}{l}\frac{1}{0} \\
\frac{0}{\pi} \\
\frac{\pi}{\sigma} \\
\frac{0}{\pi} \\
0\end{array}$ & ఏ & $\begin{array}{l}\text { If other } \\
\text { indicate } \\
\text { here }\end{array}$ \\
\hline $\begin{array}{l}\text { 24a.plan cropping } \\
\text { schedule }\end{array}$ & $(\mathrm{l})$ & $\mathrm{H}$ & $\mathrm{W}$ & $\mathrm{P}$ & C & $\$$ & $\mathrm{Ot}$ & \\
\hline $\begin{array}{l}\text { 25a.balance } \\
\text { checkbook }\end{array}$ & $(\mathrm{)}$ & $\mathrm{H}$ & $\mathrm{W}$ & $\mathrm{P}$ & $\mathrm{C}$ & $\$$ & $\mathrm{Ot}$ & \\
\hline $\begin{array}{l}\text { 26a.check market } \\
\text { prices }\end{array}$ & $(\mathrm{l})$ & $\mathrm{H}$ & $\mathrm{W}$ & $\mathrm{P}$ & C & $\$$ & $\mathrm{Ot}$ & \\
\hline $\begin{array}{l}\text { 27a.buy farm } \\
\text { supplies and } \\
\text { equipment }\end{array}$ & ( ) & $\mathrm{H}$ & W & $\mathrm{P}$ & C & $\$$ & Ot & \\
\hline $\begin{array}{l}\text { 28a.repair work on } \\
\text { machinery }\end{array}$ & $($ ) & $\mathrm{H}$ & $\mathrm{W}$ & $\mathrm{P}$ & C & $\$$ & $\mathrm{Ot}$ & \\
\hline 29a.taxes & ()$^{2}$ & $\mathrm{H}$ & W & $P$ & $C$ & $\$$ & Ot & \\
\hline 30a.pay farm Teds & $(\mathrm{l})$ & $\mathrm{H}$ & $\mathrm{W}$ & $\mathrm{P}$ & $\mathrm{C}$ & $\$$ & $\mathrm{Ot}$ & \\
\hline 31a.pay utilities & $(\mathrm{r})$ & $\mathrm{H}$ & $\mathrm{W}$ & $P$ & $\mathrm{C}$ & $\$$ & $\mathrm{Ot}$ & \\
\hline $\begin{array}{l}\text { 32a.uses the } \\
\text { computer }\end{array}$ & $(\mathrm{l})$ & $\mathrm{H}$ & $\mathrm{W}$ & $\mathrm{P}$ & C & $\$$ & $\mathrm{Ot}$ & \\
\hline 33a.buys livestock & $($ ( ) & $\mathrm{H}$ & $\mathrm{W}$ & $P$ & C & $\$$ & Ot & \\
\hline 34a.plants crops & $($ ) & $\mathrm{H}$ & W & $\mathrm{P}$ & $\mathrm{C}$ & $\$$ & Ot & \\
\hline
\end{tabular}

Select an additional category if helped

\section{Who Usually Helps?}

\begin{tabular}{|c|c|c|c|c|c|c|c|}
\hline $\begin{array}{l}\text { Task not done } \\
\text { on my farm }\end{array}$ & $\begin{array}{l}\frac{0}{c} \\
\frac{0}{0} \\
\frac{0}{0} \\
\frac{0}{T}\end{array}$ & $\stackrel{\Perp}{3}$ & 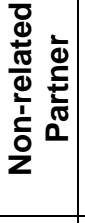 & 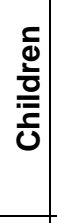 & $\begin{array}{l}\frac{1}{0} \\
\frac{0}{\pi} \\
\frac{0}{\pi} \\
0\end{array}$ & $\begin{array}{l}\frac{\bar{d}}{0} \\
\bar{\bigsqcup}\end{array}$ & $\begin{array}{l}\text { If other } \\
\text { indicate } \\
\text { here }\end{array}$ \\
\hline 24a. ( ) & $\mathrm{H}$ & $\mathrm{W}$ & $\mathrm{P}$ & $\mathrm{C}$ & $\$$ & Ot & \\
\hline $25 \mathrm{a} \quad(\quad)$ & $\mathrm{H}$ & W & $\mathrm{P}$ & C & $\$$ & Ot & \\
\hline 26a. ( ) & $\mathrm{H}$ & W & $\mathrm{P}$ & C & $\$$ & Ot & \\
\hline 27a. ( ) & $\mathrm{H}$ & W & $\mathrm{P}$ & C & $\$$ & Ot & \\
\hline 28a. ( ) & $\mathrm{H}$ & W & $\mathrm{P}$ & C & $\$$ & Ot & \\
\hline 29a. ( ) & $\mathrm{H}$ & W & $\mathrm{P}$ & C & $\$$ & $\mathrm{Ot}$ & \\
\hline 30a. ( ) & $\mathrm{H}$ & W & $\mathrm{P}$ & C & $\$$ & $\mathrm{Ot}$ & \\
\hline 31a. ( ) & $\mathrm{H}$ & $\mathrm{W}$ & $\mathrm{P}$ & $C$ & $\$$ & $\mathrm{Ot}$ & \\
\hline 32a. ( ) & $\mathrm{H}$ & W & $\mathrm{P}$ & C & $\$$ & Ot & \\
\hline 33a. ( ) & $\mathrm{H}$ & W & $\mathrm{P}$ & C & $\$$ & $\mathrm{Ot}$ & \\
\hline 34a. ( ) & $\mathrm{H}$ & W & $\mathrm{P}$ & C & $\$$ & Ot & \\
\hline
\end{tabular}




\section{Section 2; Pilot Group Information}

35. Please list the number of individuals in your farm finance group that are connected to you in the following ways. O relatives O old friends O neighbor

o acquaintance

O other

36.How did you find out about this program?

37. Have you ever participated in an Extension program?

$$
\begin{aligned}
& \text { yes } \\
& \text { O no (skip to 41) }
\end{aligned}
$$

38. What was the Extension program you participated in?

39. How long where you involved with this program?

40. How would you rank yourself as a user of Extension Services programs?
O frequent user
O occasional user
O seldom use
O never use

41. How far do you live from the meeting place of the Handheld Initiative in your county.

$$
\begin{aligned}
& O<5 \text { miles } \\
& \text { } 5 \text { to } 10 \text { miles } \\
& \text { o } 11 \text { to } 15 \text { miles } \\
& \text { o } 16 \text { to } 20 \text { miles } \\
& \bigcirc 21 \text { to } 30 \text { miles } \\
& \bigcirc>30 \text { miles }
\end{aligned}
$$

42. How often do you talk to others about this program outside of meetings?

$\mathrm{O}$ frequently talk about it

O occasionally talk about it O seldom talk about it O only talk about it at meetings

43. How would you rank the collective excitement of your group in reference to the Handheld Initiative (answer question using all individuals in which you have been in contact)?
O very excited
O excited
O not very excited
O not excited
O skeptical

44. How likely are you to speak out in a group?
O highly likely
O occasionally
O not very likely
O never 
45. Which one of these income categories does your overall family income best fit into?
$\mathrm{O}$ under $\$ 10,000$
O $\$ 10,000$ to $\$ 19,999$
O $\$ 20,000$ to $\$ 29,999$
O $\$ 30,000$ to $\$ 39,999$
O $\$ 40,000$ to $\$ 49,999$
O $\$ 50,000$ to $\$ 59,999$
O $\$ 60,000$ to $\$ 69,999$
O $\$ 70,000$ to $\$ 79,999$
O $\$ 80,000$ to $\$ 89,999$
O $\$ 90,000$ to $\$ 99,999$
O $\$ 100,000$ to $\$ 109,999$
O $\$ 110,000$ to $\$ 119,999$
O $\$ 120,000$ to $\$ 129,999$
O $\$ 130,000$ to $\$ 139,999$
O $\$ 140,000$ to $\$ 149,999$
O $\$ 150,000$ to $\$ 159,999$
O $\$ 160,000$ to $\$ 169,999$
O $\$ 170,000$ to $\$ 179,999$
O $\$ 180,000$ to $\$ 189,999$
O $\$ 190,000$ to $\$ 199,999$
O $\$ 200,000$ to $\$ 299,999$
O $\$ 300,000$ or more 


\section{Section 3: Computer Adoption}

Directions: Please check or fill in the answer that most accurately applies to you.

46. Choose the top three sources that provide you the most information for your farming enterprise?

O local market reports

$\mathrm{O}$ farming magazines

agricultural news papers

$O$ radio reports

O World Wide Web

O co-operatives

O Extension Service

O salesman

O public accountant

O other

47. Have you ever been exposed to computers in environments outside of home and farm?

O yes; off farm employment

O yes; other

O no

48. Do you currently have some anxiety related to the prospect of using a computer for record keeping?

$$
\begin{aligned}
& O \text { yes } \\
& \mathrm{O} \text { no }
\end{aligned}
$$

49. What do you believe is the likelihood that your home computer will increase your annual profit? Use the scale where $1=$ extremely likely and $5=$ no chance of being useful.
O 1 (extremely likely)
O 2 (highly likely)
O 3 (good chance)
O 4 (poor chance)
O 5 (no chance)

50. Can you access the World Wide Web (web) from your home and farm?

$O$ yes, I have access to the web at both locations

$\mathrm{O}$ only the farm has web access

$\mathrm{O}$ only the house has web access

O neither
51. Who accesses the web the most from your home or farm?
O you
O your spouse
O children
O employees
O nobody ever uses our computers
O other:

52. Who uses your computers the most?
O you
your spouse
O children
O employees
O never use computer on farm

53. How would you rate the use of technology on your farm today?

$O$ very high use

O high use

O moderate use

O seldom use

O never use technology on farm

54. Have you ever named a file on a computer?

$$
\text { O yes }
$$

55. Where is the desktop located on your home computer?

$\mathrm{O}$ on the C: drive

O I don't have one

$\mathrm{O}$ on my initial screen when I turn my computer on

O none of the above

56. Do you have an e-mail address?

$$
\begin{aligned}
& O \text { yes } \\
& \text { O no }
\end{aligned}
$$


57. Please choose the selection that looks most like an e-mail address.

O Robbie Edalgo e-mail \#1098-75

214 Riverside Ave

Westover, WV

O 1098-75

○ Robbie.edalgo@mail.wvu.edu

O not sure

58. Have you ever purchased anything online?

$O$ yes
nno

59. Have you ever sold anything online?

$O$ yes

O no

60. Which ONE of these programs do

you currently use most frequently?

\author{
O Microsoft Word \\ O Microsoft Excel \\ O tax software \\ O Microsoft Access \\ O planning software \\ O other: \\ O I don’t use my computer frequently
}

61 . How many hours do you use the computer for record keeping per month
O 1 to 5 hours
O 6 to 10 hours
O 11 to 15 hours
O 16 to 20 hours
O 21 to 25 hours per month
O other:
O I never use the computer

62. Please indicate the extent to which you think having a computer has improved your farming business by providing information or saving time.
$\mathrm{O}$ very high improvement
O high improvement
O some improvement
O almost no improvement
O no improvement

63. Identify the three most important computer applications to your farming operation (indicate with a check or $1,2,3)$.

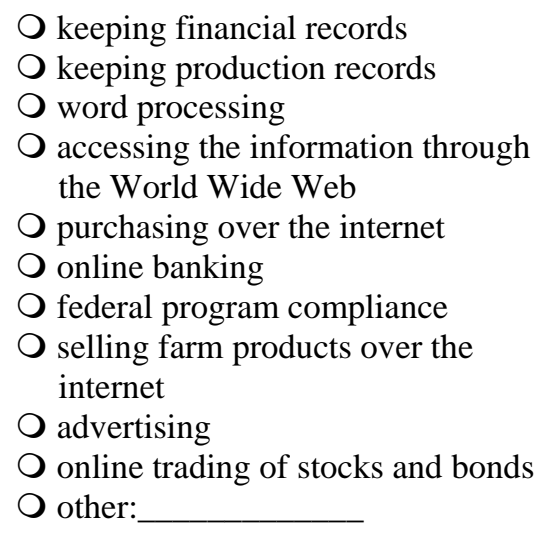




\section{Section 4: Record Keeping}

64. How much time do you estimate you spend record keeping per week in the busiest time of the year?
less than 1 hour per week
O 1 to 2 hours per week
O 3 to 4 hours per week
O 5 to 6 hours per week
O to 8 hours per week
O 9 to 10 hours per week
$\mathrm{O}$ greater than 10 hours
O none

65. When do you keep the most records?
$O$ harvest time: month:
$O$ planting month:
O selling month:
don't keep records

66. What time during each day do you maintain and study your records?

$$
\begin{aligned}
& \bigcirc \text { early morning } \\
& \bigcirc \text { mid-day } \\
& O \text { night } \\
& O \text { other }
\end{aligned}
$$

67. Rank the following professional services you used in the past three years where 1 is the most frequently used service and 5 is the least frequently used service (if you use other selection leave one of the selections blank).

\#___ : Cooperative Extension; County Agent

\#___ : Cooperative Extension; Specialist

\#___ : farm management consultant

\#___ : farm record service agents

\#___ veterinarian

\#___: other

\section{Directions: Please skip sections that do not apply to your farm operation}

\section{Forage Livestock Questions}

68. List the exact amount of acres available to grazing by livestock last year?

\author{
O the exact amount : \\ O the ball park \\ figure : \\ no, I don't have any idea
}

69. How many acres were used in production of hay last year on your farm?

the exact amount :

the ball park figure :

no, I don't have any idea

70. Do you know what your weaning percentages were last year?

$$
\begin{aligned}
& O \text { yes } \\
& O \text { no }
\end{aligned}
$$

71. How important do you think keeping records on all feeder animals' average daily gain is?

$$
\begin{aligned}
& O \text { extremely important } \\
& \text { important } \\
& \text { not very important } \\
& \text { not at all important in my } \\
& \text { operation }
\end{aligned}
$$

72. Do you know what your cost per unit was last year? (Examples of units are pound, quart, and 100 lbs of milk)

$$
\begin{aligned}
& \text { O no } \\
& \text { calves: } \\
& \text { ton of hay: } \\
& \text { quart of strawberries: } \\
& \text { others not mentioned: }
\end{aligned}
$$


73. Do you record milestones pertaining to your farm operation?

$O$ first bale fed

$O$ first and last calf born

O other:

O currently don't record milestones

71. Do you keep track of the feed conversions (lbs. feed $\div$ lbs. gain) for your herd?

$$
O \text { yes }
$$$$
\text { O no }
$$

\section{Vegetable Production}

72. What percentage of your farming operation do you consider to be vegetable production?

$$
\begin{aligned}
& \text { O }<20 \\
& \bigcirc 20 \text { to } 30 \\
& \text { O } 40 \text { to } 50 \\
& \bigcirc 50 \text { to } 60 \\
& \bigcirc 60 \text { to } 70 \\
& \text { O } 70 \text { to } 80 \\
& \text { O } 80 \text { to } 90 \\
& \text { O } 90 \text { to } 100
\end{aligned}
$$

73. Do you keep records on how long it takes to harvest specific crops in the growing season. For example blueberries may take, on average, 1.5 hours for two workers to harvest 30 half-pints?

O yes, I know harvest times for each crop

O yes, I know some of my crop's harvest time

O no, but I have a good idea in my head

no, I don’t keep track of that figure

74. Do you think it would be valuable to record the time it takes for an individual to harvest a crop and relate that figure to the price received for that crop?

\footnotetext{
O extremely valuable

O valuable

O not very valuable

not at all valuable on my farm
}

75. To what extent do you use the following two records: quantity sold for acres planted and prices received for product/amount planted per acre (the sum gives \$/acre) in making your planting decisions for the next year?

$\mathrm{O}$ my planting decisions are based heavily on these records

my planting decisions are somewhat based on these records

I strictly use sales figures to

determine what to plant

$\mathrm{O}$ I base my decisions on my experience

O other:

76. How closely do you monitor amount of product harvested and amount left over in a selling day?

$\mathrm{O}$ my planting decisions are based heavily on these records

O my planting decisions are somewhat based on these records

I don't monitor these areas in my farming enterprise

O other:

77. Select the top two places you sell your product.
farmers market
local retailers
O large corporate retailers
$\mathrm{O}$ on my property
other:

\section{Extended Line of Credit}

78. Do you have a operating loan from a conventional lender (bank)?

$$
\begin{aligned}
& \text { yes } \\
& \text { no (If you answered no to this } \\
& \text { question, skip to question } \\
& \text { \#82) }
\end{aligned}
$$

79. Do you monitor the principal balance outstanding on your loan or do you depend on the bank's figures to do this?

\footnotetext{
O we monitor the balance

we depend on the bank
} 
80. Do you have enough information at home to calculate how much you will pay in interest over the life of the loan?

$$
\begin{aligned}
& O \text { yes } \\
& \mathrm{O} \text { no }
\end{aligned}
$$

81. Do you know the date this loan will be paid in full?

$$
\begin{aligned}
& O \text { yes } \\
& O \text { no }
\end{aligned}
$$

\section{Future Planning Record Keeping}

82. How do you decide which crops you will plant this year?

O based on previous years' records of yields and the corresponding field

$O$ based on experience and knowledge of proper crop rotation

based on crop value and marketing opportunities

O no set method
83. Which of these farm management strategies decisions best describes your management philosophy? Use the number 1 for the most important and number 5 for the least important. *rank selections regardless if you keep the record or not

\#___: increased production

\#__ : make production more efficient

\# : cut cost

\#__ : monitor inputs and outputs

\#__ : other: 


\title{
WestVrrginiaUniversity
}

Eberly College of Arts and Sciences

\author{
MEMOR A N D U M
}

TO: $\quad$ Robbie Edalgo Thomas R. McConnell

Ronald Althouse

FROM:

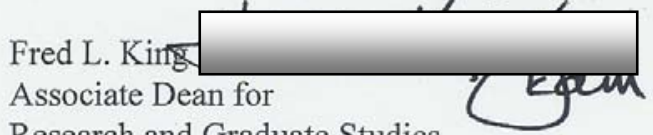

DATE: $\quad$ March 24, 2005

RE: $\quad$ Application for Exemption from Institutional Review Board

I have reviewed your application for exemption from IRB review and agree that "The Decision Enabling Data Management System Initiative: A Program Evaluation," qualifies for exemption status. Accordingly, you may begin your research. As you do so, be sure that you follow those IRB procedures and guidelines necessary for protecting the subjects of your research.

Please let me know if I can provide any additional assistance or information. Good luck with your research.

cc: Larry Nichols, Chairperson

\begin{tabular}{|c|c|}
\hline & Office of the Dean \\
\hline Phone: 304-293-4611 & 201 Woodburn Hall \\
\hline Fax: $304-293-6858$ & PO Box 6286 \\
\hline
\end{tabular}




\section{Extension Service WestVirginiaUniversity.}

John Doe (Farm Manager)

345 Lakeside Dr.

Wheeling, WV 26170-0096

Dear John,

I would first like to take this opportunity to congratulate you for making the decision to learn more about the power of record keeping in farm management and the technology used to make it more efficient. The Decision Enabling Data Management Initiative has established community record keeping groups in the following six counties of West Virginia: Ohio, Preston, Jefferson, Monroe, Randolph and Mineral. Each of these record keeping groups will be led by the county agent and each will be equipped with educational materials as well as one Dell Axim per farmer. The Decision Enabling Data Management System Initiative is made possible through the collective efforts of West Virginia Cooperative Extension Service and Sustainable Agriculture Research and Education Program (S.A.R.E.). This project's intent is to provide farmers with the resources they need to address their record keeping needs through the collective effort of fellow farmers in community groups.

The purpose of this survey research is to provide a clear picture into the farming enterprises of West Virginia farmers participating in this program. This information will be used to evaluate the degree of success our program has had in meeting your record keeping needs. The results of this research will also be used to partially fulfill the requirements for a Masters in Applied Sociology at West Virginia University.

All information produced by this survey will be kept in strict confidence. Anonymity will also be maintained in all published work unless written permission has been provided by the farmer. The service tag numbers on the front of the survey will be used as a code therefore eliminating the need to have your name to file completed work. All recordings produced from person-to-person interviews will be destroyed at the end of the pilot group activities. If you have any further questions regarding the survey or program please contact Robbie Edalgo at 304-2936131ext.4234. After completion of this survey, please seal it in the self addressed stamped envelope and mail it as soon as possible.

Sincerely,

Robbie Edalgo

Graduate Student

\author{
Dr. Ron Althouse \\ Full Professor \\ School of Applied Social
}

Science
Tom McConnell

Farm Management Specialist

Specialist WVU

Extension Service 
APPENDIX B 


\title{
The Decision Enabling Data Collection and Management System Initiative \& Executive Summary
}

\author{
By: Robbie Edalgo \\ (Robbie.Edalgo@mix.wvu.edu) \\ West Virginia University Extension Service \\ Center for Agriculture and Natural Resources \\ 2092 Agricultural Sciences Building \\ P.O. Box 6108 \\ Morgantown, WV 26506-6108 \\ Phone: 304-293-6131 ext. 4234 \\ Fax: 304-293-6954
}

Principal Investigator: Tom McConnell

TRMcConnell@mail.wvu.edu

Cooperative Organizations:

USDA farm Service Agency

WV Department of Agriculture

WVU Extension

WVU School of Agriculture

WVU School of Applied Social Sciences 
Introduction

The Decision Enabling Data Collection and Management System Initiative (DEDCMSI) is a West Virginia University Extension program. This project will start with a seven month long pilot study. This, the first phase of the project, will assess the utility of specific technologies in small family farm management as well as initiative characteristics that standout as needing attention before the project moves forward. The Research Problem Reads as follows:

Research Problem: To develop and implement a research methodology that will adequately identify factors and forces promoting and prohibiting participation in the DEDCMSI.

Project developers have wisely chosen to utilize farmer input in the initial stages of this research. This concept of democratizing the research process will be referred to as Action Research in this study. These farm families will be located in the following four counties of West Virginia: Ohio, Jefferson , Mineral and Monroe. Hardy County will serve as a comparison group in hopes of giving some insight into the general population of farmers. The pilot phase of the project will center on the influence of the Advisory Committee. This committee will consist of extension professionals as well as representatives from working farms in West Virginia, the Research Farmers. The primary purpose of this committee will be to identify immediate goals and objectives of the project and help plan and develop the next phase of the initiative, the Management Clubs. The Research Farmers involved in these committees will aid extension professionals in the evaluation of data base templates specific to their enterprises.

Project Goals

The DEDCMSI has been designed to achieve the following goal reads:

Project Goal : By Utilizing Axim X5 (handheld PC's) farmers will increase their management capabilities by collecting and organizing the real-time financial and production data they need to make accurate and timely decisions.

In the final year of the project, Management Clubs will be set up in the original four project counties. These clubs will serve as the catalyst for technology transfer and begin the process of attaining self-sufficiency as the role of the county agents as program facilitator is diminished over time by the allowing county opinion leaders to direct field many questions during meetings. By the end of the pilot study, agents will have identified the early adaptors of this technology. These farmers will have the data collection and management skills necessary to assume the role of mentor for the newer members of the group. Involving the Research Farmer in every aspect of the project and maintaining a high focus on farmer input throughout the process should help make the farmerto-farmer knowledge transfer a reality. This extension exit strategy will depend on the Research Farmers' ability to bridge the divide between innovative management methods and ethnographic norms in enterprises. The rationale reads:

Rationale \#1: By increasing the Research Farmers' practical data collection and management skills, the farmer to farmer technology transfer can be realized by the management groups. This relationship will enhance the exit strategy by replacing the 
agent with sustainable farmer-managed initiatives.

The third and final goal of this project is the development of a curriculum of ten to fifteen lesson plans with titles that range from the initial and basic handheld operation tested and approved through Farm Finance Community Circles. Posted on the web, this curriculum should prove valuable for other communities (extension or not) wanting to duplicate this project. The content of these lesson plans will be the product of enterprise specific recordkeeping by the farmers and Cooperative Extension professionals participating in the initiative.

Rationale \#2 By developing a curriculum of at least 10 lesson plans the concet of farmer knowledge in community programming will be outlined in a workable fashion enabling communities of interest to duplicate the effort.

\section{Critical Project Areas}

Ironically, the usual weaknesses found in most research projects of time and money do not apply to this project, at least at the present time. This initiative will officially begin on January 1, 2006 and go through January 1, 2007. This project is funded federally through a SARE (Sustainable Agriculture Research and Education) grant, a branch of the USDA (United States Department of Agriculture). Currently the project is on time with the milestones set in the original grant proposal. For instance, the first milestone mentioned in the grant (pg. 13) starts Fall 2004 and states that four pilot groups must be organized and meeting monthly by Fall 2005. The software and materials used for discussion in these groups will adhere to the same time-line.
While the project is on time with the first milestone, the following are some areas needing immediate attention:

- The formulation and communication of the advisory committee.

- Detailed outlines of how initial training sequences will occur with Research Farmers (Pilot Groups).

- Solidify which professionals are responsible for education, software development etc.

- The development of a website that will allow participants to access materials and post personal experiences as they realize the real-time capabilities of the Axim X5.

\section{$\underline{\text { Strategic Objectives }}$}

In this section of the summary, immediate priorities are listed. The direction that I am moving toward should be clear to all those involved, and consequently suggestions and concerns can be better expressed and applied to further planning. Currently, I have not made initial contact with all the county agents at this point. There is no question how important agents are to this project, and therefore communication; with Cooperative Extension professionals will remain a high priority. A letter of introduction written by myself was mailed the week of 9/06/04 to all of the affiliates participating in the study. A preliminary in-depth interview was developed for extension agents and will be carried out in each of the four counties during the month of September. Call lists that consist of affiliates who either have a PDA (Personal Digital Assistant; Axim X5) issued to them or have been spoken to about receiving one is now in existence. This list will be 
separated into professionals and

Research Farmers and ultimately make up the four pilot groups mentioned in the establishment strategy. The first Advisory Committee meeting will occur on October 13, 2004 from 2:00 p.m. 5:00 p.m. in Room of 1085 Ag Science Building. A phone conference will follow in November concerning the recruitment of the Research Farmers who will comprise the pilot groups that are to follow. The first meeting of the Pilot Group should take place in December. I am currently working with a Professional Technologist within WVU Extension Service at Knapp Hall to address the following issues: Internet Service Provider (ISP), network limitations on e-mails, modem connections on PDA, Virtual Private Networks (VPN's), and the software needed to realize our technological objectives. Our objective is to have an ISP in place that meets the project needs identified in October.

\section{Conclusion}

This Executive Summary was intended to outline what The Decision Enabling Collection and Management System Initiative is about. The broad goals of this project and the corresponding Research Problem for the pilot groups should be clear after reading this summary. The current objectives and the critical areas identified in this summary will be addressed at the first Advisory Committee Meeting. Track the progress of this initiative and view grant at:

http://www.ext.wvu.edu/jefferson/AxiPr oject/Axim_Home.htm 


\section{APPENDIX C}

Case Studies 


\section{Treetop Farm \\ Since 1763 \\ Owners: Ted and Pat Lancaster \\ Case Study \#1 \\ By: Robbie Edalgo}

The name 'Lancaster' rings a bell for many in the Jefferson County area, which comes as no surprise considering that they are the seventh generation of Lancasters to devote their life to the land known as Treetop Farms. Ted Lancaster, the 52 year old farm manager, acknowledges the importance of such continuity, and openly embraces the younger generations ideas in his family. "My willingness to change has been the fundamental reason why our farm is still intact and thriving, "said Lancaster. The fact that my daughter married wonderful a son-in-law doesn't hurt either.” In light of Ted's ability to adapt to new ideas, his daughter Emily was scarcely surprised when Ted agreed to participate in the Decision Enabling Data Collection and Management System

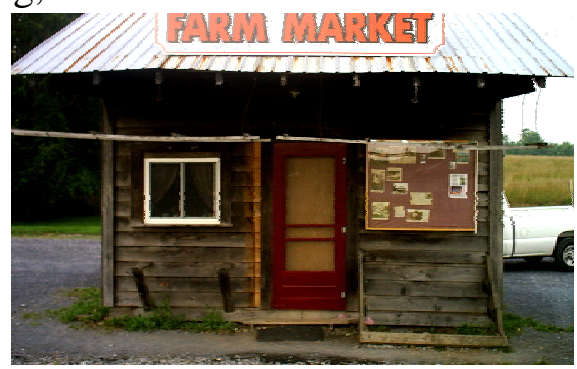
Initiative (DEDCMSI).

Emily manages the family's roadside agricultural products store, which has now been in operation for 14 years. Emily instantly recognized the benefit of data collection using a hand held computer and convinced her father, "It was too good to pass up." Once the father and daughter team decided to participate in the DEDCMSI they were given two Dell Axim X50s which Emily quickly used to develop the farms first spreadsheet entitled "Vegetable Inventory”. The spreadsheet allows Ted to track the amount of produce taken to the roadside stand and returned to the

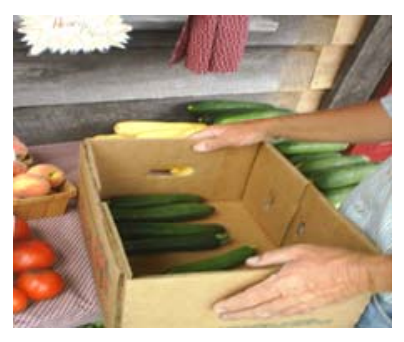
farm cooler each day. Emily also added a column for each vegetable’s price, which corresponded to a formula that calculates the totals for each item sold. Each day, Ted takes his handheld computer to fill in the template Emily has created in Microsoft Excel.

This spreadsheet is viewable on Ted's handheld computer through Pocket Excel, a 
program that is compatible with the home computer, where he can put all entries into a master copy by using Microsoft ActiveSync Software. Emily says she "no longer has to review crumpled up pieces of paper with her father's hand writing on them. The handheld reads my dad's handwriting better than I do.” The Lancaster Family expects that this type of recordkeeping will not only save them tedious data entry, but will also provide documentation of what has been sold off the farm. Such information will ultimately effect plantings in years to come. Knowing that tomatoes, potatoes and squash are the three most consistent sellers, Ted can determine yield per acre for these and other crops. Ted welcomes a more accurate recordkeeping system, and believes the DEDCMSI Program will make this possible.

Two additional recordkeeping objectives mentioned by Ted in reference to handheld technology involve price justification and customer/vendor information. Ted says he welcomes the possibility of becoming more accurate in recordkeeping and believes the DEDCMSI Program will make this possible.

Ted looks forward to a day when he can take the handheld computer out of his shirt pocket and show his price-wary customers the effect increased operating costs have on the prices he charges for Treetop Farm agricultural products. exact increases in inputs and how this filtered down to the asking price of Treetop Farm agricultural products they see today. "For example," Ted said, "most people are very aware that gas prices have gone up, but very few of those people know that petroleum is a major component in agricultural fertilizers." If inputs were recorded over time he could show people that prices were " $\mathrm{x}$ " dollars in previous years, ( and consequently the price he must charge) has been dramatically impacted by rising prices of fuel, seed, and labor.

Customer and vendor information are also areas of recordkeeping which Emily says they are interested in pursuing. Through the e-mail client software known as Outlook, Emily can enter customer contact information as she collects it during the course of a selling day. This software will also promote customer familiarity. For instance, Outlook has a contact feature that allows Ted and Emily to enter customer email addresses, mailing addresses and photos. The idea of putting a face with a name in a file that is accessible through the handheld is intriguing. The business client feature in this software provides a place for a customer picture but the size and quality of the photo are questionable and only time will tell if it is able to meet their needs. The milk and 
value added dairy products sold in the roadside stand are for Blue Highland Dairy. This vendor/distributor relationship demands detailed records in inventory and Emily is optimistic that the technology will make communication with Blue Highland Dairy more efficient. 


\section{SUNRISE FARM \\ RANDOLPH, WEST VIRGINIA}

Farm Owner: Dr. Rich Williams
A Case Study \#2
By Robbie Edalgo
Date: $7 / 18 / 05$

Edited By: Rich Williams and Kate Pulman

\section{Introduction}

Just before you get into Randolph lays a fascinating farm full of all the innovation, diversity and entrepreneurship which many think are needed to make farming successful today. The Sunrise Farm's agricultural products are all organically managed primarily for the local market of Randolph, West Virginia.

The farm is owned by Dr. Rich Williams, a local practicing dentist of 55 years in Randolph and a farmer of 33 years. Rich says this farm has evolved through a number of transitions. The overall business strategy of creating a personable relationship with the customer is still remarkably the same however. The farm has two fulltime employees in Kate Pulman (16-year employee) and Tobby Kerns (1.5 year employee) as well as two part-time workers. The farming enterprises pursued on the 113 acres comprising Sunrise Farm are extremely diverse and are listed as follows; free ranging chickens for meat and eggs, organic vegetables and fruits, coupled with lodging at Viewpoint Lodge and Conference Center. Dental instrument manufacturing is also done on the farm and is run by Kate, the farm manager. Adding to ingenuity found on this farm is the non-profit dental clinic made available through Dr. Williams on the Sunrise Farm for indigent patience. Rich says, "People associated with the farm have come and gone over the years like the group of residents that raised organic produce and some milk products on the land for the first twenty years of Sunrise Farms existence”. The fundamental principle, however, has largely remained intact. Sunrise Farm’s selling strategy is still geared toward the local consumer.

\section{The Technology}

Rich, an 81-year-old part-time farmer represents the exception in his age group when technology use and interest is considered. Rich is a participant in the Decision Enabling Data Management System Initiative because he values recordkeeping's power 
to help him make management decision and looks forward to seeing how the Dell Axim Handheld Computer will help make that possible. Rich also has a strong desire to show other people considering farming as a life's work that, "farming can be profitable" and he knows that if he is to do that convincingly it must be done through accurate records. Rich is most interested in the Axim's ability to organize tasks on the farm. Rich says priorities often get shuffled around and occasionally important jobs get moved to the backburner. The handheld computer will allow Rich to make changes to tasks, "in the field and its not much trouble". The primary program used for calendar/tasks is Outlook. Rich sees a time in the very near future when he can enter tasks as they come up on the farm. "For instance there is a tire that is low on that pickup. I don't want to stop and do that now...that would be a job for Tobby to do, if he knew to do it.” Rich says he intends to sync tasks with his home computer at night. Once these tasks are in the computer Rich says he can then print them out for Kate, Tobby and whoever else may be working on the farm that day. Rich foresees having a second computer that will be available to all workers on the farm. In this way Rich can sync his handheld computer at the end of the day and employees can access Outlook tasks in the morning and print out everything that needs to be done.

Other potential uses for the handheld computer Rich sees for Sunrise Farm exist in customer purchase history and purchase schedules. Sunrise Farm's clientele purchases eggs and vegetables on a schedule and if those schedules were placed in the handheld appointment screen with reminders that pop up the day before, efficiency could be realized. There is no doubt that a machinery inventory complete with serial and model numbers could be of use to Rich who does most of the farms purchasing. Rich has learned that, "you can't just go down to farm supply and match up mower belts. That doesn't work.” Free range chicken enterprise is also an area of recordkeeping interest. Rich says it is, "essential to know how much it costs us to raise a chicken from purchase to sell”. The Dell Axim also could provide efficiency in schedule maintenance when the Viewpoint Conference Center and Lodge is occupied $70 \%$ of the year.

\section{Farm Philosophy}

When Sunrise Farm raised the membership fee for CSA by fifty persent, all but 7 of the original 72 participants remained in CSA making it impractical to continue. After the CSA marketing strategy was stopped on the farm, Rich allowed a farmer to come and 
attempt to grow produce for the wholesale market in Pittsburgh as an endeavor that proved to costly and Sunrise Farm was faced with another year of little to no profits.

Today the philosophy of creating a personal relationship with local clientele has not been significantly changed. There are a couple of exceptions: the CSA has been replaced, with a order systems. This system is managed as far as days and items to be picked up on Rich's computer. The eggs chickens and produce are transported to Rich's home by Kate on the days customers indicate they need certain items. The pickup location has two refrigerators on Rich's porch where his customers pick up there own produce. This is a perceived positive by the customer because the selling location is in town and people do not have to drive out to the farm. The prices are listed on top of the refrigerators and the money is left by the customer in a blank envelope for collection. As to the risk associated with allowing people to purchase unnamed items out of the refrigerators Rich simply said, “ ...our society has gotten too anxious and suspicious of people. I think that most people tend to be honest, especially when it is assumed they are honest. If you assume people aren’t honest, chances are they won’t be”. The farm management practices are set up by its owner Rich, after serious consultation with employees all of which, Rich believes, have very valuable points of view. Rich's mission is to create human capital by providing his customers the opportunity to collectively identify and participate in his quest to provide nutritional foods to their local community. His management philosophy centers on their ability to fill specific market niches, making their product more appealing to the local consumer. Dr. Williams feels that the small farmer can only survive economically by finding a specialized niche which the larger commercial farms can not farm. The first way Sunrise Farm separates itself from the larger competitors originates from their unwavering dedication to grow everything organically. Farming organically was best described by Kate, "everything we do is organic. It's hard, but it's worth it. I think it tastes better.” 


\section{Agricultural Products}

A few of the vegetables at Sunrise Farm range from onions, peas, radicchio, kale, raspberries, radishes, asparagus, and finally Jerusalem Artichokes. Horseradish and Elephant Garlic are both planted in the fall. The Sunrise Farm family hopes that the variety of vegetable production will give customers a selection that will be not only desirable, but nutritionally satisfying. The typical planting regime at Sunrise Farm consist of preparing the soil in each of their 10 raised beds with manure tea which is applied from a gravity fed tank. Kate, the farm manager, has worked with Rich Williams and Sunrise Farm for sixteen years and is a big proponent of raised beds. The decreased disease and increase drainage gained from raised beds was the biggest advantages mentioned by Kate.

Dr. Williams believes you can never pay too much attention to the soil and for that reason has developed specific crop rotation with the intent of building his soil to highest fertility possible. For instance, nitrogen fixers like peas and beans are often planted to improve the soil on Sunrise Farm. Kate illustrated the extra steps that will be needed to grow organic corn due to the plants nitrogen requirements through the nitrogen fixing plants that will precede it in the field. Careful attention is also paid to soil compaction when tilling and bedding all crops that are not grown in raised beds. Free range chickens have been part of Sunrise Farm for many years and they pride themselves on the quality of the eggs produced. The chickens Rich says, “also

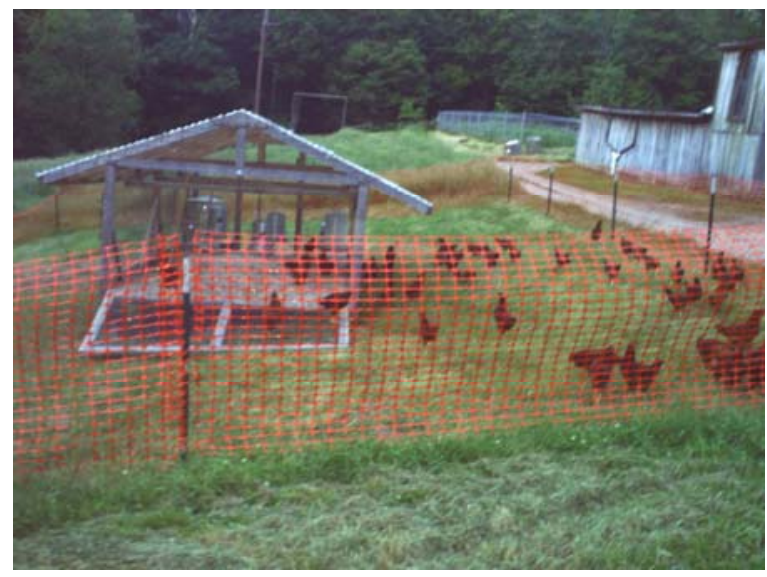
help fertilize the land.” Through the use of a fenced in portable chicken coup Rich has controlled the amount of chicken litter going into the field and hopes the soil will reap the benefits. Currently the farm has 30 laying hens, and 90 Rhode Island Reds that will be laying in October. 
Cornish cross chickens are processed and frozen in an Amish style which are sold at $\$ 3.50 / 1 b$. According to Kate this price falls far short of the $\$ 9.00 / 1$ botten by Pittsburgh organic producers.

The Viewpoint Lodge provides some of West Virginia’s best vistas. The three story lodge begs the visitor to sit out on the South and Southwest facing deck and breathe the country air as you become closer to a working farm and the critters that call Sunrise Farm home. The Southwest view of the lodge overlooks the nine total horses on the farm. My last visit I had the pleasure of watching a storm announce its presence over their heads. Kate would like to see the Viewpoint Conference Center and Lodge be utilized $70 \%$ of the year in the next five years. The lodge's is primarily done with a Red Oak timber frame construction method with Hemlock

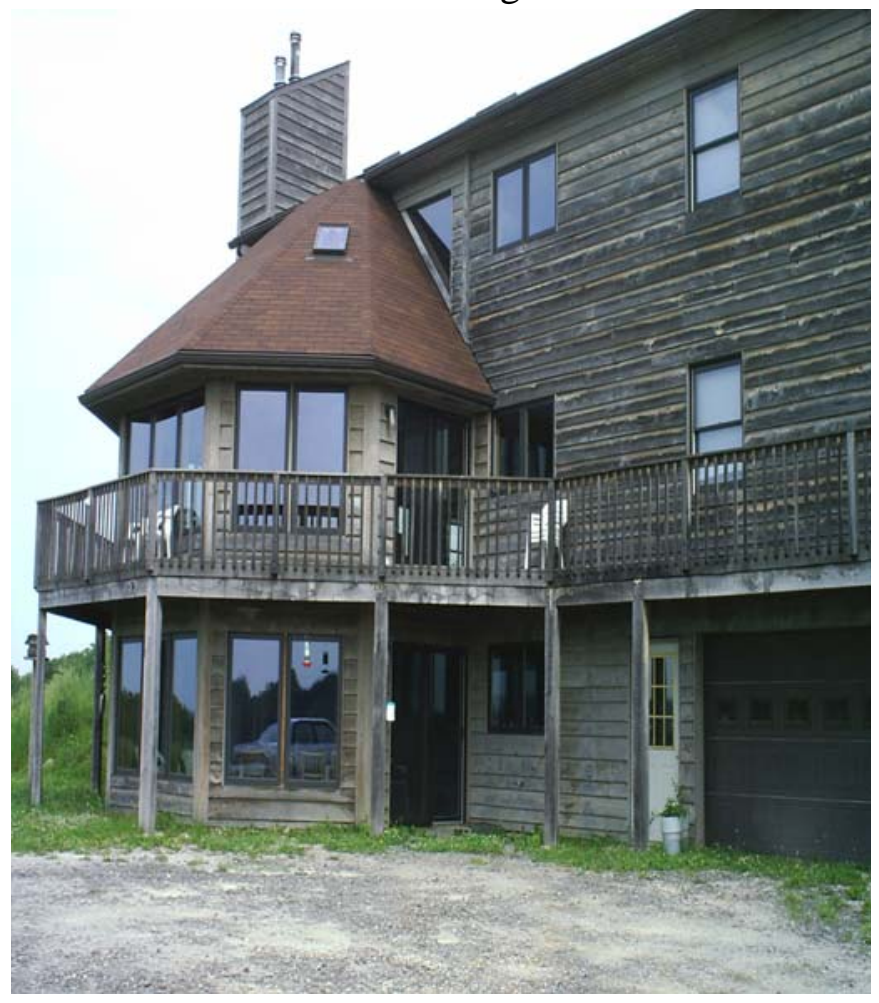
siding. The lodges water comes from two sources: rain water from the roof feeds all the hot water as well as toilets. Well water from the farm's windmill feeds all of the cold water taps. The water goes through an ultraviolet sterilization process as well as chlorination. Rich has equipped the Viewpoint with a cistern with six cells, each 8ft in circumference. Two of these

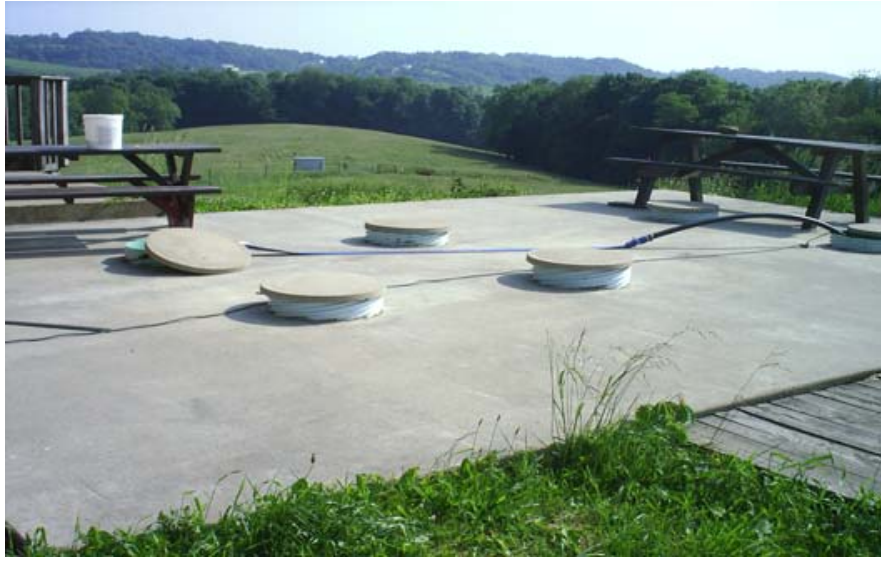
sell are for well water and the remainder for rain water.

Rich supplements his farming income through the sale of crown and bridge removing devices which he invented in 1969. The manufacturing of these instruments has in the past been the number one profit generator and Rich and Kate both remain 
optimistic about the future. It was a pleasure to sleep, eat and work on this farm for two day; and the lessons I take away from here will be lifelong. The following picture is my hat and the madox Dr. Williams let me operate.

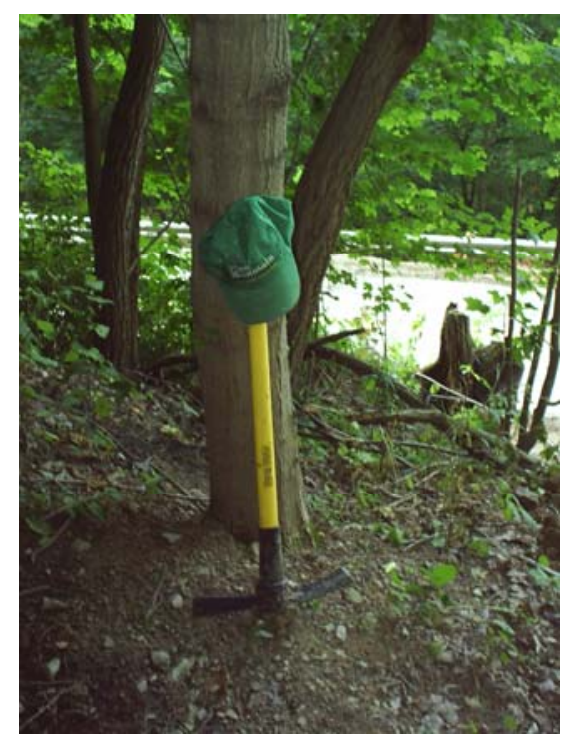




\section{John and Teresa Hopkin \\ A Case Study \#3 \\ By: Robbie Edalgo}

\section{Introduction}

John and Teresa Hopkin own a business that is common to Union, WV but the steps they have taken to organize their beef cattle farm is leading the way in embracing technology in the $21^{\text {st }}$ Century. The Hopkins cite increases in livestock production units, fulltime off farm employment for John, Teresa's pursuit of a M.A. in Public Administration and three children as reasons they need to become more efficient in their farming operations. The Hopkins have two employees on the farm one is participating in a cooperative and basically is paid through the experience gained from working on the farm. The other laborer is Teresa's brother in-law and is able to provide some part-time labor when he is not performing his duties as a civil engineer.

\section{Outlook (e-mail client)}

John also serves on the Soil Conservation District, is the president of the Monroe County Chamber of Commerce and remains engaged in other civic activities. Teresa points out, “you only have about 50 meetings a week”! The Hopkin family believes that Outlook’s (Microsoft e-mail client) compatibility with the handheld computer and home computer offer schedule management features that will be useful. By syncing the handheld computer in the afternoon when John gets home from work all of his appointments go into the Outlook calendar on the home computer making all of his appointments available in two places simultaneously. In this way Teresa can

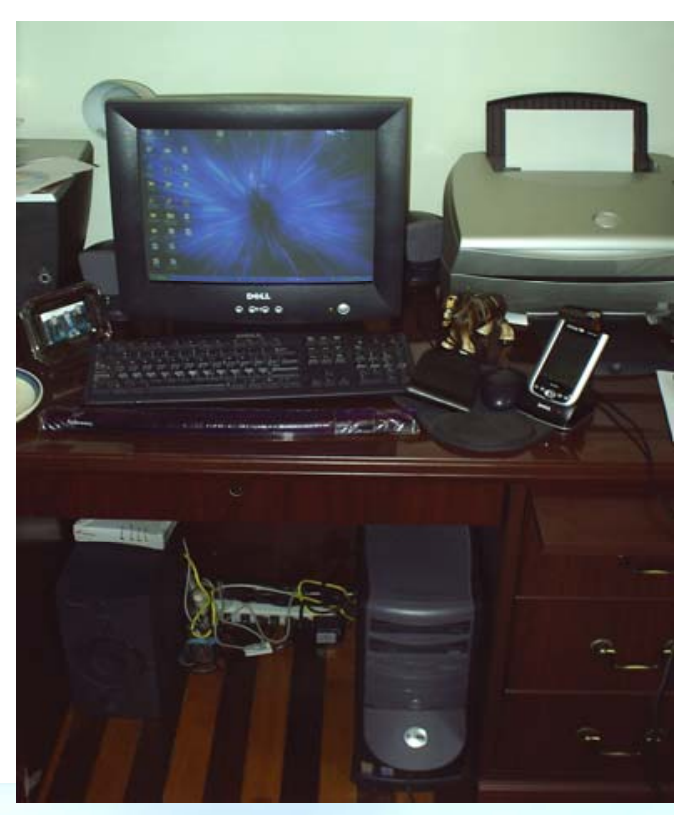
access the John's calendar with out him being present and the reverse is true for John. 


\section{Livestock}

Currently the Hopkin family own 57 cows and calves with and additional 15 Holstein bulls they bottle feed as babies. John says, "The hand held computer will be good to track what farm each animal came from... because that will be important with the new Premis I.D. program coming. I need a better system.” Among the records John wants to become more efficient in on the farm are as follows: what town purchased livestock came from, vaccination type/dates, antibiotic use and cow/calve weights.

When I asked John why he wanted to keep these records he simply said, "to determine how I market my calves.” Inputs on the Hopkin family farm dictate how they sell calves. If any of the calves have been given antibiotics they can't be sold for veal. John says, "they currently don't do a lot of veal but its an option he would like to have”. John went on to say that records, “...may determine whether I take my product to Pennsylvania...or send cattle out west and retain ownership.” Most selling decisions are made in the fall by the Hopkins. John has already started keeping cow, calf and sire Ids on his hand held computer. These spreadsheets also have corresponding birth weight/date, sex calving ease, weaning weight, and cow age. This information is made portable on the hand held and John is, " able to take it to calf pool meetings.”

\section{Participant Observation}

I had the opportunity to work cows with John. Each cow underwent the same routine of first entering into the cattle shoot, second receiving a de-worming application applied by a shot and to the skin, and finally they would be ear tagged. John

would write down the ear tag number as the cattle exited the gate with the intent on entering it into the handheld later. Based on my observations I do believe the time is coming in the very near future when John will enter the ear tag numbers directly into the handheld. A certain amount of trust must be earned by the technology before total abandonment of the paper and pen is realized.

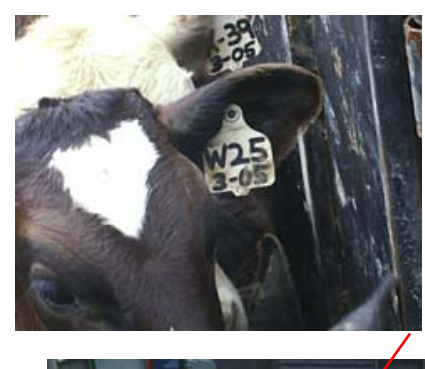




\section{Meadowbrook Farms \\ Case Study \#4 \\ Summer 2005}

By: Robbie Edalgo

Edited By: Donald Towers

One of the most dynamic farms I worked on during the pilot stage of the Decision Enabling Data Collection and Management System Initiative (DEDCMSI) was an extremely diverse operation in the eastern panhandle of West Virginia. The way in which they are currently utilizing the hand held computers as well as the many additional possibilities for real time data entry on their farm made Meadowbrook Farms a case study that could not be passed up. After a brief description of their farming enterprises I will discuss the way they are currently utilizing pocket PC technology as well as possible applications for the future.

Donald and Tracy Towers with the help of their extended family have been operating the dairy aspect of their farm since 1986. Recently other enterprises have demanded their attention, resulting in the agriculture tourism, horticulture (green houses) and vegetable production parts of their farm. The Towers have two children Kevin (age 7) and Donnie (age 5) who also pitch in from time to time. I had the pleasure of working beside Devon and lets just say if he works like that at age eight, I will pass up the opportunity when he turns 18. The Towers' farm a total of 259 acres and remain exited about what the future holds.

The Meadowbrook Farm is best split

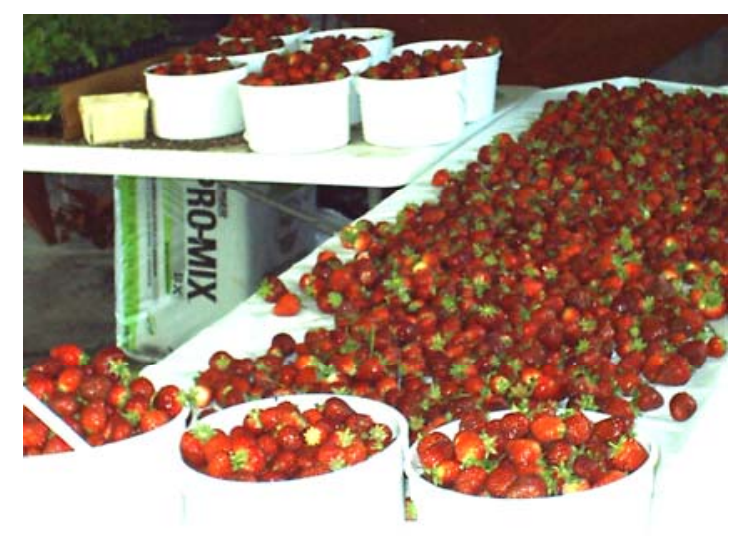
into three categories. The first and longest running enterprises of the farm are the "Heavenly Holsteins". The dairy operation is co-owned with Tracy's brother and has one fulltime employee to help with the labor demands. The dairy operation currently does not differ much from conventional management methods used in the region. The only minor difference currently used by the Towers and not others dairy operations are the 
weaning procedures. Their Holsteins are usually weaned on two to two and half months where as most take the calves at six weeks.

Out of the total 254 acres being farmed in 200513 acres was maintained in vegetable production, ranging from strawberries, melons, tomatoes, green beans, pumpkins cucumbers, squash and corn. Meadowbrook Farms sells their vegetable and some value added products at the local market which starts in June and ends on October 31. Every Tuesdays and Thursdays during the aforementioned time the Towers provide fresh fruits and vegetables to the people of Wheeling West Virginia. The Towers keep two greenhouses on 1 acre of their farmland and are in the process of expanding their greenhouse space in the very near future. These houses stay stocked with seasonal ornamentals never letting a holiday pass without providing it with

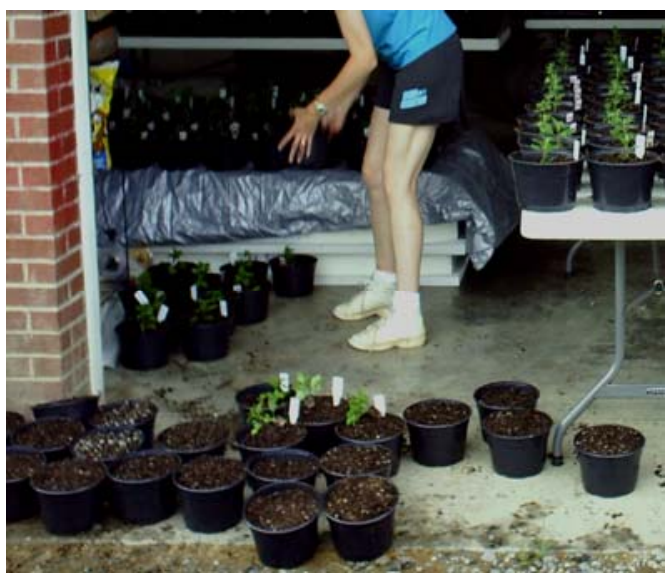
the appropriate flower. On one of my farm visits I helped pot 500 mums which could later be pinched and multiplied by two. The 5.8 acres planted in corn represents one of the fastest growing facets of their diverse farming operation, agro-tourism. The corn is planted in early June and is cut in early to late July. This agro-tourism will begin in August and continue through October. The key to the corn maize's success on their farm, besides their ability to manage a highly diverse operation, is location, location and location. Meadowbrook farm is located with in 15 minutes of five elementary schools $\left(1^{\text {st }}\right.$ through $4^{\text {th }}$ grade). At times the classroom tours attract groups as far as way as Maryland. The agriculture tourism also covers the "Country Farm Tours" that they have in October. Among the activities that takes place during “Country Farm Tours” and classroom tours range from birthdays and hay rides as well as butter making and classroom pumpkins. 
The corn maize

on the Meadowbrook

Farm was of particular

interest to the DEDMSI

due to the way in which

they cut the maize. Each

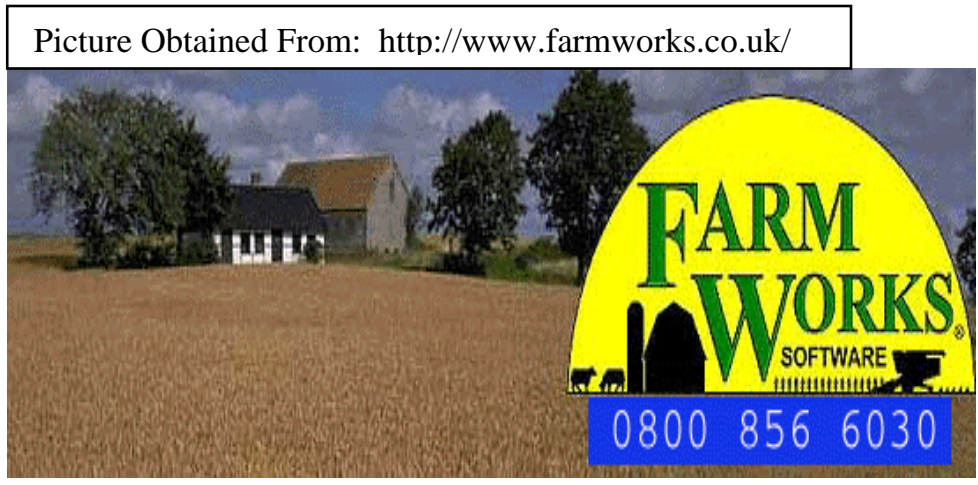

year around the first of July the 5.8 acres is cut into a specific image hand drawn by Tracy using a program called Farm Work. This image is then scanned into Photoshop and converted into a jpeg file. The next step is to obtain the waypoints for the boundary of the 5.8 acres that will be transformed into Tracy's scanned image. After the appropriate GPS waypoints are obtained the image is calibrated in Farm Works using technology called geo-referencing. The image is then downloaded into the hand held computer which will enable the tractor driver to can cut toward waypoints in the field. Once the maize is cut the stage is set for the surrounding schools and beyond to take part in down home agro-tourism. The Tower are blessed with a family friend that usually has all the answers in reference to this maize cutting technology and also actually cuts the maize each year for them. As previously mentioned the program used that makes the entire process possible is Farm Works. The Farm Work software/hardware package used currently sells for around $\$ 1,2000.00$. The GPS adaptor for the Axim can range from \$150.00 to \$200.00 depending largely on where the adaptor plugs in the hand held computer. The least expensive adaptors have wire hookups and the more advanced hardware plugs straight into the Compaq Flash slots on the hand held. 
Other potential uses of the hand held computer on the Meadowbrook Farm exist in the many advantages offered by the email client software known as Outlook. The newest version of Outlook (provided in Microsoft XP 2003 Software) allows DEDCMSI participants to sync tasks, calendar/appointments, and contacts between the home computer and the

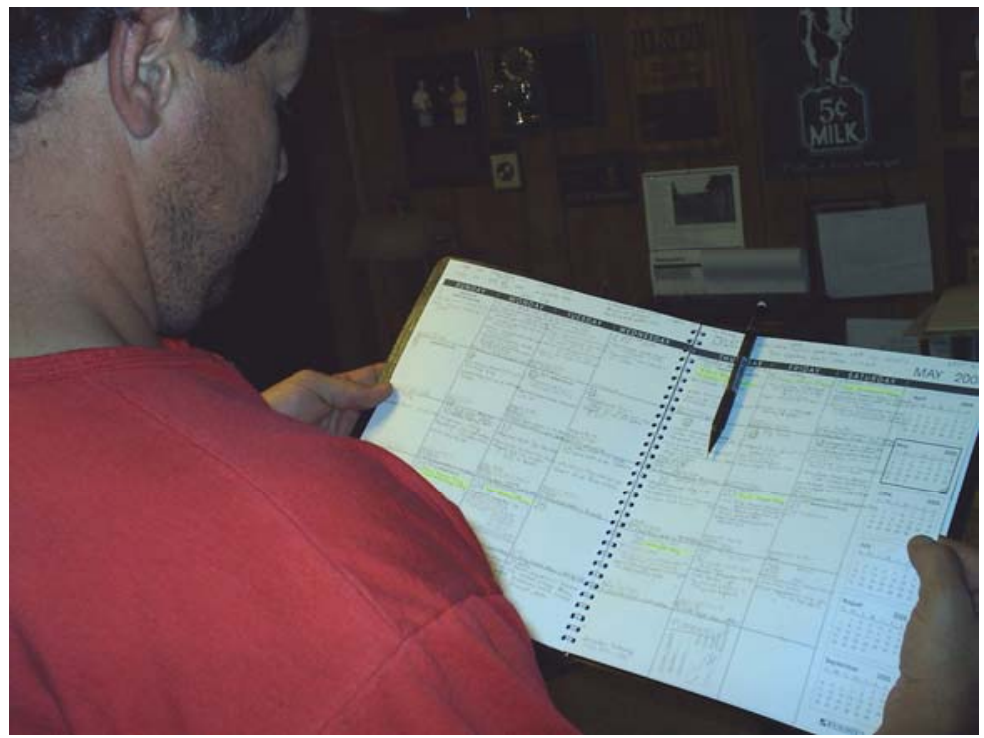
hand held computer. Both Donald and Tracy both expressed the need to mobilize their schedules as it relates to agro-tourist visitors. The possibility of knowing which schools are coming and when as well as the number being brought by each individual school is extremely appealing to the family. Beaming dates and schedules to the local Extension Agent who also owns a project Dell Axim X5 is another potential use. Donald and Tracy like the idea of beaming their farm visit schedules to their agent, who helps lead tours, without having to sit down and discuss each individual visit. The idea is that Pocket PC users can beam the days he can attend back to their unit after he has examined their calendar at his convenience. A certain level of doubts still remains however, about the reliability of the unit and only time will tell if the technology will earn the trust of this working farm family. 


\title{
APENDIX D
}

\author{
BASIC SKILLS LESSON PLAN
}




\title{
BASIC SKILLS FOR THE DELL AXIM X5
}

\author{
LESSON PLAN \\ $\# 1$
}

\section{THE MANAGEMENT SYSTEM INITITAVE}

\author{
BY: ROBBIE EDALGO \\ $1^{\mathrm{ST}}$ Edition
}

January 5, 2005

Document intended for personal use only and not for distribution 


\section{Table of Contents}

Introduction..........................................................

Book 1: Battery Basics....................................................

Chapter 1: The Backup Battery

Chapter 2: The Main Battery

Book 2: Security....................................................

Chapter 1: Security Suggestions

Book 3: Maintenance of Axim X5....................................

Chapter 1: Cleaning

Chapter 2: Screen Protection

Chapter 3: Water Damage

Chapter 4: The Power of the Soft reset

Chapter 5: The Hard Rest

Book 4: Active Sync..................................................

Chapter 1: Software Installation

Book 5: Data Management............................................6

Chapter 1: File Management

Chapter 2: Full Backup

Chapter 3: Data Backup on The Axim

Chapter 4: Backup a Single File 


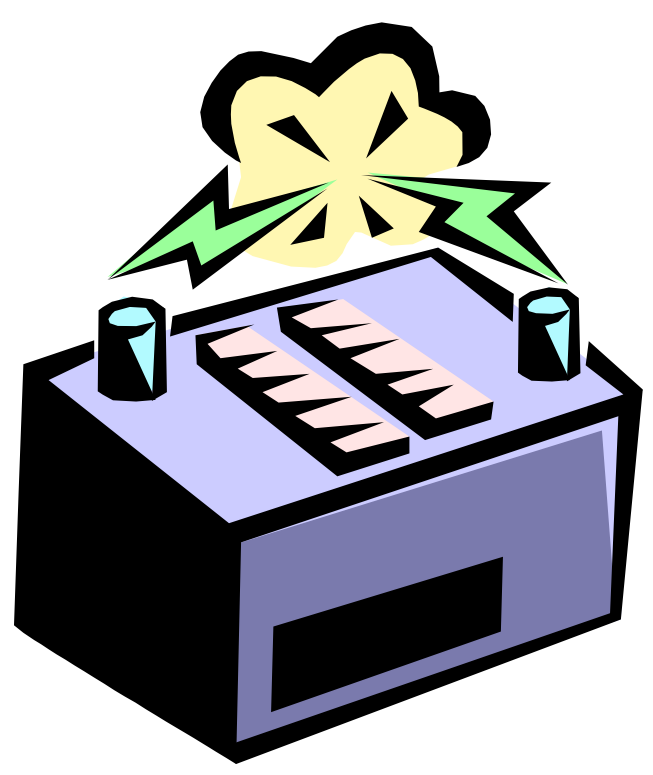




\section{Chapter 1: The Backup Battery}

The Dell Axim X5 has some operational characteristics that will serve the farmer well to know. For instance, Axim X5 is never truly shut off. This machine merely goes into sleep mode or more formally suspend mode when the power off button is pressed. For this reason and this reason only your data is never lost as long as power levels are kept at an expectable level.

The Back up battery for the Dell Axim X5 exists as a safety net for all of the operators inputs. The backup battery is not intended for operational purposes merely a safety net for your machine if the main battery become fully discharged (out of juice). In fact the backup battery for the Axim X5, unlike its predecessors, are not chargeable.

Dell recommends the backup battery code \# CR2O32, a power source commonly found in watches. CR2032 batteries can be purchased most anywhere watches are sold. If a backup battery is receiving normal use in the Dell Axim it should last one year.

Some backup batteries may read low or even experience fluctuations in power level readings for easily fixed reasons. Before a farmer can know if he/she is experiencing abnormal fluctuations they must know how to check power levels. The following diagram provides directions for this action:

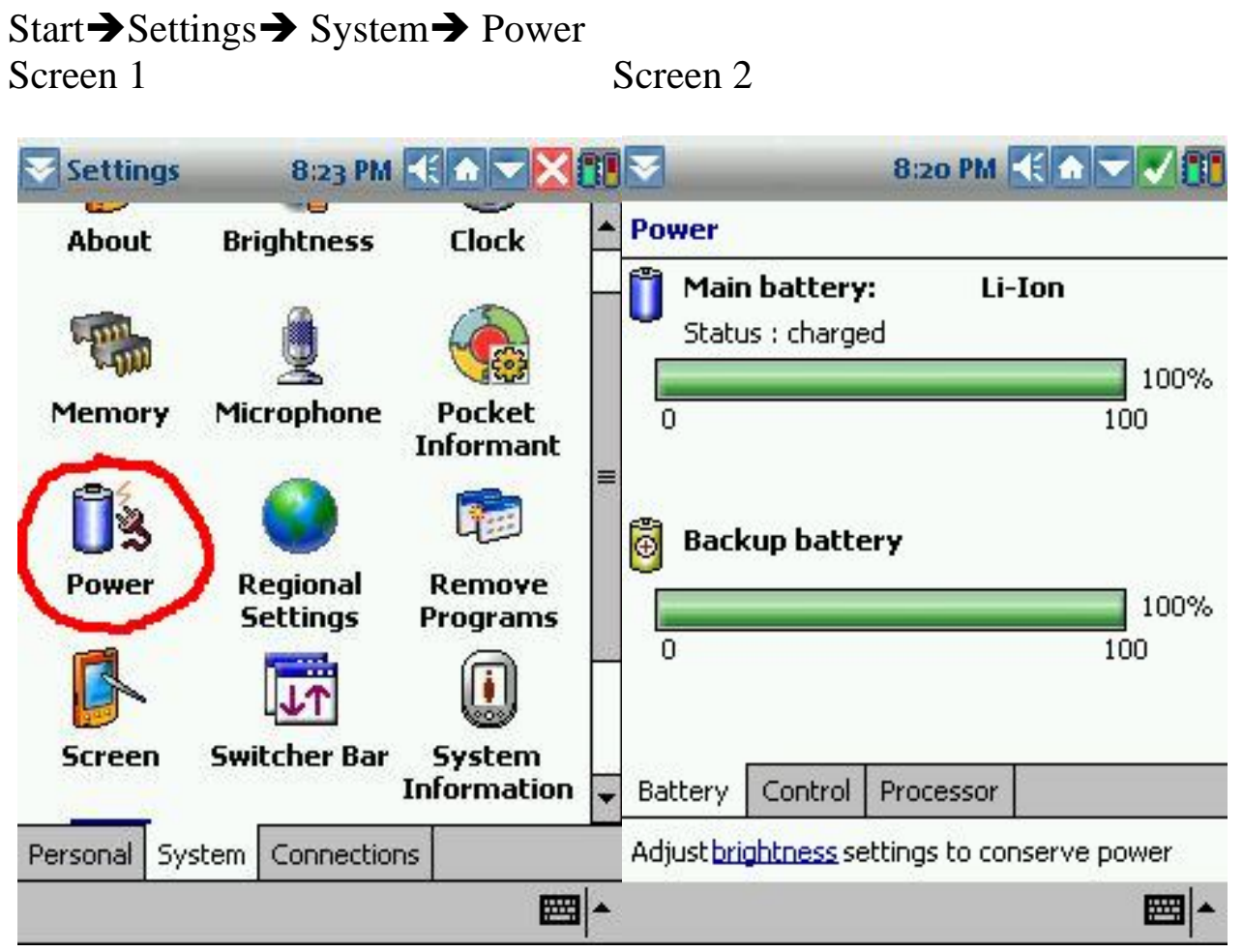




\section{Chapter 1: The Backup Battery}

Fluctuations in power levels that range from $80 \%$ to $100 \%$ are considered normal by most technology specialist. Its those fluctuations jumping from $20 \%$ to $100 \%$ and $0 \%$ somewhere in the middle that we will attempt to address in this lesson plan. The operator is asked to become an investigator checking each of the following potential causes until the problem of power level fluctuation is solved.

FIRST: Try wiping off the backup battery with a peace of cloth or check if it the battery is in backwards.

SECOND: Start by checking the metal contact connection for the backup battery. These metal receptors are located on the bottom side of the battery (negative side). It is not recommended that these metal receptors be bent, although this tactic has been used to some success. Instead try placing a folded peace of paper above the positive portion of the battery and its cover.

THIRD: Check the number of programs running on you Axim X5. The machine may be in need of freeing up some memory.

FOURTH: Try a soft reset (See Book 3; Chapter 4)

FIFTH: Do a full discharge of the main battery to allow the machine to calibrate power meters.

Note: The temperature level is another factor that effects the way battery levels read. 


\section{Chapter 2: The Main Battery}

The main battery of the Axim X5 is the very capable Lithium-ion battery. This battery is the top of the line today. This battery will provide 300 to 500 charges in a lifetime. The life span of a unused lithium-ion battery is said to be two to three years from the time it comes off the production line.

It is recommended by the Dell Corporation that a four hour charge be performed immediately after the machine is unpackaged. Remember it is not possible to over charge the machine therefore it is recommended that users get in the habit of charging every day.

Note: When charging your newly unpackaged PDA it will read fully charged after three hours. Do not be fooled! The main battery is actually at $70 \%$ and still needs an additional hour of chemical reactions for the Lithium-ion battery to reach its full potential.

It is possible however to do a full discharge of the power in the Lithium-ion battery. It is recommended to do partial discharges of the main battery during everyday use. These partial discharges not only conserve the backup battery power level but also reduce the amount of time needed to reach $100 \%$ power level. There is one exception to the partial discharge recommendation previously mentioned. Every + or 30 charges is recommended to do a full discharge of your Axim X5 main battery. By allowing your main battery to get bellow $70 \%$ the machine will re-calibrate the power meters giving a more accurate picture of the batteries running your machine. 


\section{Book 2: Security}

\section{Don’t Leave The Gate Open!}
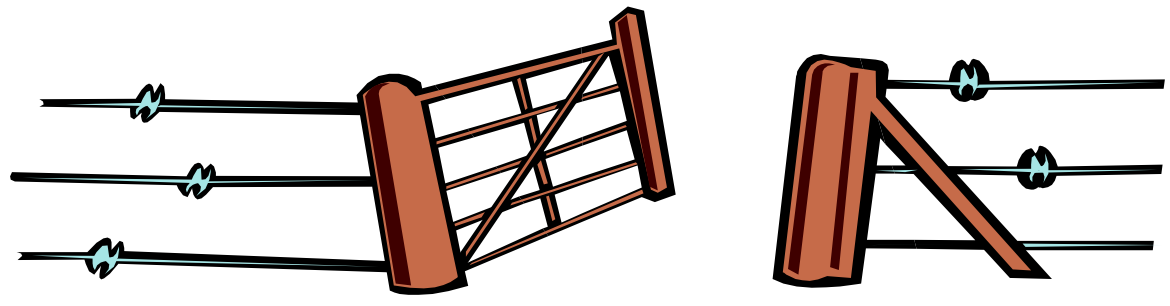


\section{Chapter 1: Security Suggestions}

This chapter of the lesson plan focuses on just a few measures that if implemented will make the Dell Axim operator's life a little easier. From a farmers perspective one could look at these suggestions as closing the gate on potential problems before they arise.

By setting owner information users will be shutting the gate on loosing their Axim. There no full proof measure that will insure your Axim will never be lost but at least a the person that finds your Axim will have the opportunity to return the PDA to its rightful owner if the following steps are taken:

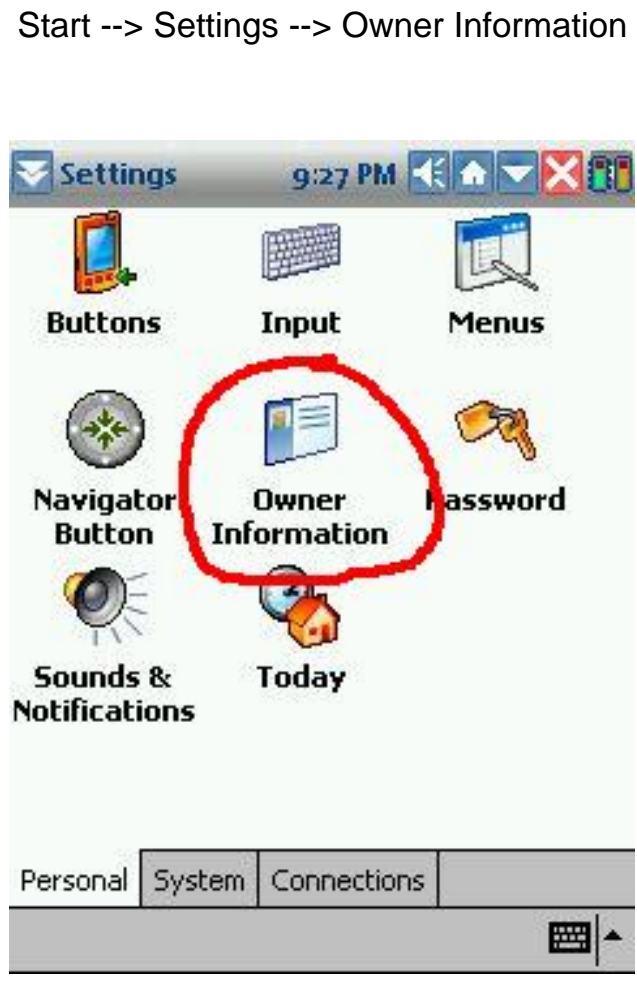

It is very important to note here that if the icon "show information when device

is turned on" is not checked your information will not flash on the screen every time the machine is powered on. The chances of someone actually going into the Axim X5 and searching for personal information of the rightful owner an returning it is far less than if personal information is right there when they turn the unit on. 


\section{Chapter 1: Security Suggestions}

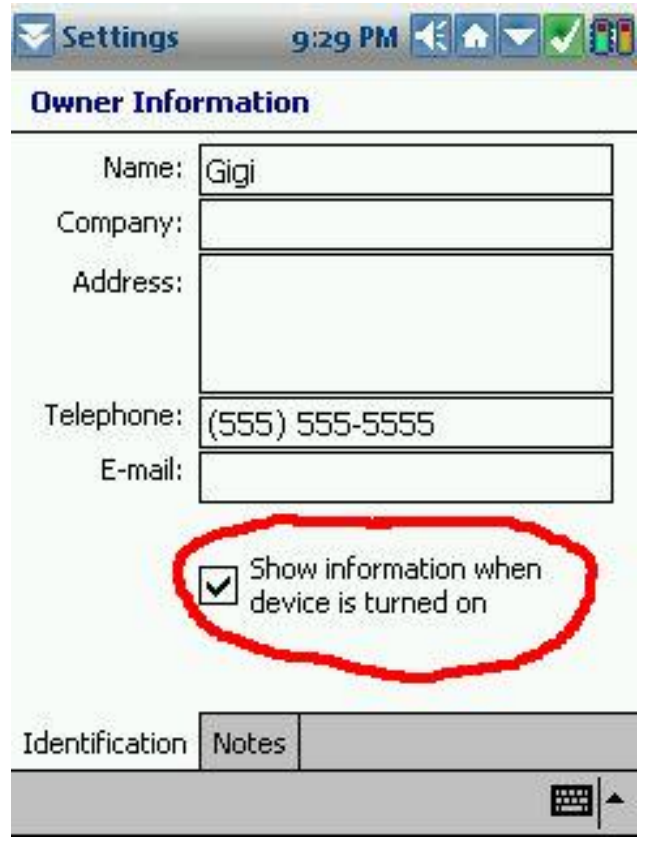


Book 3: Maintenance of The Axim X5

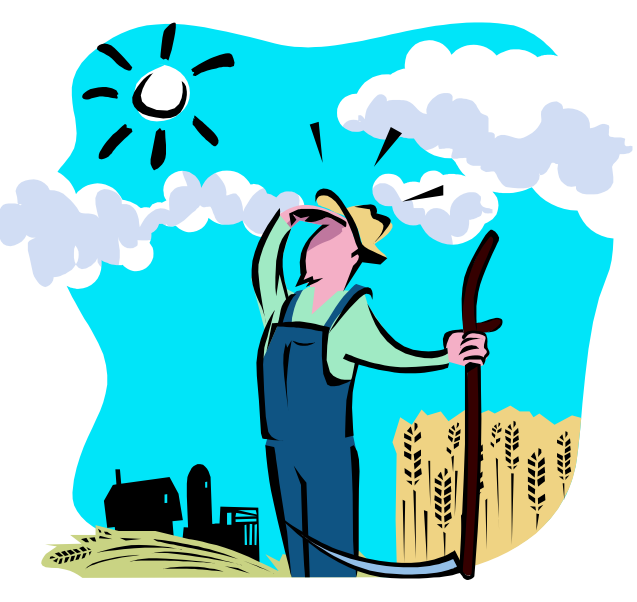




\section{Chapter 1: Cleaning}

The only area to be given great cleaning consideration, besides wiping off the backup battery, is the monitor screen. The procedure for cleaning this screen starts by taking a damp cloth at the top of the screen and wiping down.

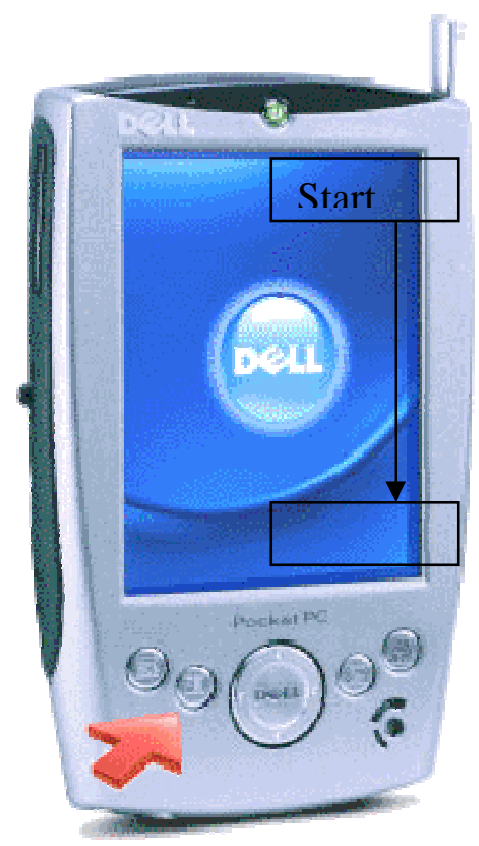

Note: Be sure not to leave any MOISTURE on the screen of your PDA.

The aforementioned cleaning method is the only way Dell recommends the monitor be cleaned. Cleaning aids such as compressed air and chemicals like Windex are never recommended. Anything besides a damp cloth will get under the digitizer (monitor) and cause it to malfunction. 


\section{Chapter 2: Screen Protection}

The screen is the most susceptible part of the Dell Axim X5 to damage. If maintained properly there is no reason to think it will not last through the dirt grime of daily use. The stylus is the tool most often used to interact with the PDA. It is important to inspect the stylus tip as it may become damaged after long periods of normal use. If stylus tip becomes frail in any way it will scratch the screen on your PDA.

Warning: Do not use writing pens are any other means other than a Dell recommended stylus.

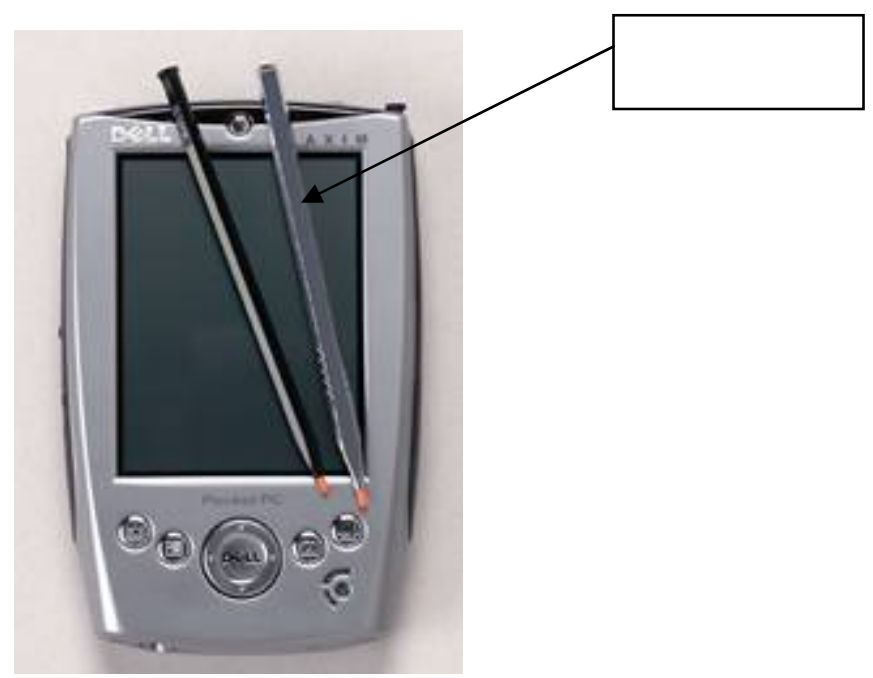




\section{Chapter 3: Water Damage}

It is highly likely that at least a few Research Farmers will expose there PDA to a considerable amount of water while entering data on the farm. While water damage is discouraged and if the working environment consist of a high potential for water exposure it is recommended that water proof cases be purchased.

For the unforeseen encounter between your Dell Axim X5 and the potentially damaging elements (water!) there may be hope if some basic steps are followed. The first thing most of us want to do when we expose in electronic device to water is to turn it on to see if it some how survived the experience. Stop! Do not turn your machine on after exposure to rain or other sources of water! Instead remove both of the batteries locations provided below:

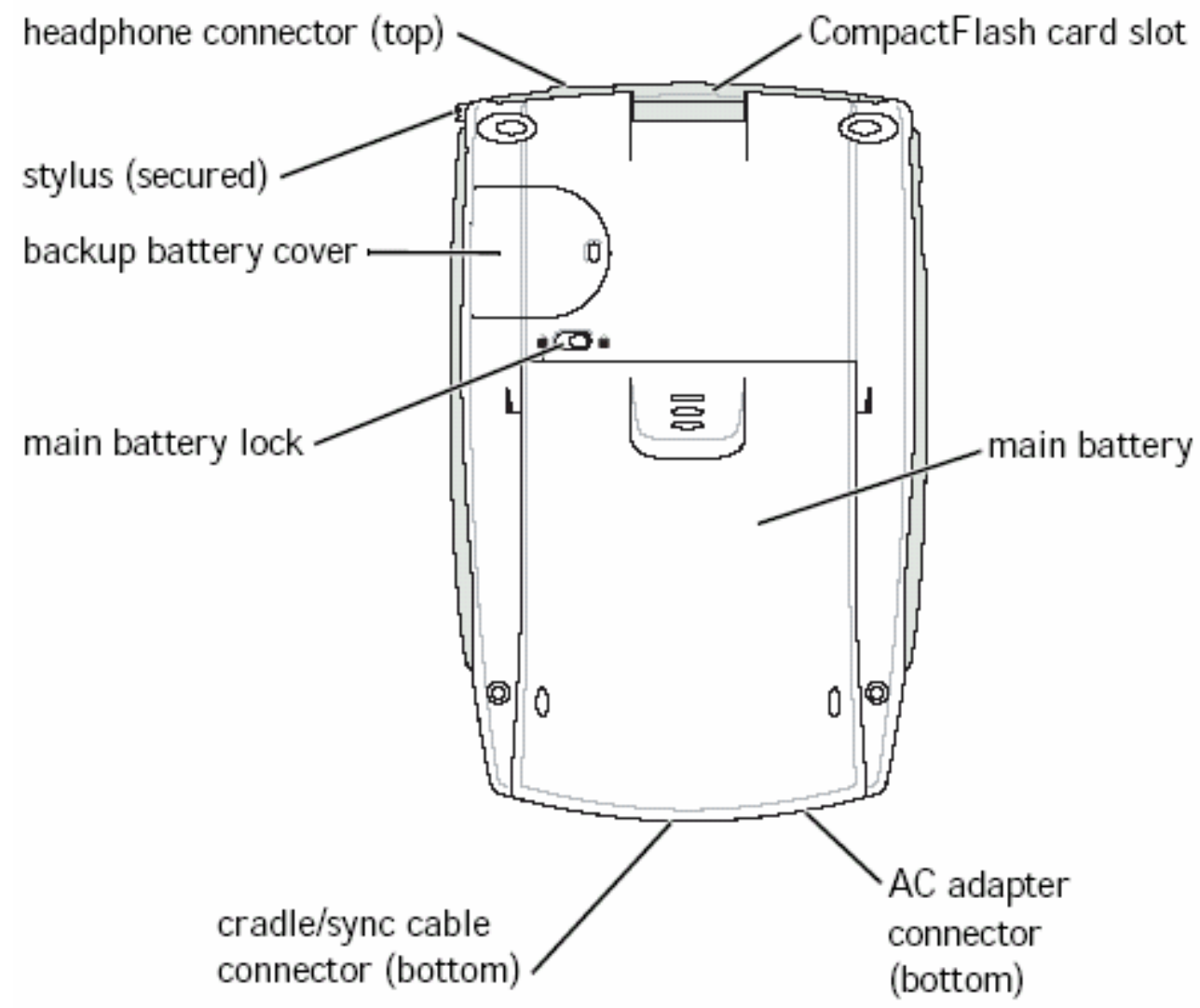

By removing the batteries the machine will be given time to dry out. The batteries should be dried as well. The recommended time for this dry out process is three days. At the end of the third day replace everything and give it a try. There are no guarantees that your device will operate properly but stranger things have happened. 


\section{Chapter 4: The Power of The Soft Reset}

The soft reset is perhaps the most powerful tool to be used when doing general maintenance on your device. The PDA soft reset is the equivalent of rebooting on your home computer, with some minor differences. The soft reset procedure is recommended anytime you feel your PDA is not operating up to acceptable standards. Examples of some minor operational problems are as follows: can't close out a program, unable to power of the unit.

Warning: A soft reset will delete all data not saved.

This procedure is an excellent way to close all programs running on your Axim. Shutting down running programs is beneficial because programs will build up over time and sloooooow your PDA down to a crawl.

NOTE: Before using the soft reset to shut down running programs there is an easier way to achieve the same result. There are two additional ways to close running programs.

1. Start $\rightarrow$ Settings $\rightarrow$ System $\rightarrow$ Memory $\rightarrow$ Running Programs $\rightarrow$ Stop All

: The second method is considered to be the easiest of the three known ways to stop running programs and speed up your axim. This method is accessed through the switcher bar. The limitation with this method is that you can not view the programs that you are shutting down.

\section{Click the Switcher Bar icon $\rightarrow$ Exit All Programs}

This reset is also used to make setting changes come into effect. By following steps 1-2 you will complete a successful soft reset.

1. With the stylus, press and hold $<$ Reset $>$ button for 2-5 seconds. 


\section{Chapter 4: The Power of The Soft Reset}

Axim Reset Button

The blue Dell logo screen temporarily appears. 


\section{Chapter 4: The Power of The Soft Reset}

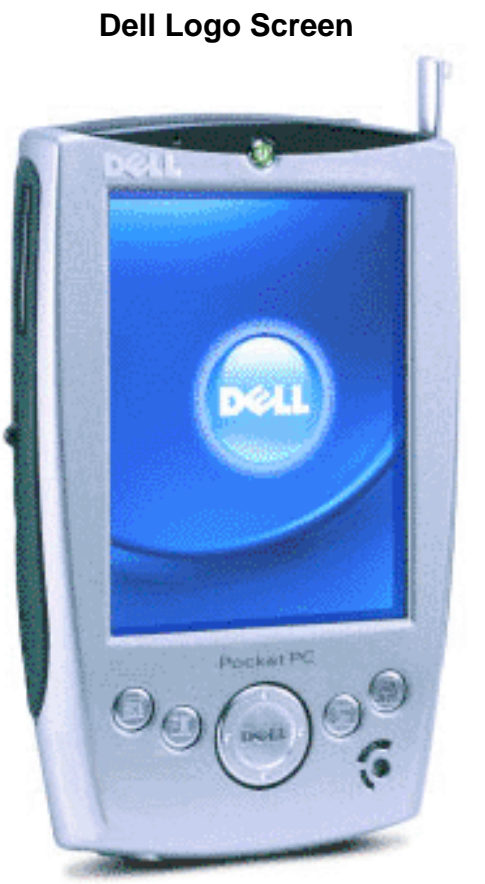

Your preset Today screen will reappear.

2. Tap the screen to begin using your device.

*These directions were taken directly from the Dell Website:

http://search.dell.com/results.aspx?k=Axim+X5\&ira=False\&s=gen\&ec=\&l=en\&cat=sup $\underline{\mathrm{eS}=\& \mathrm{c}=\mathrm{us}}$ 


\section{Chapter 5: The Hard Reset}

The hard reset is to be used as a last resort. When the soft reset has been attempted and did not meet your expectations then it may be time to try the hard reset. Other reasons for performing a hard reset are as follows:

*you wish to delete all data stored on your device

*you forget your password and need to clear it

*soft reset didn’t work

Warning: You must back up all your data before doing a hard reset (see Book 4)!

After the data is backed up on your device perform the following steps:

1. Press and hold the <Power Button>. With the stylus, press and hold $<$ Reset $>$ button for $2-5$ seconds.

The message To clear all data press the Contacts button appears.

Reset Button

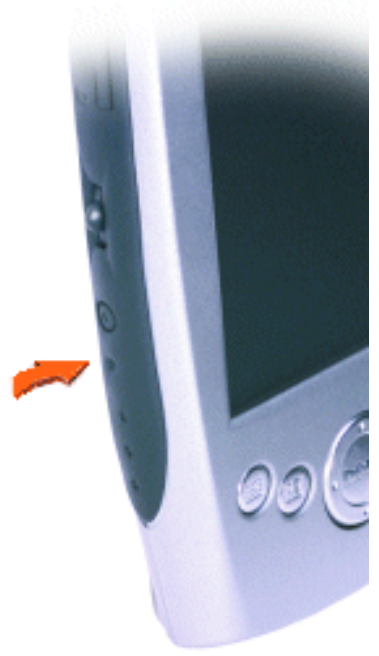

2. To clear memory, press the $<$ Contacts $>$ button.

The Contacts button is to the immediate left of the larger, centered, D-pad button. 


\section{Chapter 5: The Hard Reset}

\section{Contacts Button}

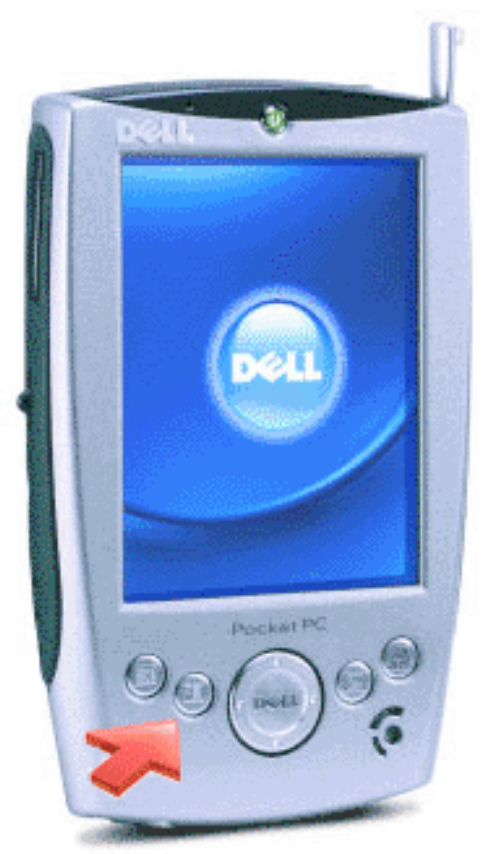

3. After a few seconds, the Pocket PC 2002 screen appears with the message: Tap the screen to set up your Pocket PC.

4. Use the stylus to tap your screen.

The align screen appears. Follow the instructions given to align the screen.

Directions taken directly from the Dell Website at :

http://support.dell.com/support/topics/global.aspx/support/kb/en/document?dn=1073114 $\underline{\& \mathrm{c}=\mathrm{us} \& \mathrm{l}=\mathrm{en} \& \mathrm{~s}=\text { gen } \& \mathrm{cs}=}$ 


\section{Book 4: Active Sync}

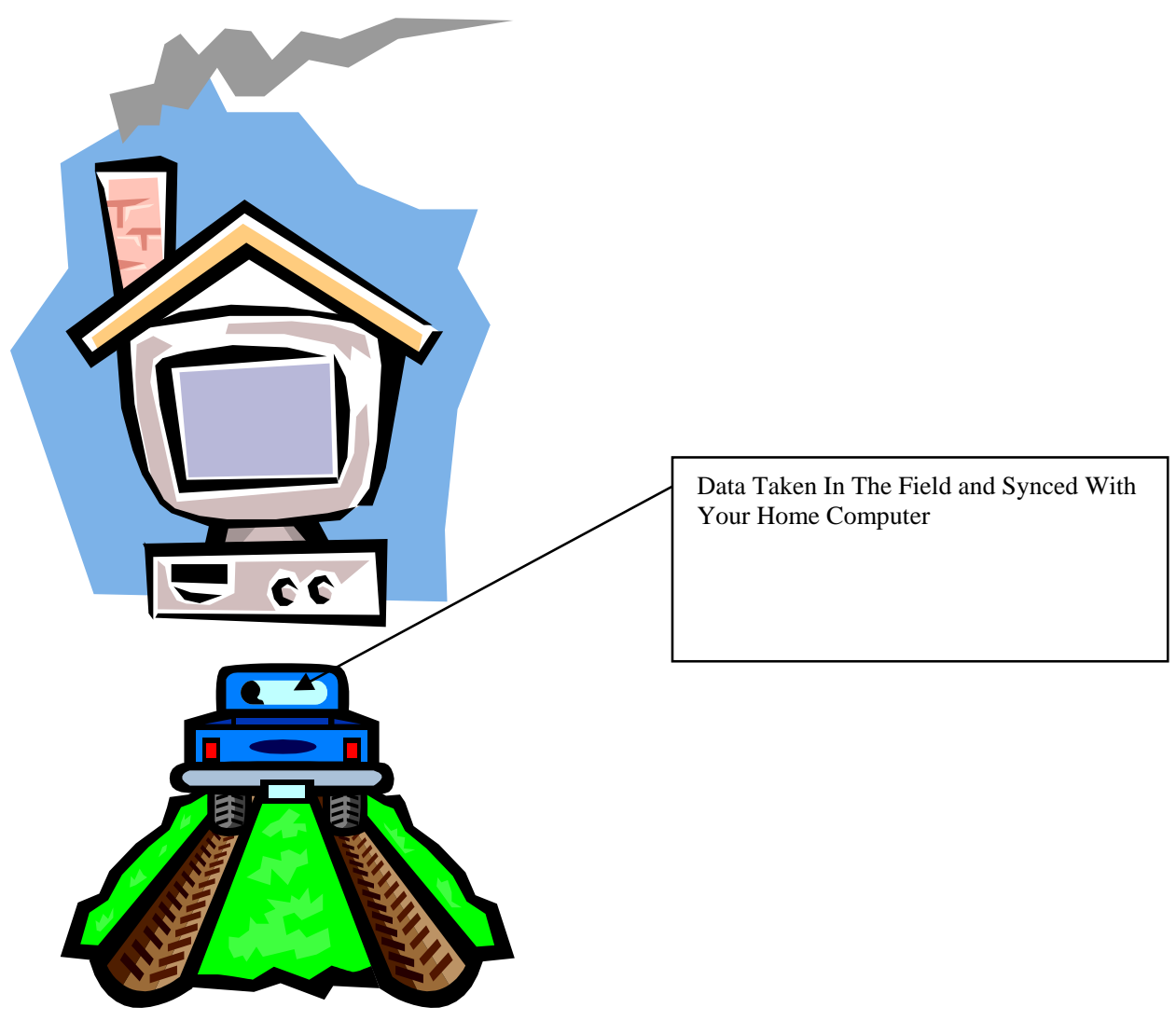




\section{Chapter 1: Software Installation}

If you have gotten a healthy grasp of the previous chapters up to this points all efforts will be lost if Research Farmers are not successful in this the most important chapter of the lesson plan. With out the realizing the potential of real-time data transference the utility of the PDA on the farm is highly will be questionable to most participants.

By using Microsoft Active Sync a Dell Axim user can take records in the field and do nothing more when he gets home other than sync his machine with home computer. We have extension professionals that are developing templates that will organize this data in reports further increasing farm managers ability to manage based on records.

Remember when you begin the installation process make sure you do not have any part of the Dell Axim connected. The proper screen will prompt you to get connected when the time is right. The first screen that appears once the software has been placed in the proper drive is appropriately enough entitled Getting Started with your Pocket PC:

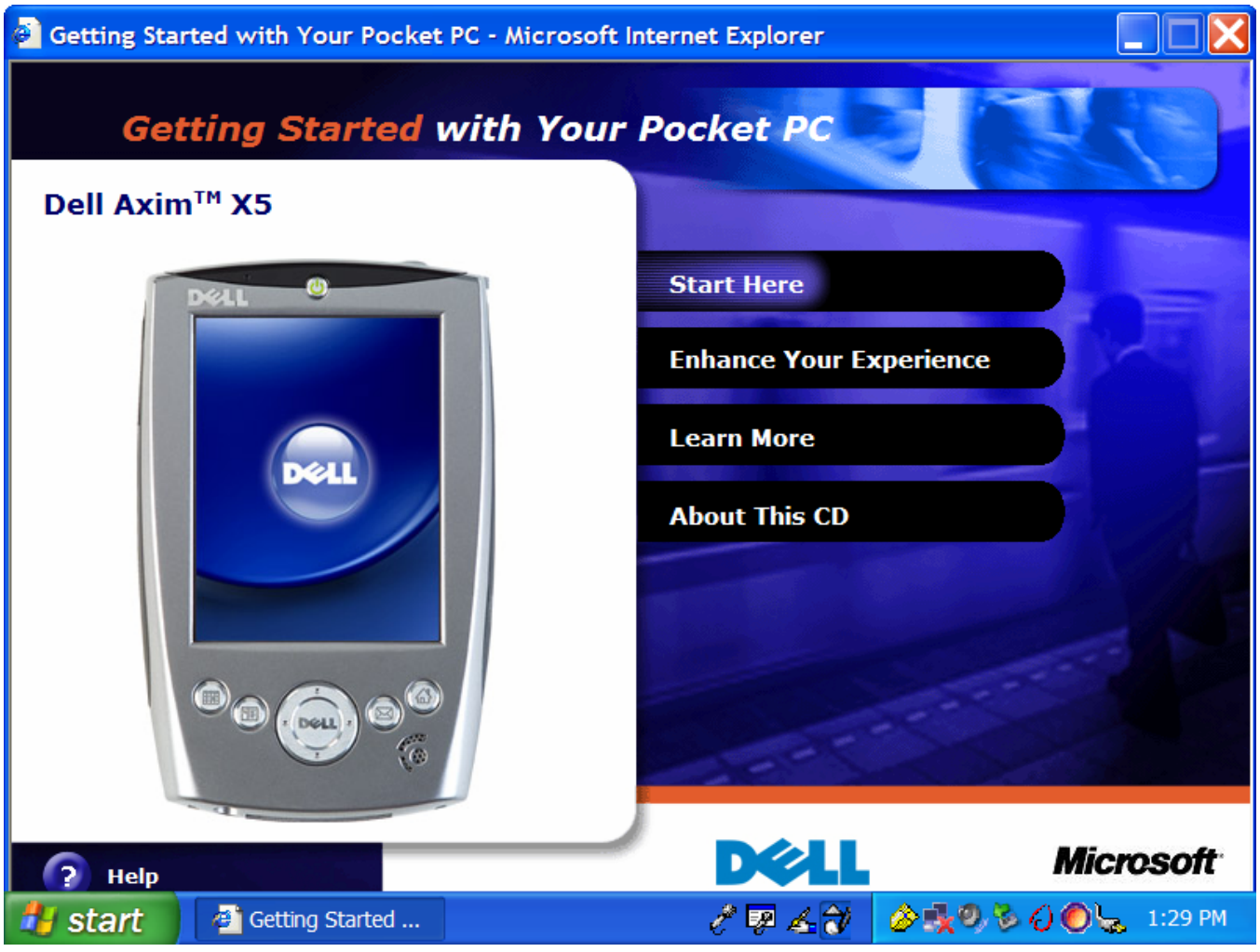




\section{Chapter 1: Software Installation}

The second screen simply requires that one of two selections be made to continue the software installation process. Choose install ActiveSync 3.7 on this screen:

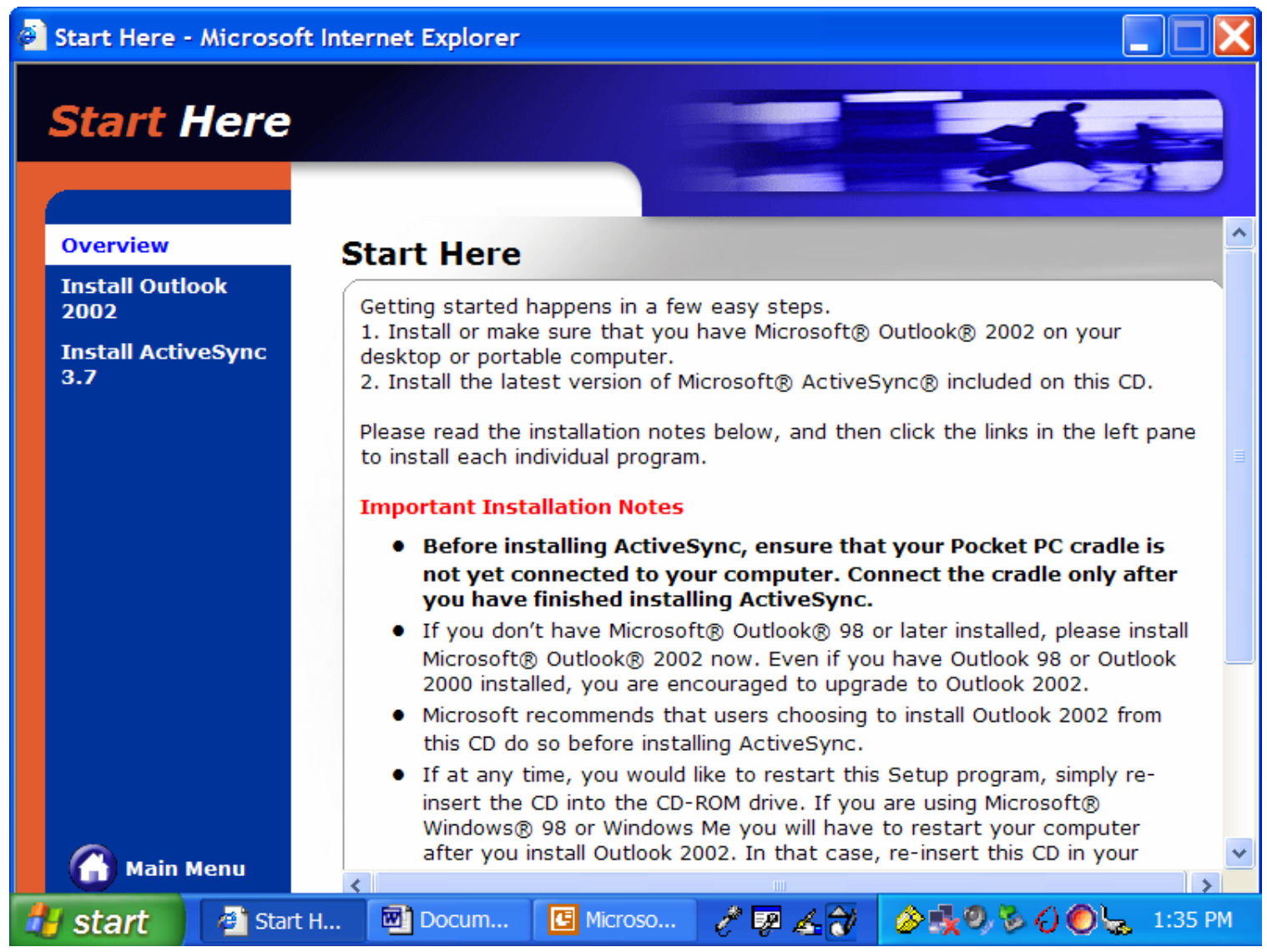




\section{Chapter 1: Software Installation}

Next Click Install:

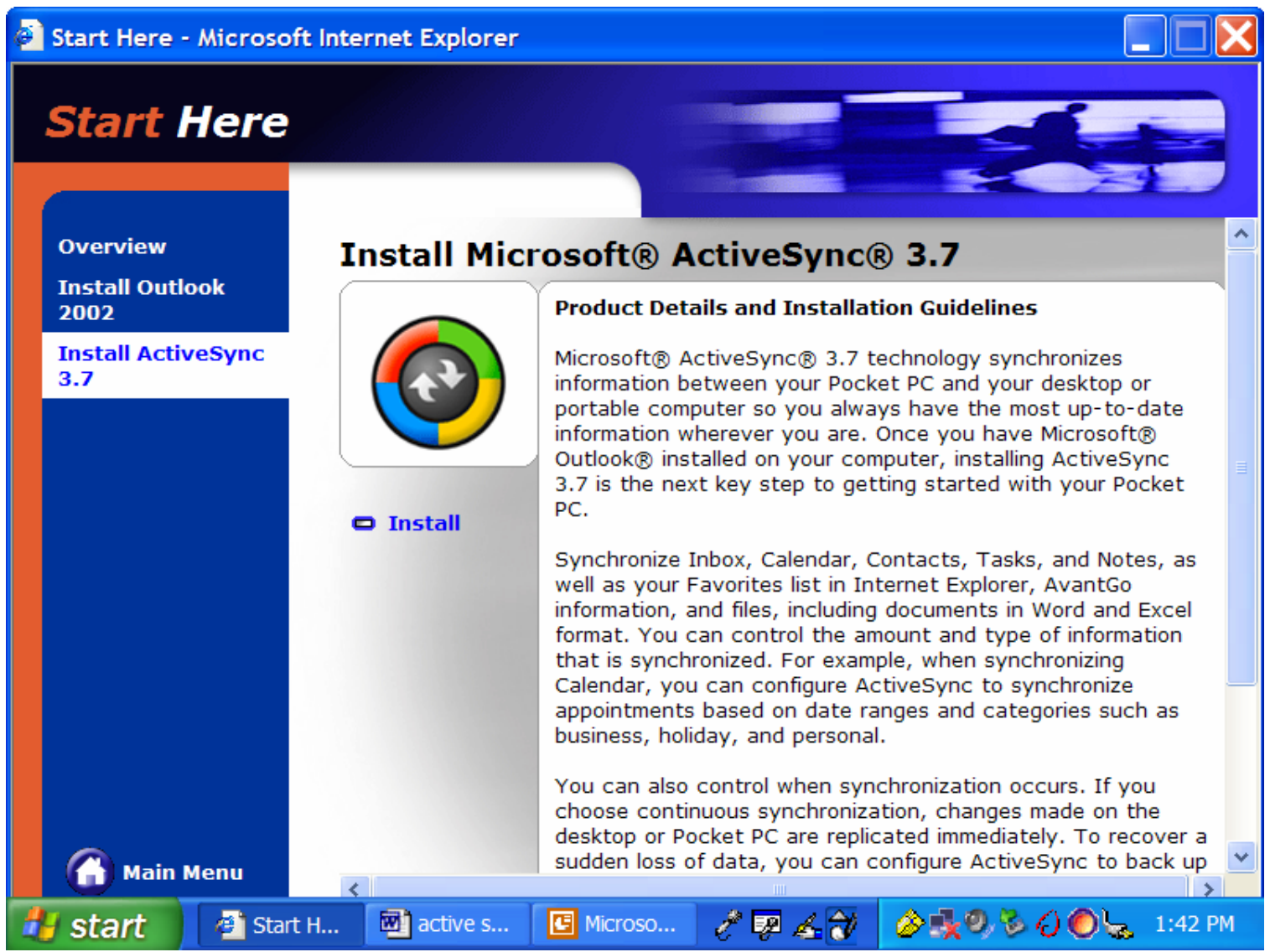




\section{Chapter 1: Software Installation}

Click Next:

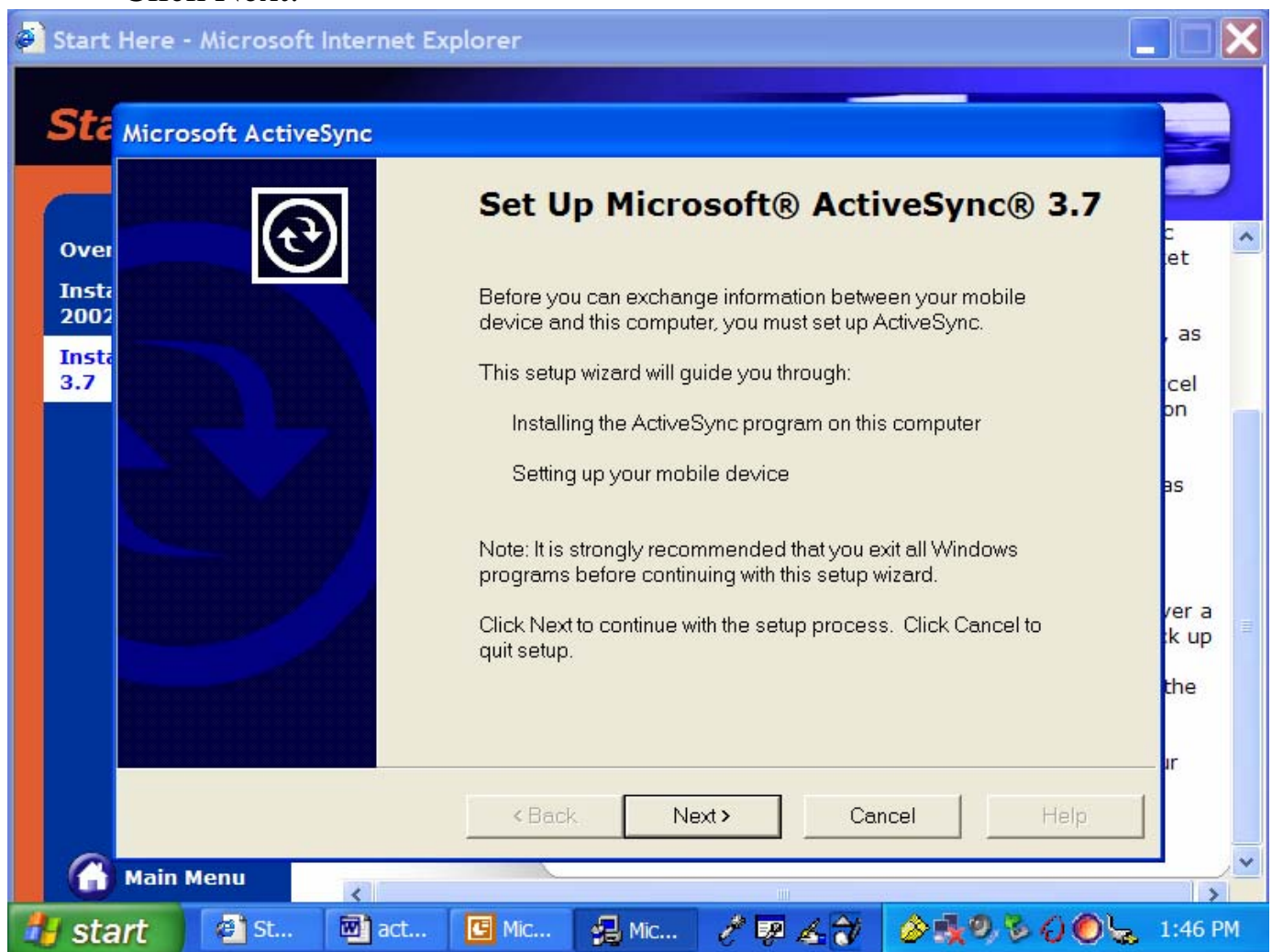




\section{Chapter 1: Software Installation}

After clicking next on the above screen it will be time to get connected. The screen that prompts the installer to connect the Axim is below:

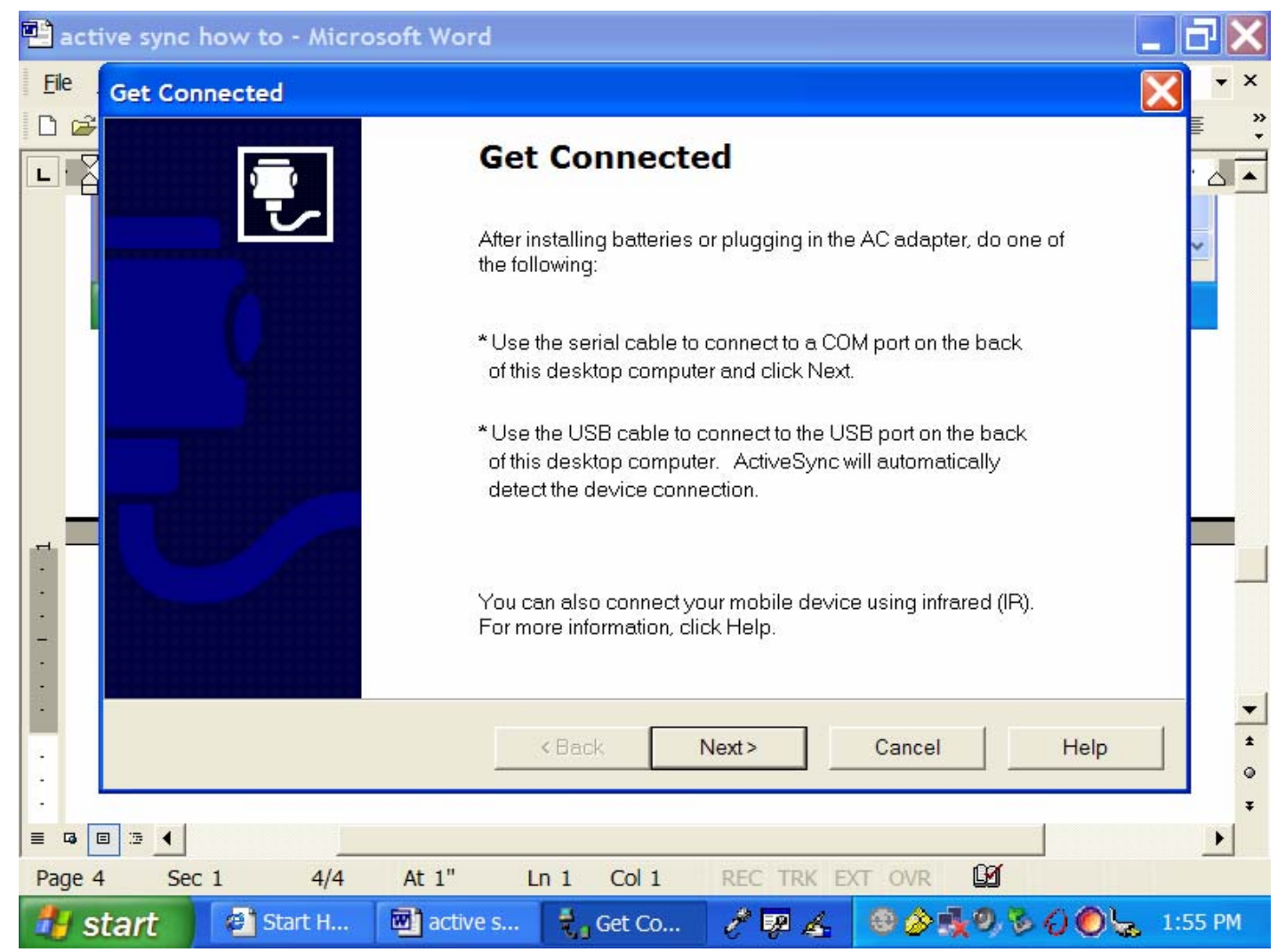

With this screen connect everything to your computer that is in the box. It is imperative that the installer know where his/her USB pots are located on the home computer before this portion of the installation process can be done correctly.

Note: If you are running Windows XP with firewalls then you must disable the security software to allow for the installation process to be accepted by the computer. The XP software should prompt the installer to make necessary selections allowing the firewall (security program) to permit active syncing. 


\section{KEEPING ELECTRONIC RECORDS \\ CAN ORGANIZE YOUR \\ FARMING OPERATION!!!}

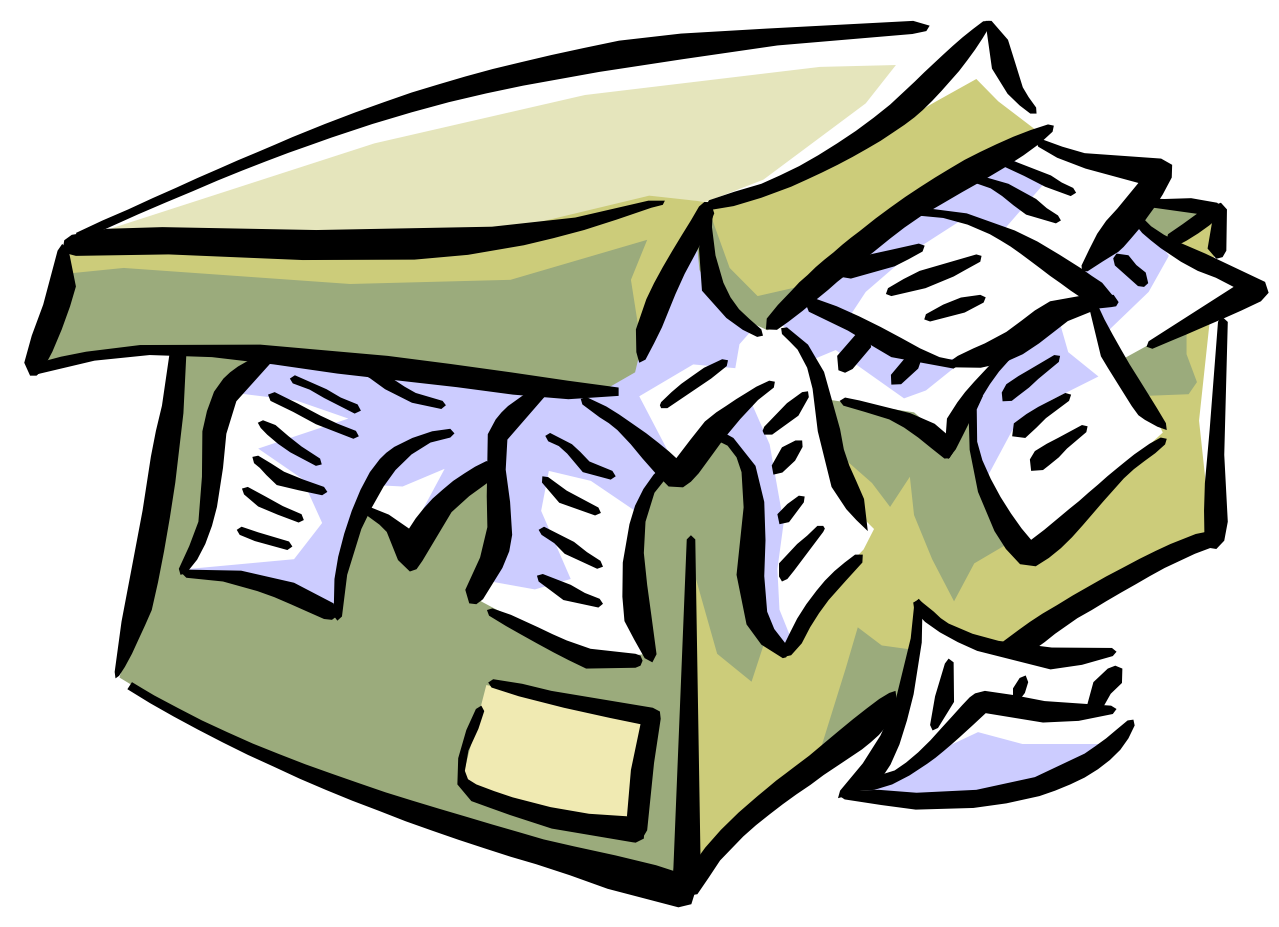




\section{Chapter 1: File Management}

The participants in the Management System Initiative will complete educational tutorials which will encourage the creation of electronic spreadsheets ranging from inventory to expenses and sales on the farm. As the entries grow the files needing organized will follow suit.

For this reason careful consideration should be given into what folders (places were files are kept) are called and what documents (files) will be placed in them. By following these steps an Axim operator can view all available folders:

Start $\rightarrow$ File Explorer $\rightarrow$ Various Folders on the Axim

To view files with the folders simply click on the folder of interest and view all document. New folders can be created with the names you give them. For instance you may want to create a folder named Excel Documents were all your spreadsheets will be found. 


\section{Chapter 2: Full Backups}

There are several types of data backups that are beneficial to the PDA operator. In this chapter we will look at the Home computer directed backup. Use this backup before you do a hard reset so all will not be lost. To start this backup find the following icon on the home computer descktop:

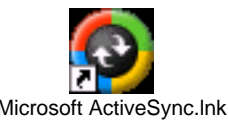

Once this is located click on the icon and then follow theses steps

Tools $\rightarrow$ Backup/Restore $\rightarrow$ The Backup/Restore Window comes up:
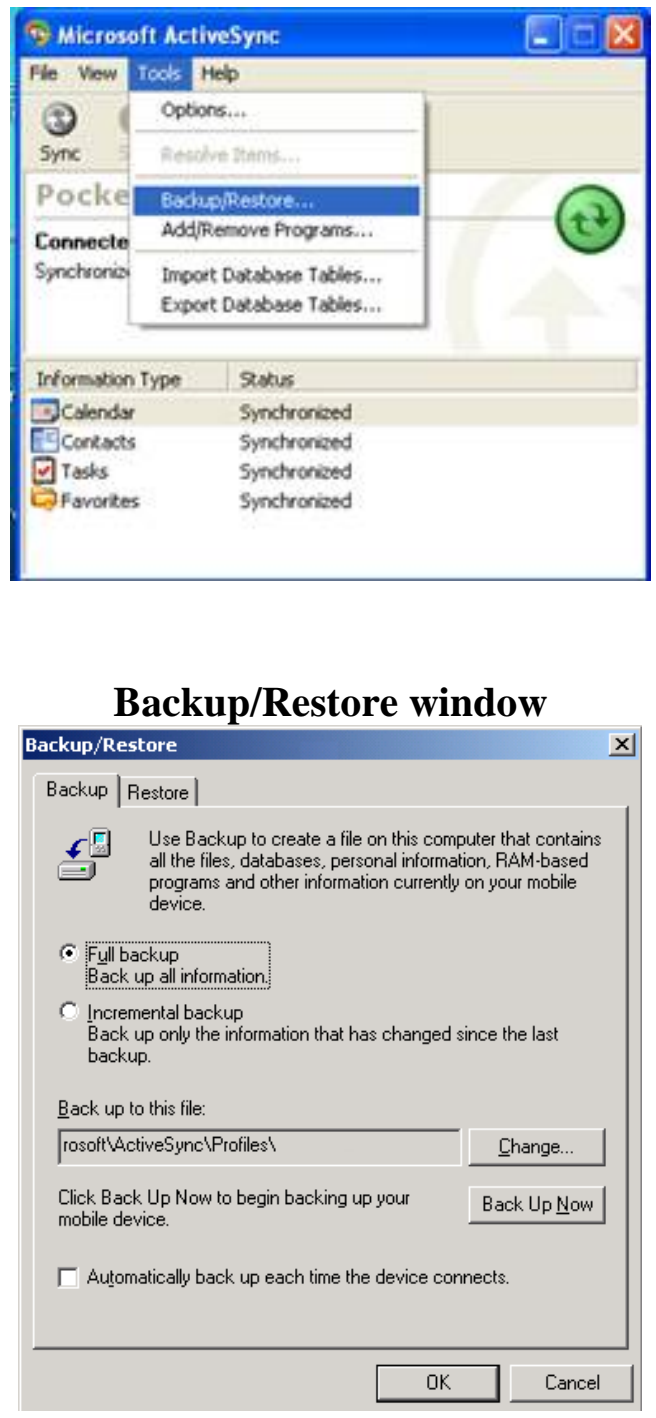


\section{Chapter 2: Full Backups}

Once the above window has appeared click Back Up Now and wait for backup to complete. This process will usually take around five minutes, give or take a few.

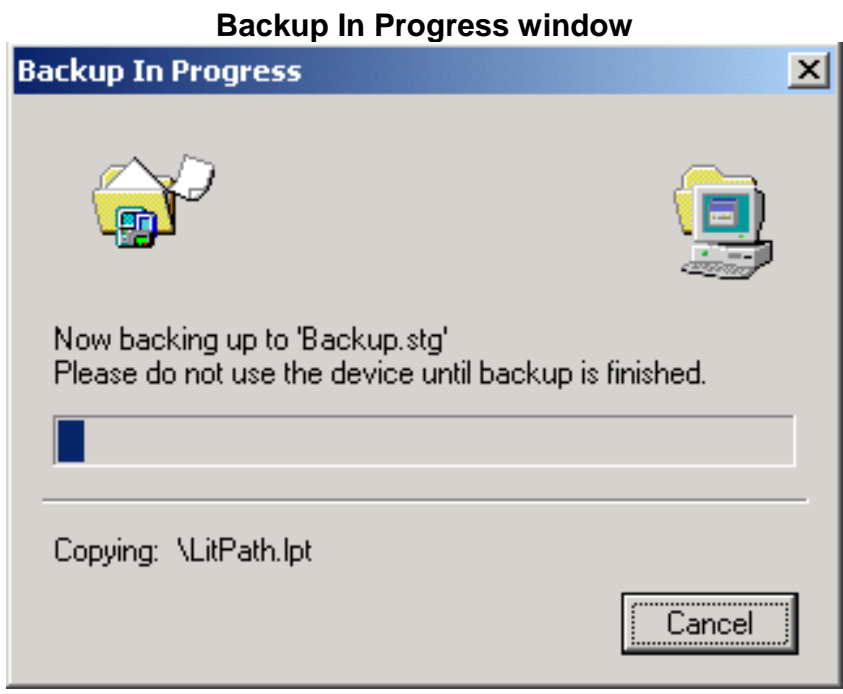

Warning: Do not use your device while this backup is being carried out. Do Not unhook the PDA from either the Sync cable or cradle which ever you were given when you received the unit. The Dell user will see the Back Up Complete screen when all data has been secured.

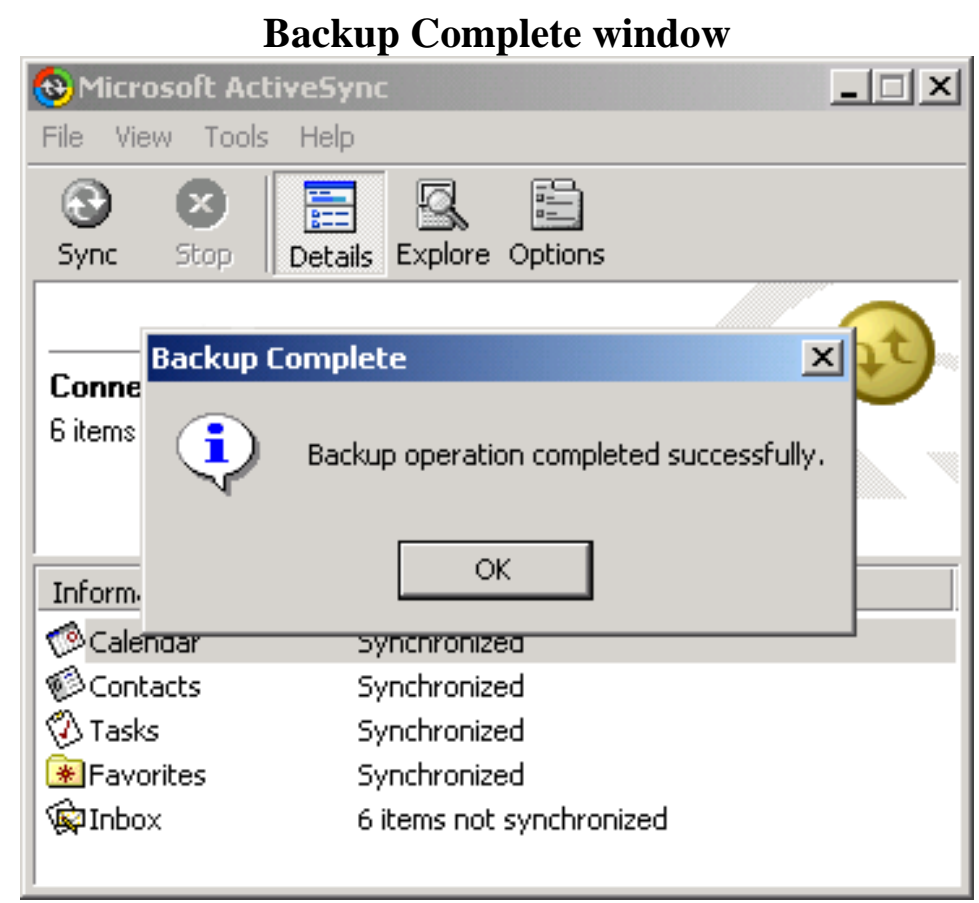




\section{Chapter 2: Data Backup on The Axim}

The Data Backup is used when you want to do a hard or soft reset. The PDA operator will insure that all data is safe by following some basic steps. It is recommended that farmers follow these steps for Data Backup:

\section{Start $\rightarrow$ Programs $\rightarrow$ Data Backup}

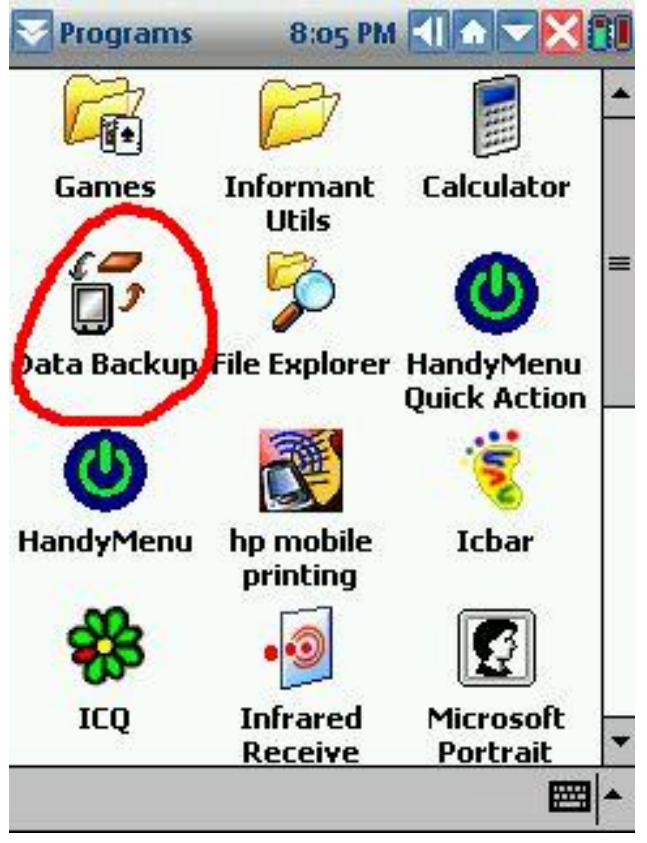




\section{Chapter 2: Data Backup on The Axim}

Once you have selected the Data backup icon on your PDA the following Data Backup screen will popup.

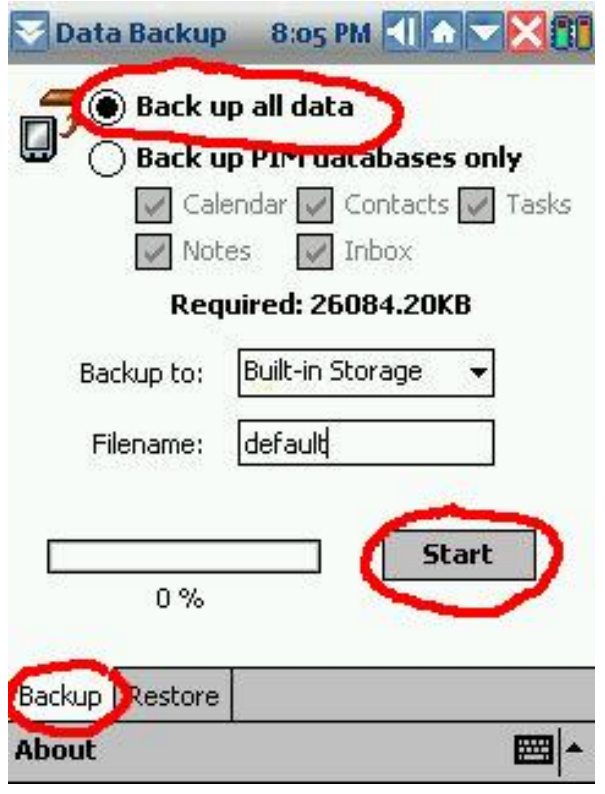

When the above window appears there is some work to do to make sure your data backup goes the way you want it. First make sure that the Back Up all data selection is chosen. Second thing you want to take care is the filename you will give the backup. Finally select start and the backup will begin.

Warning: Do not use your device until the backup and restore processes are complete. 


\section{Chapter 2: Backup A Single File}

There are many cases when a farmer may want to backup a single document on his/her Axim X5. In this case follow these steps:

Start $\rightarrow$ File Explorer $\rightarrow$ My Device $\rightarrow$ Built In Storage 


\section{APPENDIX E}

Operational System Checklist 


\section{Operational Systems Checklist For Project Participation}

Name of Participant

County

Directions: You may best answer questions numbers one through three by Right clicking My Computer on your desktop and selecting Properties. The information will be on the General Properties screen of the System Properties Screen.

1. What version of windows do you use on your home computer?
a. Windows 98 ( $2^{\text {nd }}$ edition)
b. Windows XP
c. Windows 95
d. Don't have a home computer

2. How much memory does your computer have?
a. less than $128 \mathrm{MB}$ of RAM
b. $128 \mathrm{MB}-256 \mathrm{MB}$ of RAM
c. Greater than $256 \mathrm{MB}$ of RAM

3. What kind of computer do you have (please provide as much information as possible)?
a. Gateway
b. Dell
c. Apple
d. McIntosh
e. other

4. How many years old is your home computer?
a. $<1$
b. 1
c. 2
d. 3
e. 4
f. 5
g. 6
h. 7
i. 8
j. 9
k. Greater than 9

5. Where did you buy your home computer and what type of service agreement do you have? 


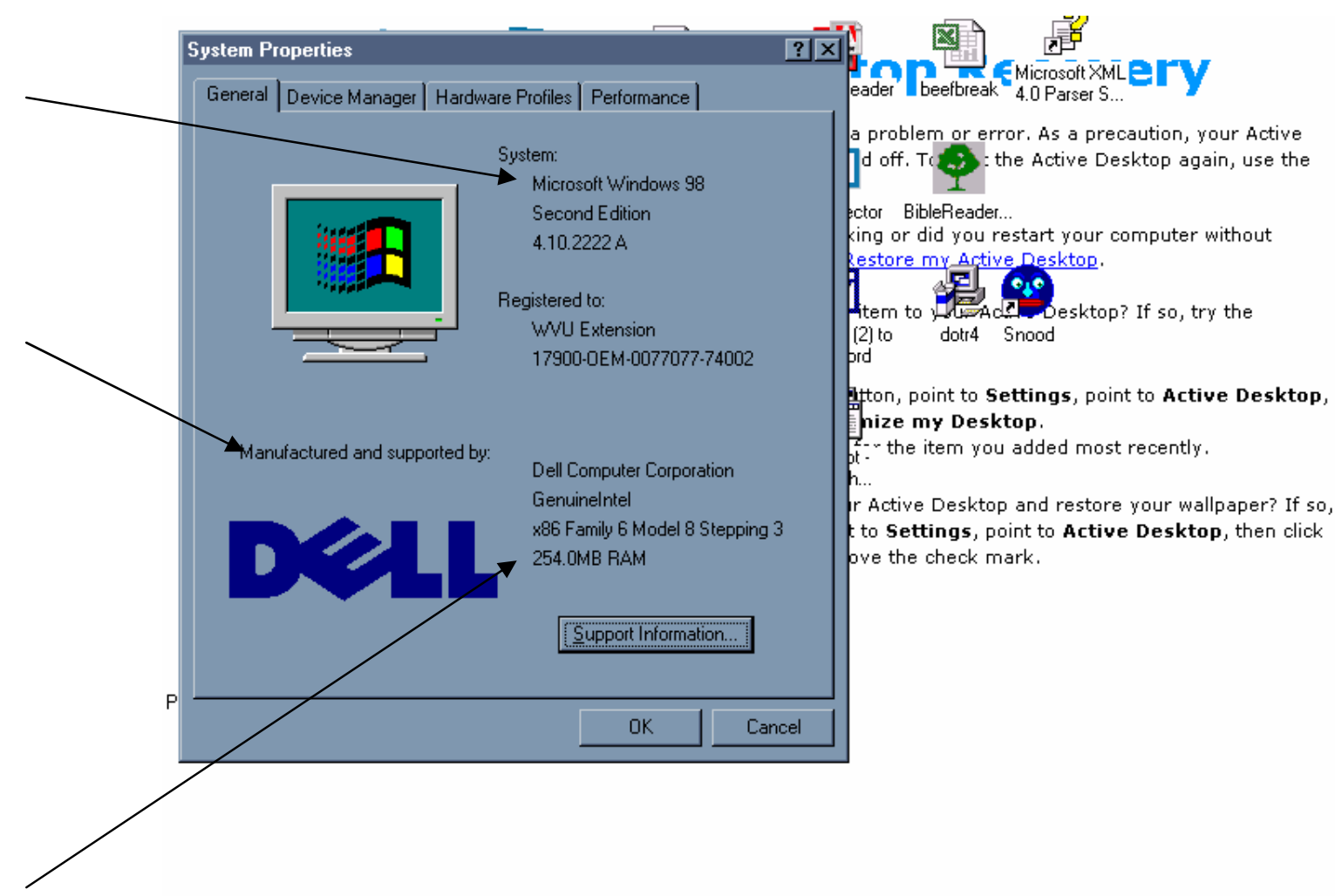

\begin{tabular}{|c|c|c|c|}
\hline Start & 国 Level of Group Cohesion -.. & Wif Operational Systems Chec... & \multirow{2}{*}{ 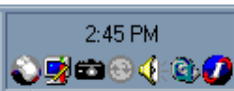 } \\
\hline & 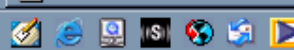 & & \\
\hline
\end{tabular}




\title{
APPENDIX F
}

\author{
Project Map for \\ Pilot Project Counties and \\ Those Counties Targeted for the Future
}




\section{Map 1: Project County Names and Location}

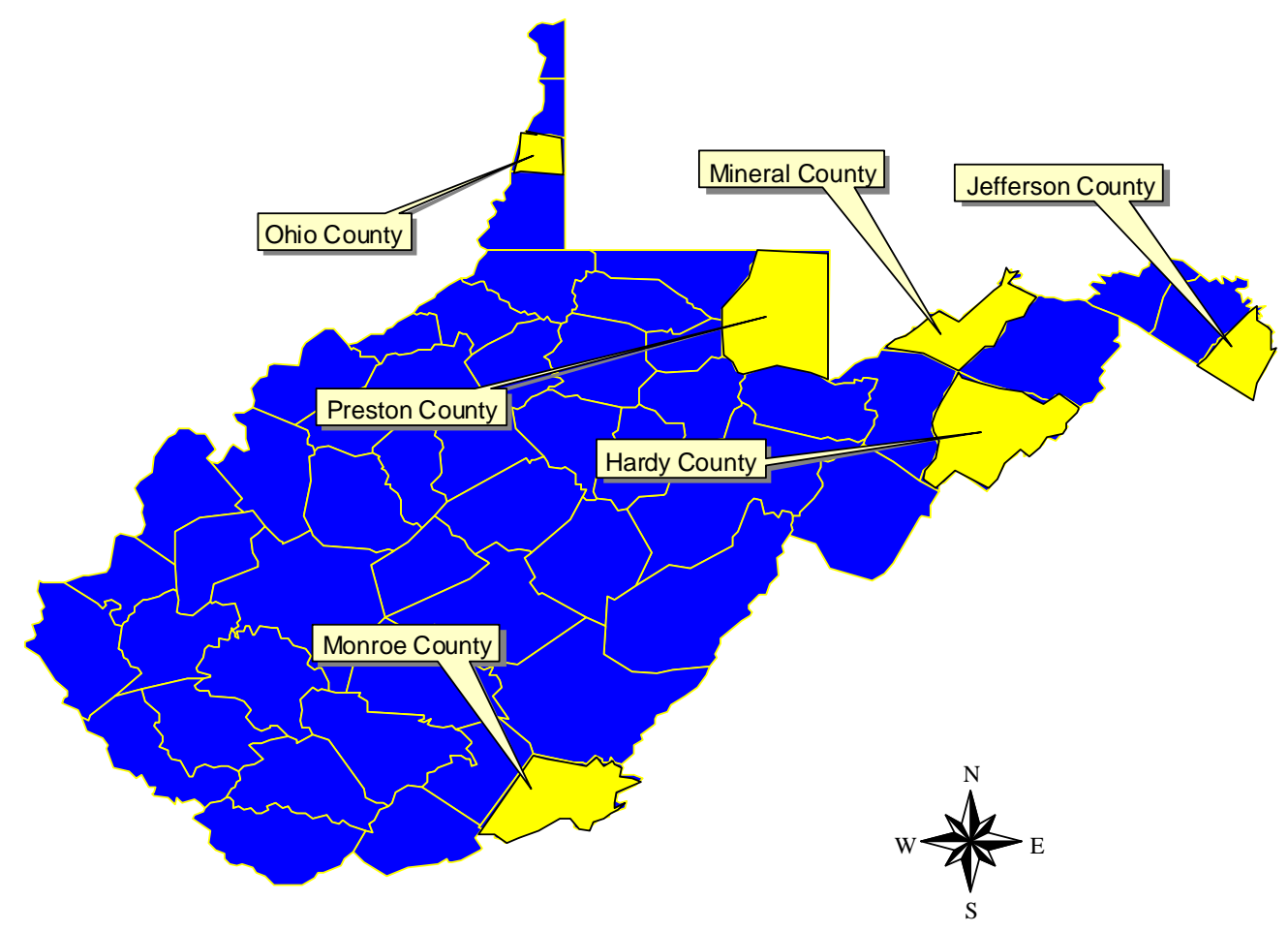

